Aus der Abteilung Psychiatrie und Psychotherapie

(Prof. Dr. med. P. Falkai)

im Zentrum Psychosoziale Medizin

der Medizinischen Fakultät der Universität Göttingen

Schizophrene Störungen und Abhängigkeitserkrankungen

\title{
INAUGURAL- DISSERTATION
}

zur Erlangung des Doktorgrades

der Medizinischen Fakultät

der Georg-August-Universität zu Göttingen

\author{
vorgelegt von \\ Jutta Buße-Renault \\ aus \\ Marburg /Lahn
}

Göttingen 2011 
Dekan : Prof. Dr. med. C Frömmel

I Berichterstatterin: Prof. Dr. rer. nat. U. Havemann-Reinecke

II Berichterstatter: Prof. Dr. rer.nat. Leibing

III Berichterstatterin: Prof. Dr. rer. nat. Virsik-Köpp

Tag der mündlichen Prüfung: 07. Mai 2012 
Inhaltsverzeichnis

Seite

1. Einleitung

1-1 Koinzidenz Sucht und Schizophrenie $\quad 8$

1-2 Das dopaminerge System 9

1-3 Pathogenese der Schizophrenie $\quad 11$

1-4 Dopamin und Drogenkonsum 12

2. Methoden 13

$\begin{array}{ll}2-1 \text { Versuchsdurchführung } & 13\end{array}$

2-2 Diagnosekriterien 16

2-2.1 DSM-IV [Saß et al. 1996]: Substanzabhängigkeit 16

2-2.2 Abhängigkeitssyndrom nach ICD 10 [Dilling et al. 1993] 17

2-3 Statistische Auswertungsverfahren $\quad 18$

2-4 Items

3. Ergebnisteil der soziodemographischen Daten 23

3-1 Alter 23

Tabelle 1: Darstellung der Altersverteilung $\quad 23$

$\begin{array}{ll}\text { Abbildung 1: Altersverteilung } & \mathbf{2 3}\end{array}$

Tabelle 2: Darstellung der Altersgruppen der Kollektive $\quad 24$

3-2 Geschlechterverteilung der Kollektive im Vergleich 25

Tabelle 3: Geschlechterverteilung $\quad 25$

Abbildung 2: Geschlechterverteilung $\quad 25$

3-3 Familienstand $\quad 26$

Tabelle 4: Familienstand $\quad 26$

3-4 Schulausbildung $\quad 26$

Tabelle 5: Schulausbildung $\quad 26$

$\begin{array}{ll}\text { 3-5 Berufsausbildung } & 27\end{array}$

Tabelle 6: Berufsausbildung $\quad 27$

$\begin{array}{lr}\text { 3-6 Erwerbstätigkeit } & 27\end{array}$

Tabelle 6a: Erwerbstätigkeit $\quad 27$

Abbildung 3: Erwerbstätigkeit $\quad 28$

Tabelle 7: Erwerbstätigkeit/Berufe $\quad 29$ 
Tabelle 8: Selbstbeurteilung des sozialen Abstieges $\quad 30$

Abbildung 4: Darstellung der Selbstbeurteilung des sozialen Abstieges 30

3-8 Statistische Auswertung der demographischen Daten 31

Tabelle 9: Nichtparametrische Tests der demographischen Daten $\quad 31$

4. Ergebnisteil und graphische Darstellung des Substanzgebrauchs 32 und der Abhängigkeitserkrankungen

4-1 Nikotinabhängigkeit/ ICD 10 [Dilling et al. 1993]: F 17.2 32

Tabelle 10: Nikotinabhängigkeit 33

Abbildung 5: Nikotinabhängigkeit $\quad 33$

4-1.1 Statistische Auswertung der Nikotinabhängigkeit 34

4-2 Riskanter täglicher Alkoholkonsum / ICD 10

[Dilling et al. 1993]: F10.1

Tabelle 11: Risikoreicher täglicher Alkoholkonsums 36

4-2.1 Statistische Auswertung des risikoreichen täglichen Alkohol- $\quad 37$ konsums

Abbildung 6: Risikoreicher täglicher Alkoholkonsum $\quad 37$

4-3 Alkoholabhängigkeit / ICD 10[Dilling et al. 1993] : F10.2 38

Alkoholabhängigkeit gegenwärtig abstinent / F10.20

[Dilling et al. 1993]: F10.20

Tabelle 11a: Alkoholabhängigkeit $\quad 38$

Abbildung 6a: Alkoholabhängigkeit $\quad 39$

4 -3.1 Statistische Auswertung der Alkoholabhängigkeit 39

4-4 Vergleich risikoreicher Alkolhokonsum und Alkoholabhängigkeit 42

Tabelle 11 b: Alkoholabhängigkeit versus riskanter Alkoholkonsum $\mathbf{4 2}$

4-5 Erhobene Alkoholmengen $\quad 42$

Tabelle $11 \mathrm{c}$ : Alkoholmengen versus Alkoholabhängigkeit 42

4-6 Benzodiazepineinnahme, Benzodiazepinmissbrauch / ICD 10

[Dilling et al. 1993] : F13.1

Tabelle 12: Benzodiazepinmissbrauch $\quad 44$

Abbildung 7:Benzodiazepinmissbrauch $\quad 45$

4-6.1 Statistische Auswertung des Benzodiazepinmissbrauchs 45 
4-7 Benzodiazepinabhängigkeit / ICD 10[Dilling et al. 1993]: F13.2 48 Tabelle 12a: Benzodiazepinabhängigkeit 48

Abbildung 7a: Benzodiazepinabhängigkeit 49

4-7.1 Statistische Auswertung der Benzodiazepinabhängigkeit 50

4-8 Cannabisgebrauch, Cannabismissbrauch/ICD 10

[Dilling et al. 1993]: F12.1 und Cannabis-

abhängigkeit/ ICD 10[Dilling et al. 1993]: F12.2

Tabelle 13: Cannabisnutzung $\quad \mathbf{5 3}$

Tabelle 14: Cannabisnutzung prozentualer Anteil $\mathbf{5 3}$

Abbildung 8: Cannabisnutzung $\quad 54$

Abbildung 8a: Cannabisgesamtnutzer $\quad 54$

4-8.1 Signifikanz der Cannabisnutzung im Gesamtkollektivergleich 55

4-8.2 Häufigkeitsverteilung der aktuellen regelmäßigen Cannabis- 57 nutzung

Tabelle 14 a: Häufigkeit der Cannabisnutzung 57

4-8.3 Häufigkeitsverteilung der regelmäßigen Cannabisnutzung in $\quad 57$ der Vergangenheit

Tabelle 14 b: Häufigkeitsverteilung der Cannabisnutzung $\quad 57$

4-8.4 Darstellung der Cannabisabhängigkeit 58

Tabelle 15: Cannabisabhängigkeit $\quad \mathbf{5 8}$

Abbildung 9: Cannabisabhängigkeit $\quad 58$

4-8.5 Statistische Auswertung der Cannabisabhängigkeit 59

4-8.6 Zeitlicher Zusammenhang der Cannabisnutzung und 61 der Erstdiagnostik einer Schizophrenie:

4-8.7 Statistische Auswertung des zeitlichen Zusammenhanges 61 zwischen der Erstdiagnostik einer Schizophrenie und des erhobenen Cannabiskonsums

4-9 Abhängigkeit von Heroin /ICD 10 [Dilling et al. 1993]: F 11.2 und 62 Abhängigkeit von Kokain/ ICD 10 [Dilling et al. 1993]: F 14.2 
4-9.1 Statistische Auswertung der Heroin-/Kokainabhängigkeit 62

4-10 Vermehrter täglicher Kaffeekonsum/ Missbrauch für Kaffee 63 /ICD 10 [Dilling et al. 1993]: F 15.1

Tabelle 17: Vermehrter Kaffeekonsum 1

Tabelle 17a: Vermehrter Kaffeekonsum 2

Abbildung 10:Vermehrter Kaffeekonsum

4-10.1 Statistische Auswertung des vermehrten Kaffeekonsums 64

4-11 Mehrfachabhängigkeiten/ ICD 10 [Dilling et al. 1993]: F19.2 65

4-11.1 Alkohol und Benzodiazepine $\quad 65$

Tabelle 18: kombinierte Alkohol- und Benzodiazepin- $\quad 65$ abhängigkeit

4-11.2 Alkohol und Cannabis

Tabelle 18a: kombinierte Alkohol- und Cannabis- $\quad \mathbf{6 5}$ abhängigkeit

4-11.3 Cannabis und Benzodiazepine $\quad 66$

Tabelle 19: kombinierte Cannabis - und Benzodiazepin- $\quad 66$ abhängigkeit

4-11.4 Cannabis und Nikotin $\quad 66$

Tabelle 20: kombinierte Cannabis-und Nikotinab- $\quad 66$ hängigkeit

4-12 Auswertungen der Blut und Urinbefunde $\quad 67$

Tabelle 21: Blutbild bei Alkoholabhängigkeit $\quad \mathbf{6 7}$

Tabelle 22: Leberwerte bei Alkoholabhängigkeit $\quad \mathbf{6 7}$

Tabelle 23: Leberwerte bei Benzodiazepinabhängigkeit $\mathbf{6 8}$

Tabelle 24: Drogenscreening bei Cannabisabhängigkeit $\quad 68$

5. Diskussion $\quad 70$

5-1 Soziodemographische Daten, Struktur und Charakter der $\quad 70$ untersuchten Gruppen

5-2 Nikotinkonsum im Kollektivvergleich $\quad 71$

5-3 Alkoholkonsum im Kollektivvergleich $\quad 74$

5-4 Benzodiazepinabhängigkeit im Kollektivvergleich 77

5-5 Cannabisnutzung/ Cannabisabhängigkeit im 79

Kollektivvergleich 
5-6 Heroin- und Kokainabhängigkeit im Kollektivvergleich

5-7 Koffeinnutzung im Kollektivvergleich

6. Zusammenfasssung

7. Literaturverzeichnis $\quad 85$

8. Anhang: Fragebogen und Patientenaufklärungsbogen und 95 Patienteneinwilligung 


\section{Einleitung}

\section{Fragestellung}

In der vorliegenden Arbeit werden Zusammenhänge zwischen Abhängigkeitserkrankungen bei schizophrenen Patienten sowie Patienten eines Kontrollkollektives, nicht an Schizophrenie erkrankten Patienten aufgezeigt. Als Arbeitshypothese wird eine höhere Anzahl von Abhängigkeitserkrankungen bei an Schizophrenie erkrankten Personen im Vergleich zu nicht schizophrenen Personen vermutet. Grundlage dieser Hypothese ist die Annahme, dass eine Überaktivität des dopaminergen Systems, die bei Schizophrenie besteht, mit einer erhöhten Suchtentstehung korreliert.

Die Ätiologie einer Abhängigkeitserkrankung ist multifaktoriell. Ein Teilaspekt ist die Erforschung der zerebralen Neurotransmitterwirkung (Dopamin) auf die Entstehung von Abhängigkeitserkrankungen, die über eine Stimulierung des mesolimbischen Belohnungssystems nach Drogeneinnahme (Beispiel Opioide) schon bereits Anfang der achtziger Jahre des letzten Jahrhunderts untersucht wurde [Havemann- Reinecke , Kuschinsky 1982,1992].

Tierexperimentell zeigte sich die Aktivierung dopaminerger Strukturen durch Suchtstoffe (Amphetamine, Kokain, Phenocyclidin) [Carboni et al. 1989], die sich in späteren Untersuchungen mit Hilfe neuroradiologischer Untersuchungen (SPECT/ PET) für menschliche Organismen und für Nikotin bestätigte [Fehr et al. 2008]. Des Weiteren wurde eine Veränderung der Anzahl zerebraler Dopaminrezeptoren bei Suchtmittelabhängigen im Vergleich zu Nichtabhängigen gefunden, die eine Erklärung sein könnte, warum einige Menschen abhängig werden und andere nicht, wenn sie gleichermaßen Kontakt zu Suchtstoffen bekommen [Klein et al. 2007].

Bei der Schizophrenie wird auf biochemischer Ebene von einer Dysbalance der Neurotransmitter (Dopamin, Serotonin, Glutamat, Acetylcholin und GABA) ausgegangen. Es wird im mesolimbischen System eine veränderte synaptische Organisation vermutet, die eine Überaktivität der Dopamin-Ausschüttung [Heinz 1999] bzw. eine gesteigerte Sensitivität postsynaptischer D2-dopaminerger Rezeptoren im System aufzeigt, die verantwortlich scheint für die Positiv Symptomatik bei Schizophrenie [Falkai, Pajonk 2003]. In diesen Kreislauf sind unter anderem die Basalganglien eingebunden, in der die antipsychotische Wirkung der Neuroleptika über die Blockade der Dopaminrezeptoren vermittelt wird. 
Zusätzlich kann eine Dopamin-Erhöhung im mesolimbischen System auf Grund einer Störung des Glutamat-Stoffwechsels vorliegen, die verantwortlich gemacht wird für kognitive Dysfunktionen und Minussymptome. Eine im präfrontalen Kortex geminderte dopaminerge Aktivität erscheint hingegen verantwortlich zu sein für die Affektiven Störungen und die Minussymptomatik bei Schizophrenie [Falkai, Pajonk 2003; Heinz et al.2004; Murray et al 2008].

Komorbide Abhängigkeitserkrankungen bei Schizophrenie werden schon lange vermutet, bereits 1909 postulierte Graeter „Alkoholismus und hebephrene Psychosen kommen häufig bei ein und demselben Individuum vor" und differenzierte das Alkoholdelir von komorbider Alkoholabhängigkeit bei Dementia praecox [Schneider 1913].

Seither erfolgten multiple Studien, die keine klaren einheitlichen Ergebnisse über die Koinzidenz beider Erkrankungen aufzeigten. In einer Studie des amerikanischen National Institut of Mental Health, Epidemiologic Catchment Area (ECA) [ Regier et al.1990 ] mit einer Stichprobe von 20.000 Personen ergaben sich Lifetime-Prävalenzen von $47 \%$ für Missbrauch/ Abhängigkeit für schizophrene Patienten, darunter 37,5\% für Alkoholmissbrauch /Abhängigkeit und 27,5 \% Missbrauch /Abhängigkeit von einer anderen Substanz. Im Vergleich dazu zeigten sich für die Allgemeinbevölkerung in der gleichen Studie 13,5\% Alkoholmissbrauch/-abhängigkeit und 6,1\% Missbrauch und Abhängigkeit für eine weitere Substanz [Gouzoulis-Mayfrank 2010]. Diskrepant dazu zeigen sich weitaus niedrigere Werte für den Alkoholmissbrauch (9\%) bei Schizophrenen in einer Studie von Linszen et al. (1994), da in dieser Untersuchung die 1 Jahres-Prävalenz erfasst wurde [D’Amelio et al. 2007]. 


\section{1-1 Koinzidenz Sucht und Schizophrenie}

In einer Vielzahl von Studien ist die Prävalenz einer Drogen- und Substanzabhängigkeit bei an Schizophrenie erkrankten Patienten untersucht worden. Die Ergebnisse zeigen differente Befunde mit einer Prävalenzrate von $15 \%$ bis $65 \%$ [Wobrock et al. 2005].

Die differenten Ergebnisse können in dem komplexen Zusammenhang zwischen süchtigem Verhalten einerseits und psychotischen Erkrankungen andererseits begründet sein:

1. Können durch den Missbrauch von Alkohol, Rauschmitteln und Drogen (wie z.B. Halluzinogene) Psychosen mit Schizophrenie ähnlichen Symptomen ausgelöst werden ? Das Suchtverhalten ist für die Genese der akut psychotischen Symptomatik ätiologisch bedeutsam.

- Verursachungshypothese einer akut psychotischen Symptomatik, z.B. Alkoholhalluzinose ICD 10 F 10.04 [Dilling et al. 1993] und Cannabis- induzierte Psychose ICD 10 F 12.04 [Dilling et al.1993].

2. Eine bestehende psychotische Erkrankung kann ihrerseits zu süchtigem Verhalten prädisponieren (sekundäre Abhängigkeit).

Alkohol- und Drogenmissbrauch können eine schizophrene Prognose verschleiern und damit zu erheblichen differentialdiagnostischen Problemen führen. Der Krankheitsverlauf kann aber auch durch eine zusätzliche Sucht kompliziert werden.

- Selbstmedikation

3. Kann Cannabiskonsum bei genetischer Konstellation zur Manifestation einer Schizophrenie im jüngeren Alter und bei Stress prädisponieren?

- Veranlagungshypothese

4. Eine zusätzliche Sucht kann, unabhängig von einer psychischen Erkrankung, psychiatrisch relevante Symptome verursachen, wie z.B. Angst, Wahnsymptome oder Sinnestäuschungen, die sich von den durch die psychische Grunderkrankung hervorgerufenen psychopathologischen Symptomen abheben. 
5. Auch andere für den Krankheitsverlauf wichtige Variablen wie z.B. soziale Integration, Krankheitsgefühl und -einsicht, Behandlungsbereitschaft, sowie die Compliance insgesamt, können durch einen Substanzgebrauch entscheidend verändert werden.

Darüber hinaus können auch Probleme der Suchtdiagnostik (z.B. verleugnendes Verhalten) und die verschiedenen Typen von Suchterkrankungen zu unterschiedlichen Ergebnissen hinsichtlich der Prävalenz von Abhängigkeitserkrankungen bei Schizophrenie führen.

\section{1-2 Das dopaminerge System}

Das dopaminerge System besteht aus drei Untereinheiten: dem nigrostriatalen, dem mesolimbischen und mesokortikalen Dopaminsystem.

Das nigrostriatale System, die größte der dopaminergen Bahnen, nimmt seinen Ursprung in der Substantia nigra im Mittelhirn und projiziert zu den Basalganglien, hauptsächlich zu dem Striatum [Havemann- Reinecke 1998]. Über die nigrostriatalen Bahnen hemmen die dopaminergen Fasern die Neurone des Striatums, die einen inhibitorischen Effekt auf motorische Impulse des Großhirns haben, somit hat die Substantia nigra eine wesentliche Funktion für die Bewegungsinitiation.

Darüber hinaus ist die Substantia nigra vermutlich auch an der Verarbeitung sensorischer Informationen im Sinne einer psycho- oder lokomotorischen Reaktion auf externe Reize beteiligt [Trepel 2008]. Die Funktion des nigrostriatalen Dopamin-Systems ist somit die Steuerung der extrapyramidalen Motorik des ZNS, Dopamin vermittelt hier die Umsetzung von den im motorischen Kortex geplanten Zielbewegungen. Das größte Vorkommen von Dopamin findet sich in einem Kerngebiet des Hirnstammes, in der Pars compacta der Substantia nigra. Diese Region ist bei Menschen mit Parkinson degeneriert, und es resultiert eine Fehlfunktion der Dopamin-produzierenden Zellen mit Verminderung der Konzentration des Neurotransmitters, die zum klinischen Bild der Akinese, Hypomimie und Ruhetremor bei betroffenen Patienten führt [Poeck 1994].

Das zweite genannte, das mesolimbische-dopaminerge System, entspringt ebenfalls im ventralen Tegmentum und zieht v.a. zum limbischen System, dem Nucleus accumbens, zum Septum, zu Amygdala-Kernen und Tuberculum olfactorium [Havemann- Reinecke 1998]. Im mesolimbischen Dopaminsystem hingegen beeinflusst der Neurotransmitter Dopamin die 
Gefühlsempfindung und die motivale Ausgangslage. Die Funktion des Systems ist in erster Linie, eine positive Verstärkung eines Verhaltens zu erzielen (Belohnungslernen).

Aus tierexperimentellen Forschungen wurde bereits Anfang der achtziger Jahre ein Zusammenhang zwischen dem mesolimbischem dopaminergen System und der Entstehung von Suchtverhalten gestellt [Kuschinsky 1981; Havemann-Reinecke und Kuschinsky 1982]. Amerikanische SPECT (Single Photon-Emissions-Computertomographien) Untersuchungen zeigten den Zusammenhang zwischen zentralem dopaminergen System und Abhängigkeitsprozessen bei Ratten [Gerrits, Van Ree 1996], die sich in späteren Forschungen auch für menschliche Organismus bewiesen ließ [Fehr et al. 2008]. Zudem trägt vermutlich die mesolimbische dopaminerge Bahn wesentlich zu den ,ppositiven“ Symptomen bei schizophrenen Störungen bei. Diese Theorie wird dadurch gestützt, dass Dopamin im mesolimbisch-dopaminergen System die Wahrnehmungsfähigkeit des Menschen erheblich steigert.

Auch bei Patienten, die an einer Psychose erkranken, ist die Wahrnehmungsfähigkeit extrem gesteigert. Gesunde nehmen von den auf sie permanent einwirkenden Sinneseindrücken, Empfindungen und Gefühlen nur ca. $10 \%$ bewusst wahr. Diese Selektion gewährleistet eine Verarbeitung der aufzunehmenden Informationen und schützt vor Überforderungen.

Bei an Psychose Erkrankten geht diese Filterfunktion verloren. Eine klare Strukturierung der aufgenommenen Gedanken und daraus resultierenden Empfindungen ist nicht mehr adäquat möglich.

In der Therapie zeigen Dopaminantagonisten (Neuroleptika) in der Behandlung von floriden Psychosen (Wahn, Gedankenüberflutung, Gedankenkreisen) wirkungsvolle Effekte, sodass eine gesteigerte dopaminerge Aktivität für die Positivsymptomatik der Schizophrenie verantwortlich gemacht wird.

Das dritte der dopaminergen Systeme, das mesokortikale System, zieht vom ventralen Tegmentum in Gebiete des limbischen Systems und des präfrontalen Cortex und wird für kognitive Störungen bei Schizophrenie verantwortlich gemacht.

Bei weiteren physiologischen Funktionen ist Dopamin die Vorstufe von Adrenalin und Noradrenalin, hemmt die Prolaktinausschüttung in der Hypophyse und reguliert über Sympathikusfasern die Durchblutung der Bauchorgane, vor allem der Niere. Medizinisch wird diese Tatsache nutzbar bei Schock, schwerer Hypotonie und drohendem Nierenversagen. Zwei Hauptgruppen an Dopaminrezeptoren (D1 bzw. D2) bzw. fünf Subtypen werden differenziert. Die Einteilung erfolgt auf Grund des unterschiedlichen intrazellulären Signalweges: D1/ D5-Gruppe (Adenylatzyklase- Aktivierung über stimulatorisches G- 
Protein) und die D2/D3/D4-Gruppe (Hemmung der Adenylatzyklase über inhibitorisches GProtein). Klinische Bedeutung erhielt die Untersuchung der D2-Dopaminrezeptoren, die vorrangig und in relativ hoher Anzahl postsynaptisch an den GABAergen Neuronen im Striatum lokalisiert sind [Asenbaum 2009].

Die physiologischen Funktionen der DA-Rezeptoren sind noch nicht vollends aufgeklärt, jedoch zeigte sich eine sechsfach höhere Anzahl D4-DA-Rezeptoren in schizophrenen Gehirnen bei post mortem Studien.

\section{1-3 Pathogenese der Schizophrenie}

Schizophrenien gab es vermutlich bereits seit dem Altertum.

Im Jahre 1896 stellte Kraepelin als erster gemeinsame Merkmale der Erkrankung dar und nannte sie Dementia praecox. 1911 wurde von Bleuer die noch heute geltende Bezeichnung Schizophrenie geprägt [Tölle 1994].

Das Life-time Risiko für das Auftreten einer Schizophrenie beträgt weltweit zwischen $0.5 \%$ und $1.6 \%$ [Kasper,Volz 2009].

Der Beginn der Erkrankung liegt zwischen der Pubertät und dem 30. Lebensjahr.

Meist werden schizophrene Patienten erst nach bereits seit Jahren bestehender

Prodromalphasen durch das Auftreten von akuter Positivsymptomatik (Halluzinationen)

klinisch relevant auffällig. In der Prodromalphase zeigen sich ungewollte Verhaltensweisen, z.B. Rückzugtendenzen des Patienten, Gedankenkreisen oder bizarres Verhalten. Oft jedoch werden Jungerwachsene durch die bestehenden Betreuungssysteme wie Schule, Studium oder Eltern über einen langen Zeitraum gestützt, sodass die bestehenden Symptome nicht zeitnah als krankhaft gedeutet werden.

Bleuer unterteilte die Symptomatik der Schizophrenie in Grundsymptome und akzessorische Symptome. Grundsymptome umfassen Störungen des Denkens, des Antriebes und der Affektivität.

Die Denkstörungen können in Form von Gedankenzerfahrenheit, Gedankenentzug und Gedankenabreißen bestehen. Der Antrieb ist oft vermindert bzw. in der akuten Phase bei Positivsymptomatik stark erhöht. Die Affektivität zeigt Schwankungen von Depressivität oder inadäquater Affektivität (Parathymie), oft in Form weniger bestehender situationsangepasster ausgeglichener Stimmungslage.

Akzessorische Symptome sind Wahn, Halluzinationen und katatone Störungen. 
Jedoch zeigt sich eine Schizophrenie in der Symptomatik und im Verlauf vielgestaltig, dies erklärt auch die bereits oben genannte spät beginnende Diagnostik und Therapie [Tölle 1994].

\section{1-4 Dopamin und Drogenkonsum}

Die Beeinflussung der kognitiven Wahrnehmung, das verstärkte Empfinden von Glück, Freude und Zuversicht nach Einnahme von einigen illegalen Drogen wird auf eine verstärkte Ausschüttung von Dopamin zurückgeführt.Verantwortlich dafür ist ein Belohnungssystem, lokalisiert im Nucleus accumbens [Trepel 2008].

Im Tierversuch zeigte sich nach Injektion von Drogen (Amphetamine, Kokain) im Bereich des Nucleus accumbens eine erhöhte Dopaminkonzentration. Andere Drogen bewirken eine Hemmung des Neurotransmitters Noradrenalin. Diese Hemmung von NA führt indirekt zu einer verstärkten Wirkung von Dopamin. Auch auf diese Weise wird das Belohnungssystem aktiviert. Drogen, die diese indirekte Stimulation vermutlich ausüben, sind Opiate, Alkohol, Barbiturate und Benzodiazepine [Havemann-Reinecke 2006]. Auch die körpereigenen Endorphine wirken auf diese Weise. Nikotin und Koffein stimulieren ebenfalls das Belohnungssystem [Schmidt et al. 2006].

Ausgehend von diesen neurobiologischen Kenntnissen galt es in der vorgelegten Studie, die Häufigkeit einer stofflichen bzw. nicht stofflichen Abhängigkeitserkrankung bei an Schizophrenie erkrankten Patienten zu erheben, und zwar anhand von Anamnesedaten, einem Interview und Hinzuziehen von Urinkontrollen und Blutwerten (Leberenzyme, kleines Blutbild). Zum Vergleich wurde ein Kontrollkollektiv gesunder nicht psychiatrischer Patienten mit gleichen Mitteln untersucht.

Daten zu Suchtmittelnutzung und Beginn der schizophrenen Erstmanifestation wurden erfragt, um einen zeitlichen Zusammenhang einer schizophrenen Erkrankung mit einer Suchtmitteleinnahme erstellen zu können. 


\section{Methoden}

\section{2-1 Versuchsdurchführung}

61 an Schizophrenie erkrankte Patienten wurden in der psychiatrischen Abteilung der Universität Göttingen rekrutiert. Die Patienten befanden sich zur Zeit der Befragung in ambulanter oder vollstationärer Therapie. Vor der Befragung erfolgte die Aufklärung der Patienten anhand eines Aufklärungsbogens. Zu jeder Zeit der Befragung konnte die Zustimmung zur Teilnahme an der Studie zurückgezogen werden. Auch erfolgte vor Beginn des Interviews eine Rücksprache der Doktorandin mit den behandelnden Ärzten über die aktuelle Teilnahmefähigkeit des Patienten, den Remissionsgrad der Schizophrenie und bestehende kognitive Einschränkungen des Patienten, die gegen eine Befragung und gegen die Studienteilnahme sprechen könnten.

Für das Kontrollkollektiv wurden insgesamt 57 Patienten befragt. Es handelte sich dabei einmal um Patienten mit elektiv geplanten operativen Eingriffen und einer kurzen stationären Verweildauer aus den Abteilungen der Allgemein- und Unfallchirurgie, sowie der Frauenklinik des Universitätsklinikums Göttingens. Zudem wurden Patienten der WerraRehabilitationsklinik der BfA in Bad Sooden-Allendorf mit einem dreiwöchigen stationären Rehabilitationsaufenthalt, die auf Grund präventiver Indikation behandelt wurde, befragt. Das Alter der Probanden lag zwischen 16 und 64 Jahren. Ausschlusskriterien für beide Kollektive waren Schwangerschaft, Tumorerkrankung, Patienten mit chronischen Schmerzzuständen (Bewegungsapparat etc.), schweren hirnorganischen Vorschädigungen, endogenen Depressionen, sowie Demenzen, Oligophrenien schweren Ausmaßes und Patienten mit chronischen Erkrankungen, die einer regelmäßigen Medikation bedurften. Für das Kontrollkollektiv bestand als zusätzliches Ausschlusskriterium ein längerer stationärer Aufenthalt im Akutkrankenhaus, weil sich aufgrund des Klinikaufenthaltes oder der verordneten Medikation Abhängigkeitserkrankungen verändert haben konnten.

Alle Patienten wurden mit einem standardisierten Fragebogen (,Suchtfragebogen“) über ihren Konsum von Alkohol, Medikamenten, illegalen Drogen, Nikotin sowie Ess- und Spielsucht befragt. Der standardisierte Fragebogen wurde bereits 1997 in einer Untersuchung von Abhängigkeitserkrankungen bei an Parkinson erkrankten Patienten von Florian de Raison [de Raison 1997] genutzt. Der Fragebogen enthält 27 Standards für die Durchführung von Katamnesen bei Suchterkrankten, die von der Gesellschaft für Suchtforschung und Suchttherapie 1984 entwickelt wurde. Es werden soziodemographische Daten, Alter, 
Geschlecht, Schul- und Berufsbildung, aktuelle Lebensfinanzierung und Familienstand erfragt. Folgend wird der Beginn und die Nutzung von Nikotin, Kaffee, Alkohol, Medikamenten und illegalen Drogen erhoben.

Die einst von de Raison fortgeführte Erweiterung des Katamnese-Bogens umfasste die Erfragung der qualitativen und quantitativen Nutzung der gebrauchten Genussstoffe, legalen und illegalen Drogen, Fragen zu Zweiterkrankungen (somatische, psychiatrische Erkrankungen), Spielsucht, Essgewohnheiten und Freizeitaktivitäten.

Dieser Fragenkatalog wurde in der jetzigen Untersuchung vollständig übernommen. Es erfolgte allein die Ergänzung, ob eingenommene Medikamente ärztlich auf Rezept verordnet wurden, bzw. missbräuchlich erworben und eingenommen wurden.

Die Befragungen wurden mit Labordaten (kleines Blutbild/ MCH und MCV/Leberenzymen: YGT,GPT,GOT) und einem Drogenscreening (Imun Assay) im Urin ergänzt.

Anhand des Fragebogens konnte eine Diagnosestellung einer Abhängigkeitserkrankung nach ICD 10 [Dilling et al. 1993] und DSM IV [Saß et al. 1996] erfolgen. Zusätzlich wurden die klinische Anamnese und soziodemographische Daten erhoben.

Die Auswertung der Daten folgte nach unten dargestellter Fragestellung:

1. Finden sich bei Schizophrenen mehr Abhängigkeitserkrankungen im Vergleich zu dem Kontrollkollektiv (keine Schizophrenie, keine psychiatrische Erkrankung)?

2. Sind bestimmte Abhängigkeitserkrankungen in den beiden Gruppen zu unterscheiden (Alkohol, Medikamente, Drogen, Nikotin, Kaffee, Spiel- oder Esssucht)? (Regressionsanalyse)

3. Bestehen multiple Abhängigkeiten in den einzelnen Kollektiven?

4. Gibt es geschlechtsspezifische Unterschiede im Konsumverhalten innerhalb des eigenen Kollektivs?

5. Geschlechtsspezifische Unterschiede im Konsumverhalten im Vergleich an Schizophrenie Erkrankten und im Vergleich zur Kontrollgruppe?

6. Einfluss soziodemographischer Daten.

Zur Ermittlung des Gruppenvergleiches an Schizophrenie erkrankter Personen versus Kontrollkollektiv (nicht an Schizophrenie erkrankten Patienten) wurde zuerst der prozentuale Anteil der Abhängigkeitserkrankungen mit den Nichtabhängigen für Nikotin, Alkohol, Benzodiazepinen, Kaffee und illegalen Drogen mit Hilfe der Kriterien des ICD 10 [Dilling et al. 1993] und DSM IV [Saß et al. 1996] ermittelt. 
In der Rubrik Alkohol wurde zudem der tägliche risikoreiche Alkoholkonsum der Probanden ermittelt und im Gruppenvergleich gegenübergestellt. Für die Berechnung des riskanten Alkoholkonsums wurde die Definition der British Medical Association [BMA 1995] genutzt, die eine tägliche Trinkmenge oberhalb der Gefährdungsgrenze von $30 \mathrm{~g}$ bei Männern und $20 \mathrm{~g}$ reinen Alkohol für Frauen definiert. Laut WHO liegen die Werte für einen riskanten Alkoholkonsum bei $20 \mathrm{~g}$ für Frauen und für Männer bei $40 \mathrm{~g}$ reinen Alkohol pro Tag.

Die täglich getrunkenen Alkoholmengen wurden folgend aufgeführt.

Für die Ermittlung der Alkoholabhängigkeit wurden Kriterien nach ICD 10 [Dilling et al. 1993] hinzugenommen und die Parameter gesteigerter Konsum, Entzugserscheinungen nach Alkoholkarenz, kompensatorisches Trinken, sowie anamnestisch durchgeführte Entgiftungsund Entwöhnungsbehandlungen mit einbezogen.

Bei Festlegung der Nikotinabhängigkeit galt der tägliche Genuss von mehr als 15 Zigaretten über einen Zeitraum von mehr als 3 Monaten und das Nennen von Entzugserscheinungen beim Absetzen, sowie der Wiederbeginn des Rauchens zur Vermeidung von Entzugserscheinungen als Kriterien für eine Nikotinabhängigkeit.

Die Medikamentenabhängigkeit bezog sich ausschließlich auf die Untersuchung von Benzodiazepinabhängigkeit und setzte die tägliche Einnahme eines Diazepampräparates von mindestens einer Dauer von vier Monaten, abweichendes Einnahmeverhalten von ärztlicher Verordnung, Entzugserscheinungen nach Absetzen und kompensatorische Wiedereinnahme zur Milderung von Entzugserscheinungen voraus. Bei nicht vorliegendenden Abhängigkeitskriterien, aber längerer Benzodiazepineinnahme wurde zwischen Missbrauch und Abhängigkeit für Benzodiazepine differenziert. 


\section{2-2 Diagnosekriterien}

\section{2-2.1 DSM-IV [Saß et al. 1996]: Substanzabhängigkeit}

( Diagnostic and Statistical Manual Disordes der American Psychiatric Association) in der Deutschen Übersetzung [Saß et al. 1996].

Mindestens drei der folgenden Kriterien müssen erfüllt sein, die zu irgendeiner Zeit in demselben 12-Monats-Zeitraum auftreten.

\section{Toleranzentwicklung}

a. ausgeprägte Dosis Steigerung, um einen Intoxikationszustand oder einen gewünschten

Effekt herbei zuführen

b. deutlich vermindere Wirkung bei fortgesetzter Einnahme derselben Dosis

II. Entzugssymptome, die sich durch eines der folgenden Kriterien äußern:

a. Charakteristische Entzugssymptome

b. Dieselben (oder eine sehr ähnliche) Substanz wird eingenommen, um Entzugssymptome zu lindern oder zu vermeiden.

III. Die Substanz wird häufig in größeren Mengen oder länger als beabsichtigt eingenommen.

IV. Anhaltender Wunsch oder erfolglose Versuche, den Substanzgebrauch zu verringern oder zu kontrollieren.

V. Viel Zeit für Aktivitäten, um die Substanz zu beschaffen, sie zu sich zu nehmen oder sich von ihrer Wirkung zu erholen.

VI. Wichtige soziale, berufliche oder Freizeitaktivitäten werden aufgrund des Substanzgebrauchs aufgegeben oder eingeschränkt.

VII. Fortgesetzter Substanzgebrauch trotz Kenntnis eines anhaltenden oder wiederkehrenden körperlichen oder psychischen Problems, das wahrscheinlich durch die Substanz verursacht oder verstärkt wurde. 


\section{2-2.2 Abhängigkeitssyndrom nach ICD 10 [Dilling et al. 1993]}

Drei der folgenden Kriterien sollen zusammen mindestens einen Monat lang oder über einen kürzeren Zeitraum wiederholt innerhalb von 12 Monaten bestanden haben [Dilling et al. 1993].

\section{Starkes Verlangen /Zwang, die Substanz zu konsumieren}

II. Verminderte Kontrollfähigkeit über den Substanzgebrauch, d.h. über Beginn, Beendigung oder Menge des Konsums.

III. Körperliches Entzugssyndrom, wenn die Substanz reduziert oder abgesetzt wird, mit typischen Entzugssymptomen oder Gebrauch derselben oder einer sehr ähnlichen Substanz, um Entzugssymptome zu mildern oder zu vermeiden.

IV. Toleranzentwicklung gegenüber den Substanzeffekten.Um eine Intoxikation oder einen gewünschten Effekt zu erzielen, müssen größere Mengen der Substanz konsumiert werden.

V. Einengung / Fixierung auf den Substanzgebrauch, Aufgabe und Vernachlässigung anderer wichtiger Interessengebiete wegen Substanzgebrauchs, oder es wird viel Zeit darauf verwandt, die Substanz zu bekommen, zu konsumieren oder sich davon zu erholen.

VI. Anhaltender Substanzgebrauch trotz eindeutiger schädlicher Folgen, obwohl der Betroffene sich über Art und Ausmaß des Schadens bewusst war oder hätte sein können. 


\section{2-3 Statistische Auswertungsverfahren}

Statistische Auswertungen erfolgten mit nichtparametrischen Tests mit Hilfe des Programmes SPSS 11.5. Der Kruskal-Wallis-Test wurde genutzt zur Ermittlung von Häufigkeitsunterschieden zwischen den vier beobachteten Gruppen (schizophrene Männer und Frauen sowie Kontrollkollektiv Männer und Frauen). Mit Hilfe der Chi-Quadratanalyse [Backhaus et al. 1996] wurden die Zuordnungen Abhängigkeit - Nichtabhängigkeit für die Kollektive der Schizophrenie-Patienten und der Patienten des Kontrollkollektivs zum Vergleich gegenübergestellt.

Diese statistische Methode dient zur Messung des Zusammenhanges zweier nominaler Merkmale. Verwendet wird das Assoziationsmaß Chi-Quadrat $x^{2}$ oder das Cramersche Assosiationsmaß V. Ausgangspunkt für beide Maßzahlen ist der Vergleich zwischen tatsächlich beobachteten Häufigkeiten und jenen Häufigkeiten, die man bei Unabhängigkeit der beiden Merkmale erwarten würde.

Folgend wurden anhand des Mann- Whitney-U-Test die Zusammenhänge jeweils zweier gegenübergestellter Gruppen aufgezeigt [Duller 2006] (schizophrene MännerKontrollkollektiv Männer / schizophrene Frauen - Kontrollkollektiv Frauen / schizophrenes Gesamtkollektiv-Kontrollgesamtkollektiv).

Die Grenze der Signifikanz wurde bei einem Wert von $\mathrm{p}<0,05$ definiert. 


\section{2-4 Items}

In der folgenden Tabelle werden die 103 Items, mit denen die statistische Auswertung erfolgte, dargestellt:

01 Geschlecht

02 Alter

03 Familienstand

04 Schulbildung

05 Berufsbildung

06 Erwerbstätigkeit

07 Arbeitslosigkeit

08 Arbeitsplatzwechsel

09 Lebensunterhalt

10 Lebensbereich

11 Trennung vom Elternhaus

12 Herz-Kreislauferkrankung

13 Stoffwechselerkrankung

14 neurologische Erkrankung

15 hämatologische Erkrankung

16 Gastro-Enterologische Erkrankung

17 Unfall

18 psychologische Behandlung

19 Abhängigkeitsbehandlung

20 Tabak im Umfeld

21 Alkohol im Umfeld

22 Medikamente im Umfeld

23 Marihuana im Umfeld

24 Heroin im Umfeld

25 Suchtmitteleinnahme am Arbeitsplatz

26 Suchtmitteleinnahme zu Hause

27 Suchtmitteleinnahme in Gesellschaft

28 Suchtmitteleinnahme bei Feiern

29 Suchtmitteleinnahme in der Freizeit 
30 Suchtmitteleinnahme ohne besonderen Grund

31 Freizeitbeschäftigung: Fernsehen

32 Freizeitbeschäftigung: Lesen

33 Freizeitbeschäftigung: Handarbeit

34 Freizeitbeschäftigung: Gartenarbeit

35 Freizeitbeschäftigung: Spazieren gehen

36 Freizeitbeschäftigung: Vereinstätigkeit

37 Freizeitbeschäftigung: Haustiere

38 keine Freizeitbeschäftigung

39 Zufriedenheit mit der Freizeitbeschäftigung

40 Geldspiele

41 Rausch durch Geldspiele

42 Rausch durch Musik

43 Musikrausch ähnlich Suchtrausch

44 Alkoholvorrat

45 Tabakvorrat

46 Medikamentenvorrat

47 Unruhe, wenn kein Vorrat Alkohol

48 Unruhe, wenn kein Vorrat Tabak

49 Unruhe, wenn kein Vorrat Medikamente

50 Bulimie

51 Halluzinationen ohne Suchtstoff

52 Drogeneinnahme

53 Entzugsbehandlung von Drogen

54 Entwöhnungsbehandlung bei Drogen

55 Medikamente bei Stress

55 Medikamente zur Beruhigung

56 Medikamente zur Anregung

57 Medikamente zur Stimmungsverbesserung

59 Medikamente ohne besonderen Grund

60 Medikamente auf Rezept

61 Entzugserscheinungen von Medikamenten

62 Medikamenteneinnahme gegen Entzugserscheinungen

63 Alkoholkonsum: Häufigkeit 
64 Alkohol: Menge

65 Anzahl der Vollräusche

66 Alkoholkonsum bei Stress

67 Alkoholkonsum zur Beruhigung

68 Alkoholkonsum zur Anregung

69 Alkoholkonsum zur Stimmungsverbesserung

70 Alkoholkonsum ohne besonderen Grund

71 Entzugserscheinungen von Alkohol

72 Alkohol gegen Entzugserscheinungen

73 Nikotinkonsum: Häufigkeit

74 Nikotinkonsum: Menge

75 Nikotinkonsum bei Stress

67 Nikotinkonsum zur Beruhigung

68 Nikotinkonsum zur Anregung

69 Nikotinkonsum zur Stimmungsverbesserung

70 Nikotinkonsum ohne besonderen Grund

80 Unruhe bei Nikotinentzug

81 Müdigkeit bei Nikotinentzug

82 Heißhunger bei Nikotinentzug

83 Verstopfung bei Nikotinentzug

84 Nikotin gegen Entzugserscheinungen

85 Entgiftung von Alkohol: Anzahl

86 Entgiftung von Alkohol: Zeitraum

87 Entwöhnung Alkohol: Anzahl

88 Entwöhnung Alkohol: Zeitraum

89 Entwöhnung Drogen: Anzahl

90 Entwöhnung Drogen: Zeitraum

91 Entwöhnung Medikamente: Anzahl

92 Entwöhnung Medikamente: Zeitraum

93 Selbstentzug: Nikotin

94 Selbstentzug: Alkohol

95 Selbstentzug: Medikamente

96 Selbstentzug: Marihuana

97 Selbstentzug: Heroin/Kokain 
98 Suchtproblem beim Ehepartner

99 Legalisierung von Drogen nein

100 Legalisierung von Drogen vielleicht (Drogentyp genannt)

101 Legalisierung von Drogen abgelehnt

102 Suizidversuch

103 Suizidversuch mit Medikamenten 


\section{Ergebnisteil der soziodemographischen Daten}

Es wurden die soziodemographischen Daten von 61 an Schizophrenie erkrankten Patienten mit Daten von 57 nichtpsychiatrischen Patienten verglichen.

\section{3-1 Alter :}

Tabelle 1

\begin{tabular}{|l|l|l|l|}
\hline Gruppe & Mittelwert/Jahre & Anzahl & Standardabweichung \\
\hline schizophrene Männer & 34,60 & 40 & 8,308 \\
\hline schizophrene Frauen & 37,33 & 21 & 11,218 \\
\hline Kontrollgruppe Männer & 36,74 & 35 & 11,110 \\
\hline Kontrollgruppe Frauen & 36,95 & 22 & 10,298 \\
\hline Insgesamt & 36,16 & 118 & 10,036 \\
\hline
\end{tabular}

Darstellung der Altersverteilung: 61 Psychose-Patienten, Kontrollkollektiv 57 Patienten

Der Altersdurchschnitt bei den schizophrenen Männern lag bei 34,60 Jahren im Vergleich dazu bei den schizophrenen Frauen bei 37,33 Jahren. In der Kontrollgruppe zeigte sich bei den Männern ein Altersdurchschnitt von 36,74 Jahren zu 36,95 Jahren bei den Frauen des Kollektivs. Untersucht wurden insgesamt 118 Personen, der Gesamtaltersdurchschnitt entsprach 36,16 Jahre. Das Minimum lag beim Alter von 16 Jahren, das Maximum bei 65 Jahren.

Abbildung 1

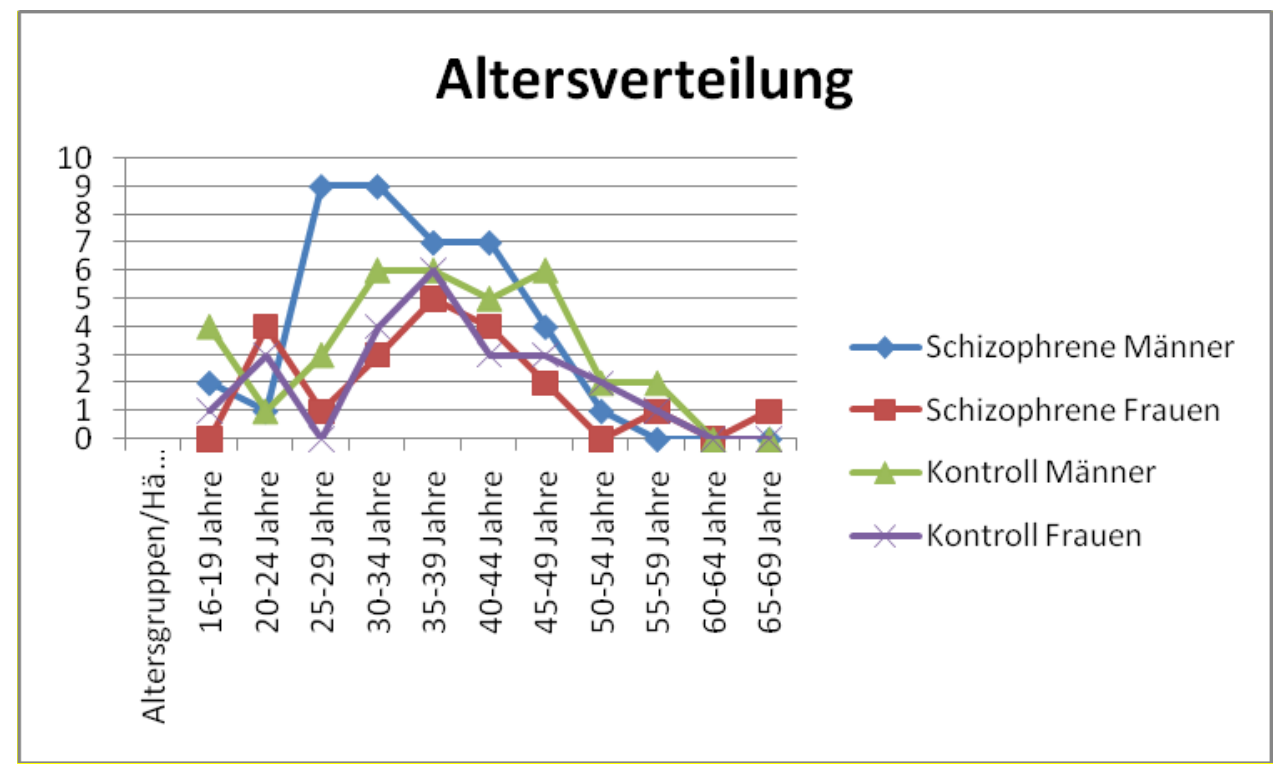

Altersverteilung: 61 Psychose-Patienten, Kontrollkollektiv 57 Patienten 
Tabelle 2

\begin{tabular}{|l|l|l|l|l|}
\hline Altersgruppe & $\begin{array}{l}\text { schizophrene } \\
\text { Männer }\end{array}$ & $\begin{array}{l}\text { Kontrollkollektiv } \\
\text { Männer }\end{array}$ & $\begin{array}{l}\text { schizophrene } \\
\text { Frauen }\end{array}$ & $\begin{array}{l}\text { Kontrollkollektiv } \\
\text { Frauen }\end{array}$ \\
\hline 16-19 Jahre & 2 & 0 & 0 & 1 \\
\hline 20-24 Jahre & 1 & 4 & 4 & 3 \\
\hline 25-29 Jahre & 9 & 1 & 1 & 0 \\
\hline 30-34 Jahre & 9 & 3 & 3 & 4 \\
\hline 35-39 Jahre & 7 & 5 & 5 & 6 \\
\hline 40-44 Jahre & 7 & 4 & 4 & 3 \\
\hline 45-49Jahre & 4 & 2 & 2 & 3 \\
\hline 50-54 Jahre & 1 & 0 & 0 & 1 \\
\hline 55-59 Jahre & 0 & 1 & 1 & 1 \\
\hline 60-64 Jahre & 0 & 0 & 0 & 0 \\
\hline 65-69 Jahre & 0 & 1 & 1 & 0 \\
\hline
\end{tabular}

Darstellung der Altersgruppen der Kollektive: 61 Psychose-Patienten, Kontrollkollektiv 57 Patienten

Bei den schizophrenen Männern lag das Mindestalter bei 19 Jahren und das maximal erhobene Alter bei 51 Jahren. Bei den schizophrenen Frauen hingegen fand sich das jüngste Befragungsalter bei 21 Jahren, auch zeigten sich in diesem Kollektiv die ältesten Teilnehmerinnen bis zum Alter von 65 Jahren.

Im männlichen Kontrollkollektiv wurden die jüngsten Teilnehmer mit 16 Jahren befragt, hier lag das maximale Befragungsalter bei 58 Jahren. Bei den Frauen des vergleichenden Kollektivs war die jüngste Befragte 17 Jahre, die älteste Teilnehmerin war 56 Jahre alt. 


\section{3-2 Geschlechterverteilung der Kollektive im Vergleich}

Tabelle 3

\begin{tabular}{|l|l|}
\hline Geschlechterverteilung & Anzahl \\
\hline Schizophrene Männer & 40 \\
\hline Schizophrene Frauen & 21 \\
\hline Kontrollkollektiv Männer & 35 \\
\hline Kontrollkollektiv Frauen & 22 \\
\hline
\end{tabular}

Geschlechterverteilung: 61 Psychose-Patienten, Kontrollkollektiv 57 Patienten

Abbildung 2

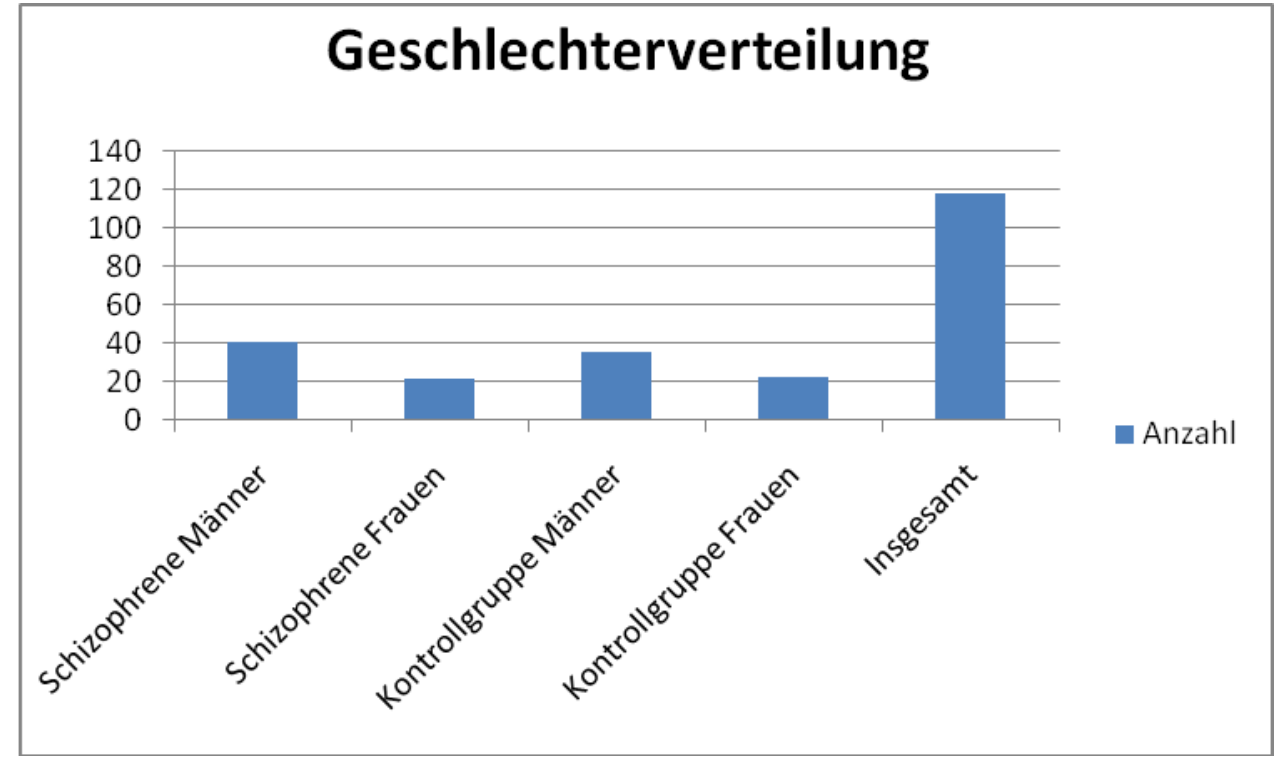

Geschlechtsverteilung: 61 Psychose-Patienten, Kontrollkollektiv 57 Patienten

Die Geschlechterverteilung ergab im Kollektiv der schizophrenen Patienten 65,57\% männliche Teilnehmer und 34,43\% weibliche Teilnehmerinnen gezählt. Im Kontrollkollektiv wurden 61,40\% männliche Probanden und 38,60\% weibliche Probandinnen befragt. Die sehr ähnliche prozentuale Verteilung von Frauen und Männern in beiden Kollektiven ermöglichte eine gute Vergleichbarkeit auch innerhalb der Geschlechtergruppen. 


\section{3-3 Familienstand}

Tabelle 4

\begin{tabular}{|l|l|l|}
\hline Familienstand & $\begin{array}{l}\text { schizophrene Patienten, prozentualer } \\
\text { Anteil am Eigenkollektiv }\end{array}$ & $\begin{array}{l}\text { Kontrollkollektiv, prozentualer Anteil } \\
\text { am Eigenkollektiv }\end{array}$ \\
\hline Ledig & $85,2 \%$ & $33,3 \%$ \\
\hline eheähnliche Gemeinschaft & $0 \%$ & $1,8 \%$ \\
\hline Verheiratet & $4,9 \%$ & $56,1 \%$ \\
\hline verheiratet, aber getrennt lebend & $1,6 \%$ & $1,8 \%$ \\
\hline Geschieden & $8,2 \%$ & $5,3 \%$ \\
\hline Verwitwet & $0 \%$ & $1,8 \%$ \\
\hline
\end{tabular}

Familienstand: 61 Psychose-Patienten, Kontrollkollektiv 57 Patienten

Die deutlichste Diskrepanz der erhobenen Daten zeigt sich bei der prozentualen Verteilung der ledigen und verheirateten Probanden im Kollektivvergleich, ein weitaus größerer Anteil der schizophrenen Probanden ist im Vergleich zu denen des Kontrollkollektives ledig $(85,2 \%$ versus $33,3 \%)$.

\section{3-4 Schulausbildung}

Tabelle 5

\begin{tabular}{|l|l|l|}
\hline Besuchte Schule & $\begin{array}{l}\text { schizophrene Patienten,prozentualer } \\
\text { Anteil am Eigenkollektiv }\end{array}$ & $\begin{array}{l}\text { Kontrollkollektiv, prozentualer Anteil } \\
\text { am Eigenkollektiv }\end{array}$ \\
\hline Sonderschule & $1,6 \%$ & $1,8 \%$ \\
\hline Hauptschule ohne Abschluss & $0 \%$ & $1,8 \%$ \\
\hline Hauptschulabschluss & $24,6 \%$ & $36,8 \%$ \\
\hline weiterführende Schule ohne Abschluss & $8,2 \%$ & $5,3 \%$ \\
\hline weiterführende Schule mit Abschluss & $47,5 \%$ & $40,4 \%$ \\
\hline Hoch/Fachschule ohne Abschluss & $13,1 \%$ & $3,5 \%$ \\
\hline Hoch/Fachschule mit Abschluss & $4,9 \%$ & $10,5 \%$ \\
\hline
\end{tabular}

Schulbildung: 61 Psychose-Patienten, Kontrollkollektiv 57 Patienten

In der schulischen Ausbildung ergaben sind keine signifikanten Unterschiede zwischen beiden Kollektiven. 


\section{3-5 Berufsausbildung}

Tabelle 6

\begin{tabular}{|l|l|l|}
\hline Berufsausbildung & schizophrene Patienten & Kontrollkollektiv \\
\hline keine Berufsausbildung & $11,50 \%$ & $1,80 \%$ \\
\hline angelernte Tätigkeit & $3,30 \%$ & $0 \%$ \\
\hline in Berufsausbildung & $6,6 \%$ & $14 \%$ \\
\hline abgebrochene Berufsausbildung & $14,8 \%$ & $0 \%$ \\
\hline abgeschlossene Berufsausbildung & $44,3 \%$ & $80,7 \%$ \\
\hline Sonstiges & $19,7 \%$ & $3,5 \%$ \\
\hline
\end{tabular}

Berufsausbildung: 61 Psychose-Patienten, Kontrollkollektiv 57 Patienten

In der Rubrik der Berufsausbildung zeigte sich ein nominaler Unterschied

bei der Betrachtung der abgeschlossenen Berufsausbildung, auch wenn sich in der statistischen Auswertung keine Signifikanz zeigte. Es scheint für die Prodromalphasen bzw. die Frühmanifestation der Schizophrenie charakteristisch zu sein, dass berufliche Qualifikationen nicht abschließend erlangt werden können.

\section{3-6 Erwerbstätigkeit}

Tabelle $6 \mathrm{a}$

\begin{tabular}{|l|l|l|l|l|}
\hline & $\begin{array}{l}\text { Schizophrene } \\
\text { Männer }\end{array}$ & Schizophrene Frauen & $\begin{array}{l}\text { Kontrollkollektiv } \\
\text { Männer }\end{array}$ & $\begin{array}{l}\text { Kontrollkollektiv } \\
\text { Frauen }\end{array}$ \\
\hline Arbeitslos & $30 \%$ & $28,56 \%$ & $5,71 \%$ & $0 \%$ \\
\hline $\begin{array}{l}\text { nicht erwerbstätig, } \\
\text { ohne Arbeits- } \\
\text { losigkeit }\end{array}$ & $27,5, \%$ & $19,04 \%$ & $79,99 \%$ & $22,7 \%$ \\
\hline Erwerbsttätig & $27,5 \%$ & & $14,28 \%$ & $77,27 \%$ \\
\hline Berentet & $15 \%$ & $33,33 \%$ & $0 \%$ & 0 \\
\hline
\end{tabular}

Erwerbstätigkeit: 61 Psychose-Patienten, Kontrollkollektiv 57 Patienten 


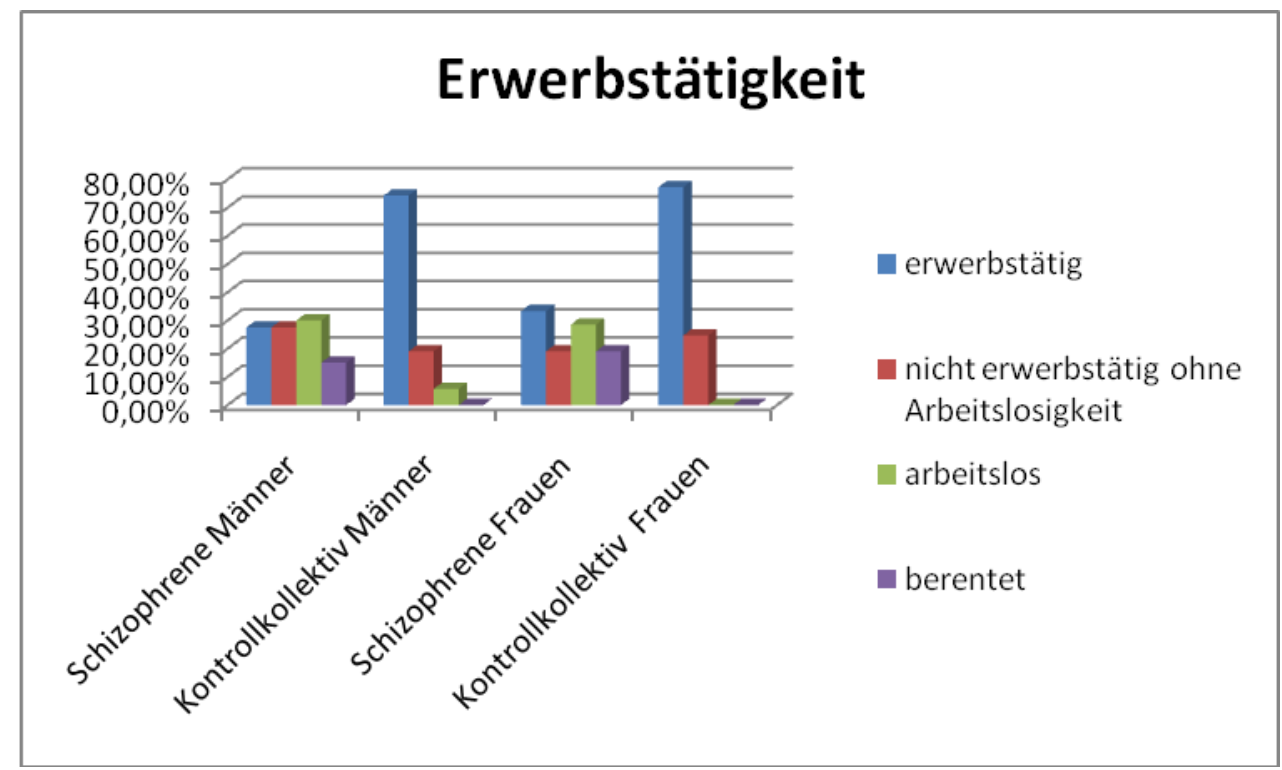

Erwerbstätigkeit: 61 Psychose-Patienten, Kontrollkollektiv 57 Patienten

Es fand sich ein weitaus höherer Anteil erwerbstätiger Frauen und Männer im Kontrollkollektiv im Vergleich zu dem Kollektiv der schizophrenen Patienten.

In der Rubrik „entfällt“ sind Schüler und Studenten, Hausfrauen, Erziehungsurlaub und die Arbeit in Werkstätten für Behinderte zusammengefasst. Eine Aufgliederung der Erwerbstätigkeit in die einzelnen Rubriken ist folgender Tabelle aufgezeichnet. 
Tabelle 7

\begin{tabular}{|c|c|c|c|c|}
\hline Erwerbstätigkeit/Berufe & $\begin{array}{l}\text { Schizophrene } \\
\text { Männer }\end{array}$ & $\begin{array}{l}\text { Schizophrene } \\
\text { Frauen }\end{array}$ & $\begin{array}{l}\text { Kontrollkollektiv } \\
\text { Männer }\end{array}$ & $\begin{array}{l}\text { Kontrollkollektiv } \\
\text { Frauen }\end{array}$ \\
\hline arbeitslos < 3 Monate & $7,5 \%$ & 0 & $5,71 \%$ & 0 \\
\hline arbeitslos $<6$ Monate & $7,5 \%$ & $4,76 \%$ & 0 & 0 \\
\hline arbeitslos $<1$ Jahr & $5 \%$ & $9,52 \%$ & 0 & 0 \\
\hline arbeitslos $>2$ Jahre & $2,5 \%$ & $9,52 \%$ & 0 & 0 \\
\hline arbeitslos $>3$ Jahre & $7,5 \%$ & $4,76 \%$ & 0 & 0 \\
\hline Hilfsarbeiter & $5 \%$ & $4,76 \%$ & 0 & 0 \\
\hline Arbeiter & $5 \%$ & $4,76 \%$ & $11,43 \%$ & 0 \\
\hline Auszubildender & $0 \%$ & 0 & $5,71 \%$ & 0 \\
\hline Schüler & $2,5 \%$ & $4,76 \%$ & $11,43 \%$ & $4,54 \%$ \\
\hline Student & $25 \%$ & $4,76 \%$ & 0 & $4,54 \%$ \\
\hline Umschüler & 0 & 0 & $2,85 \%$ & 0 \\
\hline Hausfrau & 0 & $9,52 \%$ & 0 & 0 \\
\hline Mitarbeit elterlicher Betrieb & 0 & $4,76 \%$ & 0 & 0 \\
\hline Erziehungsurlaub & 0 & 0 & 0 & $13,62 \%$ \\
\hline Selbstständig & $2,5 \%$ & 0 & 0 & 0 \\
\hline Angestellter & $5 \%$ & $14,29 \%$ & $60 \%$ & $77,27 \%$ \\
\hline Rentner & $15 \%$ & $19,04 \%$ & 0 & 0 \\
\hline Werkstatt für Behinderte & $10 \%$ & $4,76 \%$ & $2,85 \%$ & 0 \\
\hline Insgesamt & $100 \%$ & $100 \%$ & $100 \%$ & $100 \%$ \\
\hline
\end{tabular}

Erwerbstätigkeit/Berufe: 61 Psychose-Patienten, Kontrollkollektiv 57 Patienten

Die differenzierte Analyse, welche Patienten berentet waren, stellte sich wie folgt dar:

Sechs männliche schizophrene Patienten waren zum Zeitpunkt der Befragung berentet, bei keinem der Patienten bestand eine Alkoholabhängigkeit oder ein Zustand nach

Alkoholabhängigkeit, auch war bei allen keine Cannabisabhängigkeit zu erheben. Bei einem schizophrenen Patienten bestand eine Benzodiazepinabhängigkeit bzw. Zustand nach Benzodiazepinabhängigkeit.

Unter den vier berenteten schizophrenen Patientinnen bestand ausschließlich bei einer Patientin eine Alkohol- und Benzodiazepinabhängigkeit.

Fünf weitere schizophrene männliche Patienten, bei denen eine Abhängigkeitserkrankung erhoben wurde (Alkohol, Benzodiazepine, THC, Heroin, Kokain) waren alle arbeitslos. 
Bei den schizophrenen Frauen mit Abhängigkeitserkrankung waren wie oben beschrieben, zum Zeitpunkt der Befragung zwei arbeitslos, eine berufstätig und zwei nicht berufstätig, jedoch nicht arbeitslos gemeldet, somit Schüler, Studentin oder Hausfrau.

\section{3-7 Soziale Integration}

Mit der Frage des sozialen Abstiegs wurde eine Selbstbeurteilung der sozialen Integration der Patienten erhoben.

Tabelle 8

\begin{tabular}{|l|l|l|}
\hline & Schizophrene Patienten & Kontrollkollektiv \\
\hline Nein & $52,5 \%$ & $98,2 \%$ \\
\hline Ja & $47,5 \%$ & $1,8 \%$ \\
\hline
\end{tabular}

Selbstbeurteilung des sozialen Abstieges: 61 Psychose-Patienten, Kontrollkollektiv 57 Patienten

Abbildung 4

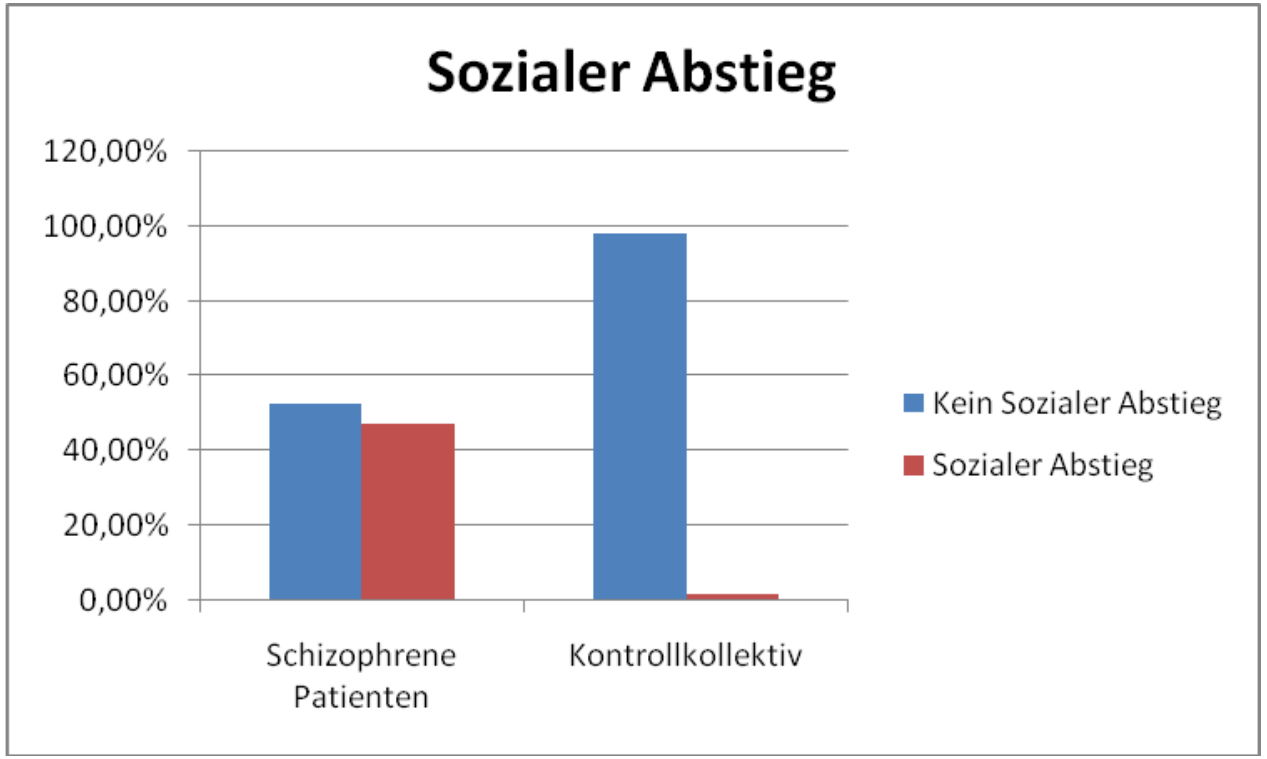

Darstellung der Selbstbeurteilung des sozialen Abstieges: 61 Psychose-Patienten, Kontrollkollektiv 57 Patienten

Zusammenfassend zeigte die Auswertung der demographischen Daten, dass beide Kollektive (schizophrene Patienten versus Kontrollkollektiv) in Bezug auf Geschlecht und Altersverteilung gut vergleichbar sind. 
Abweichungen der Berufstätigkeit, des sozialem Status, aber auch des Familienstandes bei vergleichbarer und ähnlicher Schulbildung und Berufsausbildung, resultieren wahrscheinlich aus der Manifestation der Schizophrenie im jungen Erwachsenenalter.

Daraus folgend ergaben sich bei einem erheblichen Anteil der schizophrenen Patienten Veränderungen der Berufstätigkeit, Lebens- und Familienplanung. Eine Signifikanz der in dieser Arbeit erhobenen Daten zeigte sich jedoch nur beim Familienstand und der Frage nach einem sozialen Abstieg.

\section{3-8 Statistische Auswertung der demographischen Daten}

\section{Nichtparametrische Tests}

Statistik für Test $a, b$

Tabelle 9

\begin{tabular}{|c|c|c|c|c|c|}
\hline & Alter & $\begin{array}{l}\text { Familien- } \\
\text { Stand }\end{array}$ & $\begin{array}{l}\text { Schul - } \\
\text { Ausbildung }\end{array}$ & $\begin{array}{l}\text { Berufs- } \\
\text { Ausbildung }\end{array}$ & $\begin{array}{l}\text { Besteht ein } \\
\text { sozialer } \\
\text { Abstieg }\end{array}$ \\
\hline $\begin{array}{l}\text { Chi-Quadrat } \\
\text { df } \\
\text { asymptotische } \\
\text { Signifikanz }\end{array}$ & $\begin{array}{l}1,738 \\
3 \\
, 628\end{array}$ & $\begin{array}{l}26,894 \\
3 \\
, 000\end{array}$ & $\begin{array}{l}2,382 \\
3 \\
, 497\end{array}$ & $\begin{array}{l}2,407 \\
3 \\
, 492\end{array}$ & $\begin{array}{l}34,339 \\
3 \\
, 000\end{array}$ \\
\hline
\end{tabular}

\begin{tabular}{|l|l|l|}
\hline & Erwerbstätigkeit & Berufe \\
\hline Chi-Quadrat & $\mathbf{1 , 7 2 5}$ & $\mathbf{4 , 3 6 3}$ \\
df & $\mathbf{3}$ & $\mathbf{3}$ \\
asymptotische Signifikanz &, 631 &, 225 \\
\hline
\end{tabular}
a. Kruskal-Wallis-Test
b. Gruppenvariable: Gruppe 


\section{Ergebnisteil und graphische Darstellung des Substanzgebrauchs und der}

Abhängigkeitserkrankungen

\section{4-1 Nikotinabhängigkeit/ ICD 10 [Dilling et al. 1993]: F 17.2}

Die Nikotinabhängigkeit wurde ermittelt unter Einbeziehung der täglich gerauchten Anzahl der Zigaretten, Dauer des Konsums und auftretenden Entzugserscheinungen nach Rauchstop bzw. kompensatorischem Rauchen.

Im Kollektiv der schizophrenen Männer zeigten sich 22,5\% Nichtraucher, $17.5 \%$ ehemalige Raucher, 15\% nichtabhängige Raucher und 45\% abhängige Raucher. Bei den schizophrenen Frauen fanden sich 28,57\% Nichtraucherinnen, keine ehemalige Raucherin, 28,57\% nichtabhängige Raucherinnen und 42,86\% abhängige Raucherinnen. Im Vergleich dazu ergaben sich bei den Kontrollkollektivdaten deutlich niedrigere Werte für abhängiges Rauchen, bei den männlichen Probanden 25,71\% und bei den weiblichen Probandinnen 9,09\%. Dementsprechend zeigten sich Nichtraucher im Kontrollkollektiv Männer bei 37,14\% und bei den Frauen bei 63,64\% vermehrt. Nichtabhängige Raucherinnen fanden sich im weiblichen Kontrollkollektiv nicht, bei den Männern des Kontrollkollektivs waren es 14,29\%, sodass sich in dieser Rubrik kein deutlicher Unterschied zwischen den männlichen Befragten ergab. Interessant ist auch der relativ hohe Anteil ehemaliger Raucherinnen mit 27,27\% bei den weiblichen Patienten des Kontrollkollektivs, im Vergleich zu den schizophrenen Patientinnen ( 0\%), gegebenfalls bedingt durch Raucherentwöhnung im Rahmen von Schwangerschaften. Bei den männlichen Probanden ergaben sich keine gravierenden Unterschiede. Die Werte für ehemalige Raucher lagen bei den schizophrenen Männern bei 17,5\% und 22,86\% bei den Männern des Kontrollkollektivs. 
Tabelle 10

\begin{tabular}{|l|l|l|l|l|}
\hline Raucher & Nichtraucher & ehemalig. Raucher & $\begin{array}{l}\text { nichtabhängige } \\
\text { Raucher }\end{array}$ & $\begin{array}{l}\text { abhängige } \\
\text { Raucher }\end{array}$ \\
\hline $\begin{array}{l}\text { Schizophrene } \\
\text { Männer }\end{array}$ & $22,5 \%$ & $17,5 \%$ & $15 \%$ & $45 \%$ \\
\hline $\begin{array}{l}\text { Kontrollkollektiv } \\
\text { Männer }\end{array}$ & $37,14 \%$ & $22,86 \%$ & $14,29 \%$ & $\mathbf{2 5 , 7 1 \%}$ \\
\hline $\begin{array}{l}\text { Schizophrene } \\
\text { Frauen }\end{array}$ & $\mathbf{2 8 , 5 7 \%}$ & 0 & $\mathbf{2 8 , 5 7 \%}$ & $\mathbf{4 2 , 8 6 \%}$ \\
\hline $\begin{array}{l}\text { Kontrollkollektiv } \\
\text { Frauen }\end{array}$ & $\mathbf{6 3 , 6 4 \%}$ & $\mathbf{2 7 , 2 7 \%}$ & $\mathbf{0}$ & $\mathbf{9 , 0 9 \%}$ \\
\hline
\end{tabular}

Nikotinabhängigkeit: 61 Psychose-Patienten, Kontrollkollektiv 57 Patienten

Abbildung 5

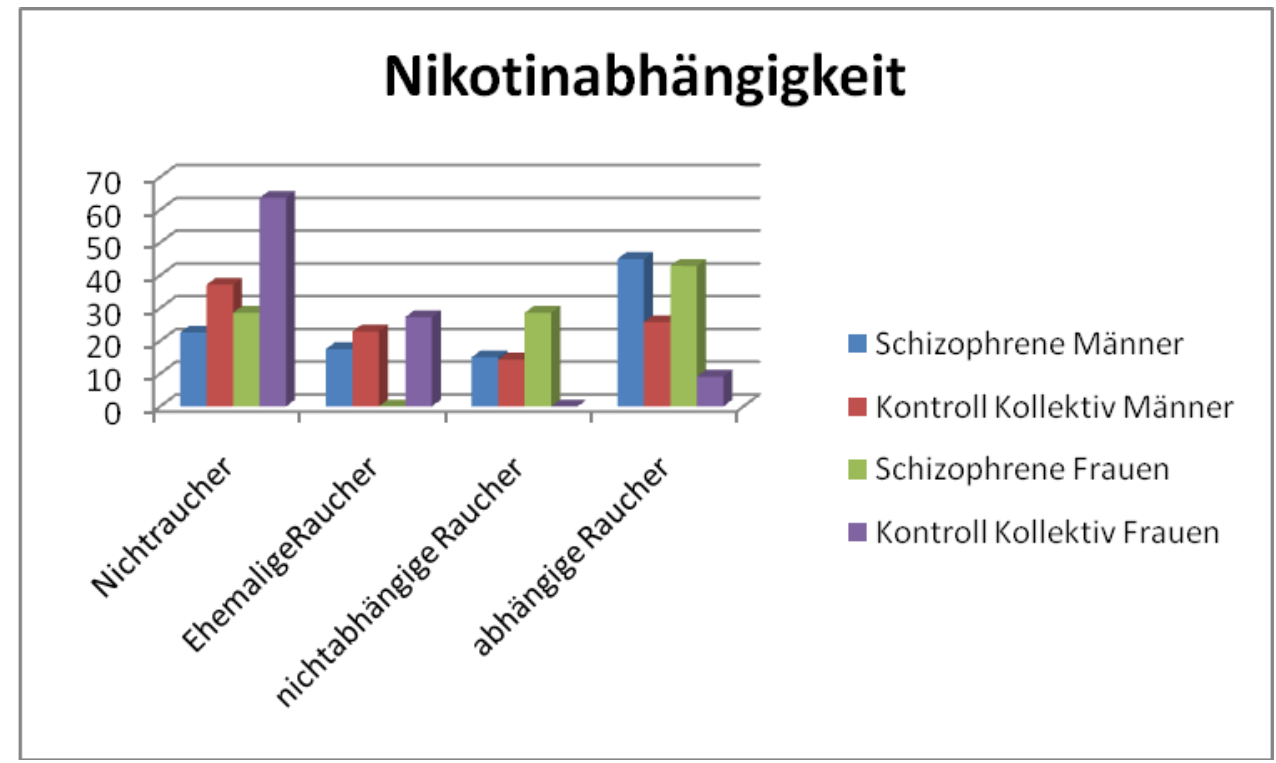

Nikotinabhängigkeit: 61 Psychose-Patienten, Kontrollkollektiv 57 Patienten

Ermittlung der Abhängigkeit für Nikotin:

1. Anzahl der täglich gerauchten Zigaretten ( > $15 \mathrm{Zig} / \mathrm{d}$ )

2. Entzugserscheinungen bei Beendigung oder Reduktion des Rauchen

3. Kompensatorisches Rauchen zur Vermeidung der Entzugserscheinungen

Wenn Item 2 und 3 nicht eindeutig auszuwerten waren, wurden weitere Items: Wiederbeginn des Rauchens, Unruhe wenn keine Zigaretten vorhanden etc. mit einbezogen 


\section{4-1.1 Statistische Auswertung der Nikotinabhängigkeit}

\section{a-Gesamtkollektivvergleich/Kruskal-Wallis- Test}

Ränge

\begin{tabular}{|l|l|l|}
\hline Gruppe & N & $\begin{array}{l}\text { mittlerer } \\
\text { Rang }\end{array}$ \\
\hline $\begin{array}{l}\text { schizophrene } \\
\text { Männer }\end{array}$ & 40 & 69,69 \\
\hline $\begin{array}{l}\text { schizophrene } \\
\text { Frauen }\end{array}$ & 21 & 69,36 \\
\hline $\begin{array}{l}\text { Kontrollkollektiv } \\
\text { Männer }\end{array}$ & 35 & 55,97 \\
\hline $\begin{array}{l}\text { Kontrollkollektiv } \\
\text { Frauen }\end{array}$ & 22 & 37,18 \\
\hline Gesamt & 118 & \\
\hline
\end{tabular}

Statistik für Test a,b

\begin{tabular}{|l|l|}
\hline & Nikotinkonsum \\
\hline Chi-Quadrat & 16,461 \\
\hline Df & 3 \\
\hline $\begin{array}{l}\text { asymptotische } \\
\text { Signifikanz }\end{array}$ &, 001 \\
\hline
\end{tabular}

a. Kruskal-Wallis- Test

b. Gruppenvariable : Gruppe

\section{b-Einzelkollektivvergleich/Nikotinkontrolle Mann-Withney-Test}

Ränge

\begin{tabular}{|l|l|l|l|}
\hline Nikotinabhängigkeit & N & Mittlerer Rang & Rangsumme \\
\hline schizophrene Männer & 40 & 42,19 & 1687,50 \\
\hline Kontrollkollektiv änner & 35 & 33,21 & 1162,50 \\
\hline Gesamt & 75 & & \\
\hline
\end{tabular}

Statistik für Test a

\begin{tabular}{|l|l|}
\hline & Nikotinabhängigkeit \\
\hline Mann-Withney-U & $\mathbf{5 3 2 , 5 0 0}$ \\
Wilcoxon-W & 1162,500 \\
Z & $-1,857$ \\
asymptotische & \\
Signifikanz (2 seitig) & $\mathbf{0 , 0 6 3}$ \\
\hline
\end{tabular}


Ränge

\begin{tabular}{|l|l|l|l|}
\hline Nikotinabhängigkeit & N & mittlerer Rang & Rangsumme \\
\hline schizophrene Frauen & 21 & 27,71 & 582,00 \\
\hline Kontrollkollektiv Frauen & 22 & 16,55 & 364,00 \\
\hline Gesamt & 43 & & \\
\hline
\end{tabular}

\section{Statistik für Test a}

\begin{tabular}{|l|l|}
\hline & Nikotinabhängigkeit \\
\hline Mann-Withney-U & $\mathbf{1 1 1 , 0 0 0}$ \\
Wilcoxon-W & 364,000 \\
Z & $-3,112$ \\
asymptotische &, 002 \\
Signifikanz (2 seitig)
\end{tabular}

Ränge

\begin{tabular}{|l|l|l|l|}
\hline Nikotinlabhängigkeit & N & mittlerer Rang & Rangsumme \\
\hline schizophrene Patienten & 61 & 69,57 & 4244,00 \\
\hline $\begin{array}{l}\text { Kontrollkollektiv } \\
\text { Patienten }\end{array}$ & 57 & 48,72 & 2777,00 \\
\hline gesamt & 118 & & \\
\hline
\end{tabular}

Statistik für Test a

\begin{tabular}{|l|l|}
\hline & Nikotinabhängigkeit \\
\hline Mann-Withney-U & 1124,0000 \\
Wilcoxon-W & 2777,000 \\
Z & $-3,463$ \\
asymptotische & \\
Signifikanz (2 seitig) &, 001 \\
\hline
\end{tabular}

Ein signifikantes Ergebnis hinsichtlich der Nikotinabhängigkeit ergab sich im Vergleich des Gesamtkollektivs und in der Gegenüberstellung schizophrener Frauen und Kontrollkollektiv Frauen, sowie beim Vergleich schizophrene Patienten und Kontrollkollektiv.

Es bestand keine Signifikanz bei der Betrachtung schizophrener Männer und Kontrollkollektiv Männer bezüglich der erhobenen Daten zum Rauchverhalten und der Nikotinabhängigkeit. 


\section{4-2 Riskanter täglicher Alkoholkonsum / ICD 10 [Dilling et al. 1993]: F10.1}

Bei der Auswertung der Daten zur Frage der Alkoholnutzung wurde zuerst der tägliche risikoreiche Alkoholkonsum erhoben. Zur Berechnung wurde der reine Alkoholgehalt der angegebenen Getränke ermittelt und daraus der Wert für den täglich getrunkenen reinen Alkohol ermittelt. Laut Definition besteht ein riskanter Alkoholkonsum bei Werten von $20 \mathrm{~g}$ reinem Alkohol/d bei Frauen und $30 \mathrm{~g} / \mathrm{d}$ reinem Alkohol für Männer.

Bei den Spirituosen wurde folgende Volumenberechnungen zu Grunde gelegt: für Bier 5 Volumenprozent, Wein 10 Volumenprozent, Schnaps 20 Volumenprozent.

Bei den schizophrenen Männern zeigte sich die Gruppe mit dem höchsten täglichen riskanten Alkoholkonsum mit 37,5\% im Vergleich zu dem Kontrollkollektiv Männer, die einen Wert von $25,71 \%$ erreichten. Bei den Frauen lagen die Werte für die schizophrenen Frauen bei 19,05\% und bei dem Kontrollkollektiv Frauen bei 9,09\%.

Tabelle 11

\begin{tabular}{|l|l|l|l|}
\hline & riskanter Konsum & kein riskanter Konsum & Gesamt \\
\hline schizophrene Männer & 15 & 25 & 40 \\
\hline $\begin{array}{l}\text { Kontrollkollektiv } \\
\text { Männer }\end{array}$ & $37,5 \%$ & $62,5 \%$ & \\
\hline & 9 & 26 & 35 \\
\hline schizophrene Frauen & 4 & & 21 \\
\hline & $19,05 \%$ & $74,29 \%$ & \\
\hline Kontrollkollektiv Frauen & 2 & 17 & 22 \\
\hline & & $80,05 \%$ & \\
\hline
\end{tabular}

Risikoreicher täglicher Alkoholkonsums: 61 Psychose-Patienten, Kontrollkollektiv 57 Patienten 


\section{4-2.1 Statistische Auswertung des risikoreichen täglichen Alkoholkonsums}

\section{a-Signifikanz des risikoreichen täglichen Alkoholkonsums im Gesamtkollektiv/}

\section{Kruskal- Wallis- Test}

Ränge

\begin{tabular}{|l|l|l|}
\hline Gruppe & N & $\begin{array}{l}\text { Mittlerer } \\
\text { Rang }\end{array}$ \\
\hline $\begin{array}{l}\text { schizophrene } \\
\text { Männer }\end{array}$ & 40 & 66,63 \\
\hline $\begin{array}{l}\text { schizophrene } \\
\text { Frauen }\end{array}$ & 21 & 55,74 \\
\hline $\begin{array}{l}\text { Kontrollkollektiv } \\
\text { Männer }\end{array}$ & 35 & $\mathbf{5 9 , 6 7}$ \\
\hline $\begin{array}{l}\text { Kontrollkollektiv } \\
\text { Frauen }\end{array}$ & 22 & 49,86 \\
\hline Gesamt & 118 & \\
\hline
\end{tabular}

Statistik für Test a

\begin{tabular}{|l|l|}
\hline & Alkoholmissbrauch \\
\hline Chi-Quadrat & $\mathbf{6 , 5 6 8}$ \\
\hline Df & $\mathbf{3}$ \\
\hline $\begin{array}{l}\text { Asymptotische } \\
\text { Signifikanz }\end{array}$ & $\mathbf{, 0 8 7}$ \\
\hline
\end{tabular}

Abbildung 6

\section{Risikoreicher täglicher Alkoholkonsum}

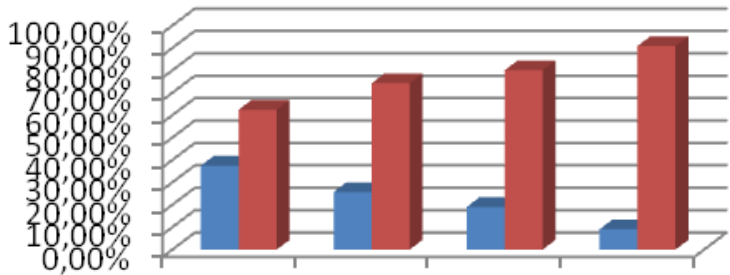

n riskanter Konsum

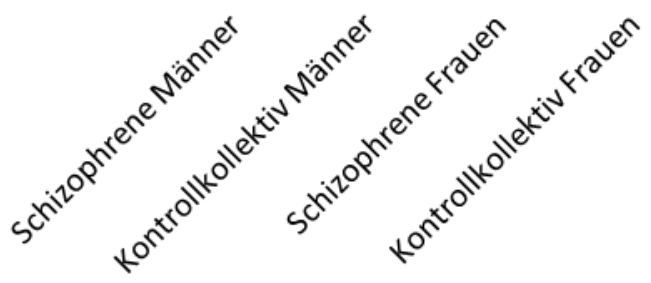

kein riskanter Konsum

Risikoreicher täglicher Alkoholkonsum: 61 Psychose-Patienten, Kontrollkollektiv 57 Patienten,

Ermittlung des risikoreichen Alkoholkonsums:

Items: Berechnung der täglichen Alkoholmenge / oder der durchschnittlichen Alkoholmenge für Tageswerte. Riskanter Konsum bei Werten von $20 \mathrm{~g}$ reinen Alkohol/d bei Frauen und $30 \mathrm{~g}$ reinen Alkohol/d für Männer. 
4-3 Alkoholabhängigkeit / ICD 10 [Dilling et al. 1993]: F10.2

\section{Alkoholabhängigkeit gegenwärtig abstinent / [Dilling et al. 1993]: F10.20}

Die Alkoholabhängigkeit wurde untersucht unter Betrachtung der täglich getrunkenen Alkoholmenge, Dauer des erhöhten Alkoholkonsums, auftretenden Entzugserscheinungen nach Beendigung des Alkoholtrinkens bzw. kompensatorisches Alkoholtrinkens und unter Einbeziehen von Vorbefunden und anamnestischen Angaben von Entgiftungs- bzw. Entwöhnungstherapien.

Bei 10\% der schizophrenen Männern bestand nach den oben genannten Kriterien eine Alkoholabhängigkeit versus 5,71\% bei den Männern des Kontrollkollektivs. Die Werte für Frauen lagen bei 14,28\% Alkoholabhängige im Klientel der schizophrenen Patientinnen und 0 Prozent bei den Frauen des Kontrollkollektivs.

Tabelle 11a

\begin{tabular}{|l|l|l|l|}
\hline & Alkoholabhängigkeit & keine Alkoholabhängigkeit & Gesamt \\
\hline schizophrene Männer & 5 & 35 & 40 \\
\hline $\begin{array}{l}\text { Kontrollkollektiv } \\
\text { Männer }\end{array}$ & $10 \%$ & $90 \%$ & \\
\hline & 2 & 33 & 35 \\
\hline schizophrene Frauen & $3,71 \%$ & $94,29 \%$ & 21 \\
\hline & 3 & 18 & \\
\hline Kontrollkollektiv Frauen & 0 & $85,72 \%$ & 22 \\
\hline & $0 \%$ & 22 & \\
\hline
\end{tabular}

Alkoholabhängigkeit: 61 Psychose-Patienten, Kontrollkollektiv 57 Patienten 
Abbildung 6a

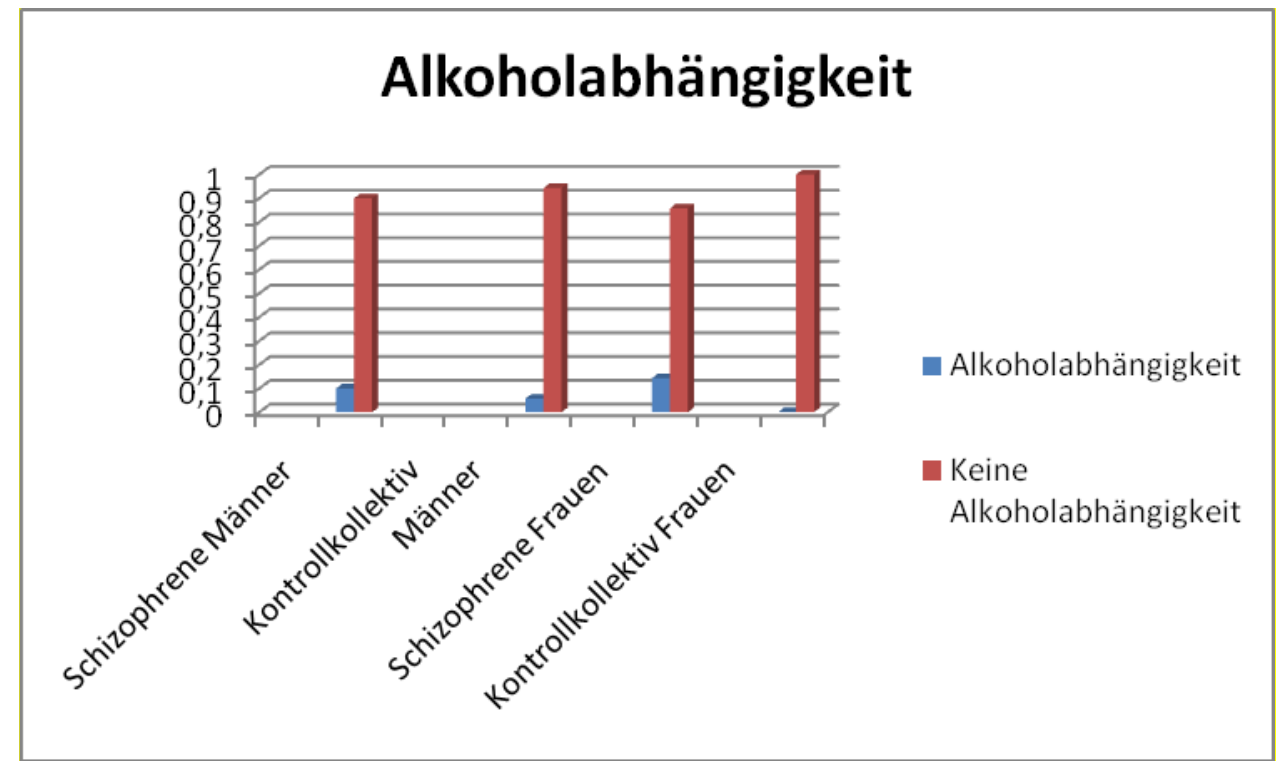

Alkoholabhängigkeit: 61 Psychose-Patienten, Kontrollkollektiv 57 Patienten

Ermittlung der Alkoholabhängigkeit :

-tägliche Alkoholmenge, Dauer des Alkoholkonsums

- Entzugserscheinungen nach Beendigung des Alkoholkonsums, Kompensatorisches Trinken wegen Entzugserscheinungen

- Entgiftungs- und Entwöhnungstherapien.

\section{4-3.1 Statistische Auswertung der Alkoholabhängigkeit} a-Gesamtgruppenvergleich/ Kruskal- Wallis-Test

Ränge

\begin{tabular}{|c|c|c|c|c|}
\hline & \multicolumn{4}{|c|}{ Statistik für Test a } \\
\hline & & & & Alkoholabhängigkeit \\
\hline & & & Chi-Quadrat & 3,609 \\
\hline & & & $D f$ & 3 \\
\hline & & & $\begin{array}{l}\text { asymptotische } \\
\text { Signifikanz }\end{array}$ & ,307 \\
\hline Gruppe & $N$ & $\begin{array}{l}\text { Mittlerer } \\
\text { Rang }\end{array}$ & & \\
\hline $\begin{array}{l}\text { schizophrene } \\
\text { Männer }\end{array}$ & 40 & 66,90 & & \\
\hline $\begin{array}{l}\text { schizophrene } \\
\text { Frauen }\end{array}$ & 21 & 63,43 & & \\
\hline $\begin{array}{l}\text { Kontrollkollektiv } \\
\text { Männer }\end{array}$ & 35 & 58,37 & & \\
\hline $\begin{array}{l}\text { Kontrollkollektiv } \\
\text { Frauen }\end{array}$ & 22 & 55,00 & & \\
\hline gesamt & 118 & & & \\
\hline
\end{tabular}


b-Einzelkollektivvergleich: Mann- Withney -Test

Ränge

\begin{tabular}{|l|l|l|l|}
\hline Alkoholabhängigkeit & N & Mittlerer Rang & Rangsumme \\
\hline Schizophrene Männer & 40 & 38,75 & 1550,00 \\
\hline $\begin{array}{l}\text { Kontrollkollektiv } \\
\text { Männer }\end{array}$ & 35 & 37,14 & 1300,00 \\
\hline gesamt & 75 & & \\
\hline \hline
\end{tabular}

\section{Statistik für Test a}

\begin{tabular}{|l|l|}
\hline & Alkoholabhängigkeit \\
\hline Mann-Withney-U & 670,00 \\
Wilcoxon-W & 1300,00 \\
Z & -.678 \\
asymptotische & \\
Signifikanz (2 seitig) &, 498 \\
\hline
\end{tabular}

\section{Ränge}

\begin{tabular}{|l|l|l|l|}
\hline Alkoholabhängigkeit & N & mittlerer Rang & Rangsumme \\
\hline Schizophrene Frauen & 21 & 23,57 & 495,00 \\
\hline Kontrollkollektiv Frauen & 22 & 20,50 & 451,00 \\
\hline Gesamt & 43 & & \\
\hline
\end{tabular}

\section{Statistik für Test a}

\begin{tabular}{|l|l|}
\hline & Alkoholabhängigkeit \\
\hline Mann-Withney-U & 198,00 \\
Wilcoxon-W & 451,00 \\
Z & $-1,817$ \\
asymptotische & \\
Signifikanz (2 seitig) &, 069 \\
\hline
\end{tabular}




\begin{tabular}{|l|l|l|l|}
\multicolumn{2}{|c|}{ Ränge } \\
\hline Alkoholabhängigkeit & N & mittlerer Rang & Rangsumme \\
\hline schizophrene Patienten & 61 & 61,77 & 3768,00 \\
\hline $\begin{array}{l}\text { Kontrollkollektiv } \\
\text { Patienten }\end{array}$ & 57 & $\mathbf{5 7 , 0 7}$ & $\mathbf{3 2 5 3 , 0 0}$ \\
\hline gesamt & 118 & & \\
\hline
\end{tabular}

Statistik für Test a

\begin{tabular}{|l|l|}
\hline & Alkoholabhängigkeit \\
\hline Mann-Withney-U & 1600,000 \\
Wilcoxon-W & 3253,000 \\
Z & $-1,622$ \\
asymptotische & \\
Signifikanz (2 seitig) &, 105 \\
\hline
\end{tabular}

In der Auswertung zeigten sich keine signifikante Daten in der Betrachtung der Einzelkollektive und des Gesamtkollektives bezüglich der Alkoholabhängigkeit. Jedoch ist ein Trend bei dem Vergleich schizophrener Frauen zum Kontrollkollektiv Frauen zu erkennen. 


\section{4-4 Vergleich risikoreicher Alkoholkonsum und Alkoholabhängigkeit}

Beim Vergleich der Daten des risikoreichen täglichen Alkoholkonsums mit den Daten der Alkoholabhängigkeit zeigte sich bei den schizophrenen Männern und den Männern des Kontrollkollektives eine ähnlich hohe Differenz für ermittelte Alkoholabhängigkeit und risikoreichen Alkoholkonsum.

Tabelle $11 \mathrm{~b}$

\begin{tabular}{|l|l|l|l|l|}
\hline & Alkoholabhängigkeit & $\begin{array}{l}\text { riskanter } \\
\text { Alkoholkonsum }\end{array}$ & Differenz & \\
\hline $\begin{array}{l}\text { Männer } \\
\text { Kontrollkollektiv } \\
\text { Männer }\end{array}$ & $5,71 \%$ & $37,5 \%$ & $27,5 \%$ & \\
\hline $\begin{array}{l}\text { schizophrene } \\
\text { Frauen }\end{array}$ & $14,28 \%$ & $25,71 \%$ & $20 \%$ & \\
\hline $\begin{array}{l}\text { Kontrollkollektiv } \\
\text { Frauen }\end{array}$ & $0 \%$ & $19,05 \%$ & $4,77 \%$ & \\
\hline
\end{tabular}

Alkoholabhängigkeit versus riskanter Alkoholkonsum: 61 Psychose- Patienten, Kontrollkollektiv 57 Patienten

\section{4-5 Erhobene Alkoholmengen}

Die erhobene täglich getrunkene Alkoholmengen zeigten bei den schizophrenen Männern maximale Werte bei $150 \mathrm{~g} / \mathrm{d}$, bei den schizophrenen Frauen $280 \mathrm{~g} / \mathrm{d}$, für das Kontrollkollektiv Männer 300 g/d und für das Kontollkollektiv Frauen maximale Werte bei $30 \mathrm{~g} / \mathrm{d}$.

Tabelle $11 \mathrm{c}$

\begin{tabular}{|l|l|l|}
\hline $\begin{array}{l}\text { Tägliche } \\
\text { Alkoholmenge }\end{array}$ & $\begin{array}{l}\text { Prozentuale } \\
\text { Alkoholabhängigkeit }\end{array}$ & $\begin{array}{l}\text { Tägliche maximale } \\
\text { Alkoholmengen }\end{array}$ \\
\hline schizophrene Männer & $10 \%$ & $60 \mathrm{~g} / \mathrm{d}$ \\
\hline $\begin{array}{l}\text { Kontrollkollektiv } \\
\text { Männer }\end{array}$ & $5,71 \%$ & $300 \mathrm{~g} / \mathrm{d}$ \\
\hline schizophrene Frauen & $14,28 \%$ & $280 \mathrm{~g} / \mathrm{d}$ \\
\hline $\begin{array}{l}\text { Kontrollkollektiv } \\
\text { Frauen }\end{array}$ & $0 \%$ & $30 \mathrm{~g} / \mathrm{d}$ \\
\hline
\end{tabular}

Alkoholmengen versus Alkoholabhängigkeit: 61 Psychose-Patienten,

Kontrollkollektiv 57 Patienten 


\section{4-6 Benzodiazepineinnahme, Benzodiazepinmissbrauch / ICD 10 [Dilling et al. 1993]: F13.1}

Unter der Rubrik der Benzodiazepineinnahme bzw. des Benzodiazepinmissbrauchs wurde in den Untergruppen zwischen legaler Verordnung mit und ohne Missbrauch, Z.n. Missbrauch und aktueller Missbrauch bei Verordnung und illegalem Missbrauch differenziert.

Ein Benzodiazepinmissbrauch lag vor, wenn der Gebrauch von der ärztlichen Verordnung der Benzodiazepine Abweichungen in der Dosierung und dem Einnahmezeitraum aufzeigte, die tägliche Einnahme von Benzodiazepinen über einen Zeitraum von mehr als vier Monaten betrug oder ein illegaler Gebrauch von Benzodiazepine (keine ärztliche Verordnung) vorlag. In der Gruppe der schizophrenen Männer bekamen 77,50\% nie Benzodiazepine verordnet, 15\% hatten Benzodiazepine verordnet bekommen und zeigten keinen Missbrauch, 2,5\% hatten bei aktueller Verordnung einen Missbrauch. 5\% der schizophrenen Männer hatten früher unter ärztlicher Verordnung von Benzodiazepinen einen Missbrauch eingeräumt und bei keinem Befragten wurde ein illegaler Missbrauch von Benzodiazepinen ohne ärztliche Verordnung festgestellt.

Im Vergleich gab es bei den Männern des Kontrollkollektives eine höhere Anzahl von Klienten, die nie Benzodiazepine verordnet bekamen, insgesamt $80 \%$. Die reguläre ärztliche Verordnung lag bei 17,14\% ohne Missbrauch und 2,86\% Zustand nach ärztlicherVerordnung und Missbrauch. Aktueller Missbrauch oder illegale Anwendung von Benzodiazepinen zeigten sich hingegen nicht.

Die höchste Anzahl der Klienten mit ärztlicher Benzodiazepinverordnung ohne Missbrauch fand sich mit 23,81\% in der Gruppe der schizophrenen Frauen, zusätzlich 9,52\% aktueller Benzodiazepinmissbrauch bei ärztlicher Verordnung und 19,05\%. Zustand nach Missbrauch. Auch in diesem Klientel zeigte sich keine illegale Beschaffung der Benzodiazepine, jedoch eine deutliche Diskrepanz zu den genannten Daten der weiblichen Patienten des Kontrollkollektivs. Dort gab es insgesamt nur eine Verordnung von 13,36\% ohne Missbrauch, 4,54\% Zustand nach Missbrauch bei ärztlicher Verordnung, aktuell wurde keine missbräuchliche oder illegale Benzodiazepineinnahme berichtet. Die Diskrepanz der Daten zeigt eine statistische Signifikanz bei Betrachtung der schizophrenen Frauen versus der Kontrollkollektivgruppe Frauen. 
Tabelle 12

\begin{tabular}{|l|l|l|}
\hline Benzodiazepinmissbrauch & keine Verordnung/kein Missbrauch & $\begin{array}{l}\text { Verordnung von Benzodiazepinen, } \\
\text { kein Missbrauch }\end{array}$ \\
\hline Kontrollkollektiv Männer & $80 \%$ & $17,14 \%$ \\
\hline schizophrene Männer & $77,50 \%$ & $15 \%$ \\
\hline schizophrene Frauen & $47,62 \%$ & $23,817 \%$ \\
\hline Kontrollkollektiv Frauen & $81,81 \%$ & $13,36 \%$ \\
\hline
\end{tabular}

\begin{tabular}{|l|l|l|l|}
\hline & $\begin{array}{l}\text { Verordnung Benzo- } \\
\text { diazepine, aktueller } \\
\text { Missbrauch }\end{array}$ & $\begin{array}{l}\text { Z.n. Missbrauch bei } \\
\text { Verordnung }\end{array}$ & Illegaler Missbrauch \\
\hline Kontrollkollektiv Männer & $0 \%$ & $2,86 \%$ & $0 \%$ \\
\hline schizophrene Männer & $2,50 \%$ & $5 \%$ & $0 \%$ \\
\hline schizophrene Frauen & $9,52 \%$ & $19,05 \%$ & $0 \%$ \\
\hline Kontrollkollektiv Frauen & $0 \%$ & $4,54 \%$ & $0 \%$ \\
\hline
\end{tabular}

Benzodiazepinmissbrauch: 61 Psychose-Patienten, Kontrollkollektiv 57 Patienten 


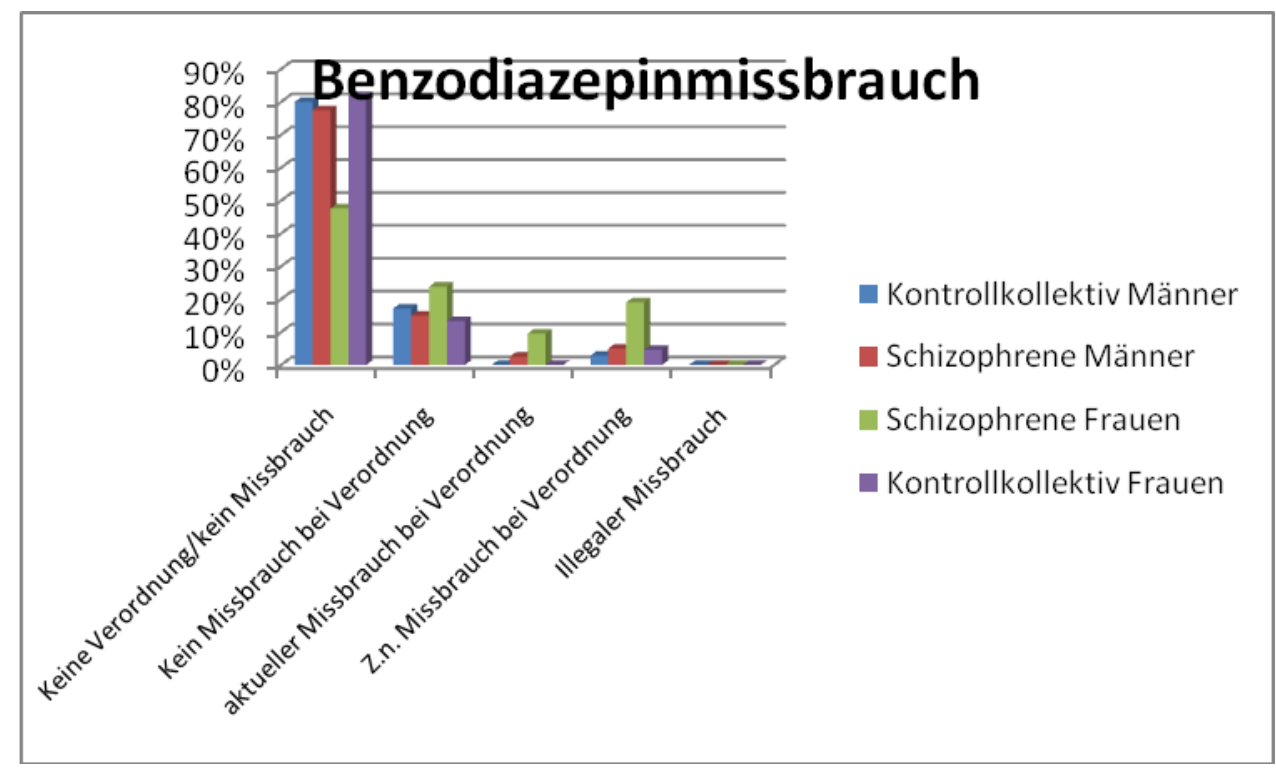

Benzodiazepin Missbrauch: 61 Psychose-Patienten, Kontrollkollektiv 57 Patienten.

Ermittlung des Missbrauchs für Benzodiazepine/items:

- Von der ärztlichen Verordnung abweichender Gebrauch der Benzodiazepine.

- Tägliche Einnahme von Benzodiazepinen über einen Zeitraum von > 4 Monaten

- Illegaler Gebrauch von Benzodiazepinen ohne ärztliche Verordnung

- Einbezug des aktuellen Missbrauchs und des zurückliegenden Benzodiazepinmissbrauchs

\section{4-6.1 Statistische Auswertung des Benzodiazepinmissbrauchs}

\section{a-Gesamtkollektivvergleich Benzodiazepinmissbrauch/Kruskal-Wallis-Test}

Ränge

\begin{tabular}{|l|l|l|}
\hline Gruppe & N & $\begin{array}{l}\text { Mittlerer } \\
\text { Rang }\end{array}$ \\
\hline $\begin{array}{l}\text { schizophrene } \\
\text { Männer }\end{array}$ & 40 & $\mathbf{5 7 , 1 8}$ \\
\hline $\begin{array}{l}\text { schizophrene } \\
\text { Frauen }\end{array}$ & 21 & $\mathbf{7 6 , 3 6}$ \\
\hline $\begin{array}{l}\text { Kontrollkollektiv } \\
\text { Männer }\end{array}$ & 35 & $\mathbf{5 5 , 1 9}$ \\
\hline $\begin{array}{l}\text { Kontrollkollektiv } \\
\text { Frauen }\end{array}$ & 22 & $\mathbf{5 4 , 5 0}$ \\
\hline Gesamt & 118 & \\
\hline
\end{tabular}

Statistik für Test a 


\begin{tabular}{|l|l|}
\hline & $\begin{array}{l}\text { Benzodiazepin } \\
\text { Missbrauch }\end{array}$ \\
\hline Chi-Quadrat & $\mathbf{1 0 , 6 2 4}$ \\
\hline Df & $\mathbf{3}$ \\
\hline $\begin{array}{l}\text { asymptotische } \\
\text { Signifikanz }\end{array}$ & $\mathbf{, 0 1 4}$ \\
\hline
\end{tabular}

Statistik für Test a,b

a. Kruskal-Wallis- Test

b. Gruppenvariable : Gruppe

\section{b- Signifikanz des Benzodiazepinmissbrauchs im Einzelkollektivvergleich/} Mann-Withney-Test

Ränge

\begin{tabular}{|l|l|l|l|}
\hline Benzodiazepinmissbrauch & $\mathbf{N}$ & Mittlerer Rang & Rangsumme \\
\hline schizophrene Männer & $\mathbf{4 0}$ & $\mathbf{3 8 , 5 8}$ & $\mathbf{1 5 4 3 , 0 0}$ \\
\hline Kontrollkollektiv Männer & $\mathbf{3 5}$ & $\mathbf{3 7 , 3 4}$ & $\mathbf{1 3 0 7 , 0 0}$ \\
\hline gesamt & $\mathbf{7 5}$ & & \\
\hline
\end{tabular}

\section{Statistik für Test a}

\begin{tabular}{|l|l|}
\hline & Benzodiazepinmissbrauch \\
\hline Mann-Withney-U & $\mathbf{6 7 7 , 0 0}$ \\
Wilcoxon-W & 1307,000 \\
Z &,- 342 \\
asymptotische & \\
Signifikanz (2 seitig) & .732 \\
\hline
\end{tabular}


Ränge

\begin{tabular}{|l|l|l|l|}
\hline Benzodiazepinmissbrauch & N & Mittlerer Rang & Rangsumme \\
\hline schizophrene Frauen & 21 & $\mathbf{2 6 , 0 2}$ & $\mathbf{5 4 6 , 5 0}$ \\
\hline Kontrollkollektiv Frauen & 22 & 18,16 & $\mathbf{3 9 9 , 5 0}$ \\
\hline Gesamt & 43 & & \\
\hline \hline
\end{tabular}

Statistik für Test a

\begin{tabular}{|l|l|}
\hline & Benzodiazepinmissbrauch \\
\hline Mann-Withney-U & $\mathbf{1 4 6 , 5 0 0}$ \\
Wilcoxon-W & $\mathbf{3 9 9 , 5 0 0}$ \\
Z & $\mathbf{- 2 , 4 2 6}$ \\
asymptotische & \\
Signifikanz (2 seitig) &, 015 \\
\hline
\end{tabular}

\begin{tabular}{|l|l|l|l|}
\multicolumn{2}{|l}{ Ränge } \\
\hline Benzodiazepinmissbrauch & N & Mittlerer Rang & Rangsumme \\
\hline schizophrene Patienten & 61 & $\mathbf{6 3 , 7 8}$ & $\mathbf{3 8 9 0 , 5 0}$ \\
\hline $\begin{array}{l}\text { Kontrollkollektiv } \\
\text { Patienten }\end{array}$ & $\mathbf{5 7}$ & $\mathbf{5 4 , 9 2}$ & $\mathbf{3 1 3 0 , 5 0}$ \\
\hline gesamt & 118 & & \\
\hline
\end{tabular}

\section{Statistik für Test a}

\begin{tabular}{|l|l|}
\hline & Benzodiazepinmissbrauch \\
\hline Mann-Withney-U & $\mathbf{1 4 7 7 , 5 0 0}$ \\
Wilcoxon-W & $\mathbf{3 1 3 0 , 5 0 0}$ \\
Z & $-1,824$ \\
asymptotische & \\
Signifikanz (2 seitig) &, 068 \\
\hline
\end{tabular}

Die Daten zeigten eine statistische Signifikanz im Einzelkollektivvergleich

bei Betrachtung der schizophrenen Frauen versus der Kontrollkollektivgruppe Frauen.

Schizophrene Patientinnen erhielten im Vergleich zu schizophrenen Männern und

Frauen des Kontrollkollektives weitaus häufiger Benzodiazepine verordnet.

Auch zeigte sich eine deutliche höhere Rate des Benzodiazepinmissbrauchs und

Zustand nach einem Benzodiazepinmissbrauchs in der Gruppe der schizophrenen Frauen im Gegensatz zur Kontrollgruppe. 


\section{4-7 Benzodiazepinabhängigkeit / ICD 10 [Dilling et al. 1993]: F13.2}

Die Benzodiazepinabhängigkeit wurde auf Grund der ermittelten Daten des Missbrauchs mit Hinzunahme der Daten Entzugserscheinungen beim Absetzen der Benzodiazepine, kompensatorischer Wiedereinnahme von Benzodiazepinen bei Auftreten von Entzugserscheinungen, sowie anamnestischen Daten über Entgiftungs- und Entwöhnungsbehandlungen ermittelt. Es ergaben sich Werte für Benzodiazepinabhängigkeit, die für die schizophrenen Männern bei 7,5\% versus 2,86\% bei den Männern des Kontrollkollektives lagen. Demgegenüber betrugen die Werte für Benzodiazepinabhängigkeit bei den schizophrenen Frauen 19,05\% und 0\% bei den Frauen des Kontrollkollektivs.

Tabelle 12a

\begin{tabular}{|l|l|l|l|}
\hline & $\begin{array}{l}\text { Benzodiazepinabhängigkeit/Z.n. } \\
\text { Benzodiazepinabhängigkeit }\end{array}$ & $\begin{array}{l}\text { Keine } \\
\text { Benzodiazepinabhängigkeit }\end{array}$ & Gesamt \\
\hline Schizophrene Männer & 3 & 37 & 40 \\
\hline & $7,5 \%$ & $92,5 \%$ & 35 \\
\hline $\begin{array}{l}\text { Kontrollkollektiv } \\
\text { Männer }\end{array}$ & 1 & 34 & 21 \\
\hline & $2,86 \%$ & $97,14 \%$ & \\
\hline Schizophrene Frauen & 4 & 17 & 22 \\
\hline & $19,05 \%$ & 80,95 & \\
\hline Kontrollkollektiv Frauen & 0 & 22 & $100 \%$ \\
\hline & $0 \%$ & & \\
\hline
\end{tabular}

Benzodiazepinabhängigkeit: 61 Psychose-Patienten, Kontrollkollektiv 57 Patienten 
Abbildung 7a

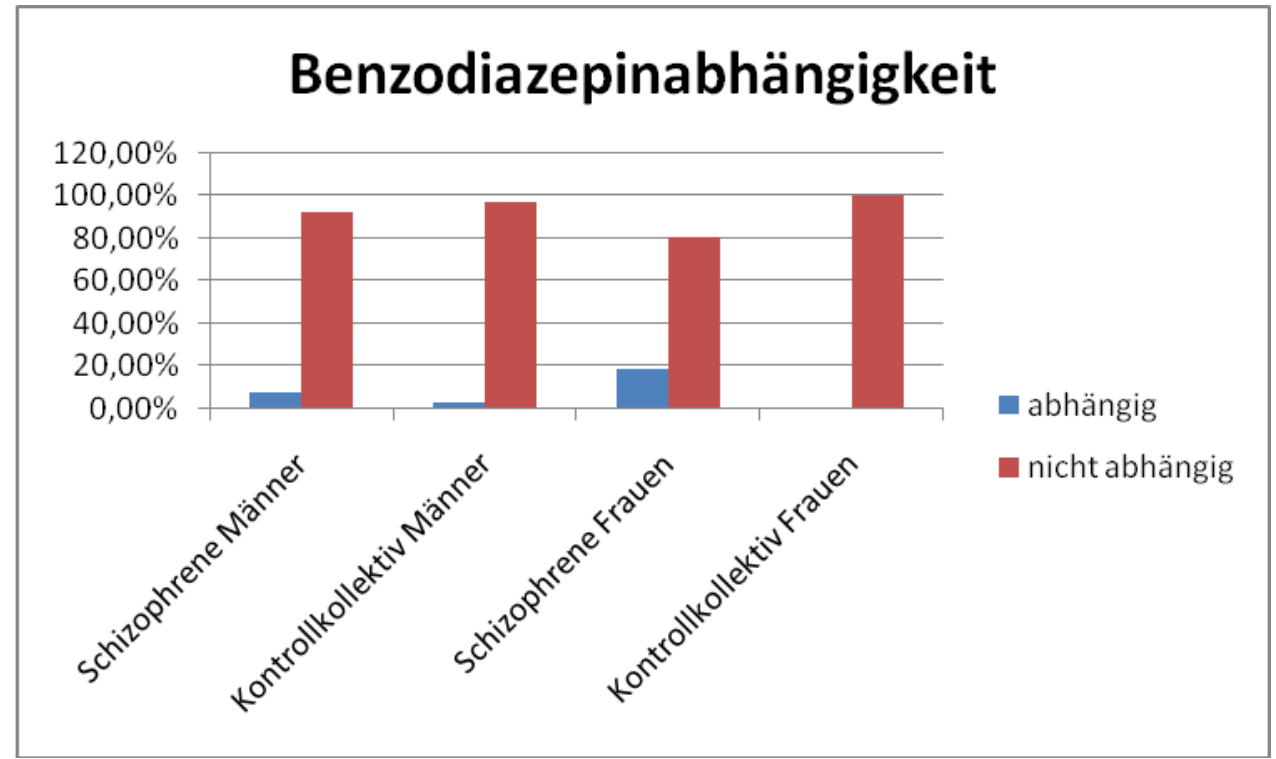

Benzodiazepinabhängigkeit: 61 Psychose-Patienten, Kontrollkollektiv 57 Patienten:

Items :

- Von der ärztlichen Verordnung abweichender Gebrauch der Benzodiazepine.

-Tägliche Einnahme von Benzodiazepinen über einen Zeitraum von > 4 Monaten

- Illegaler Gebrauch von Benzodiazepinen ohne ärztliche Verordnung

- Einbezug des aktuellen Missbrauchs und des zurückliegenden Benzodiazepinmissbrauchs

- Entzugserscheinungen nach Absetzen und kompensatorische Einnahme von Benzodiazepinen wegen Entzugserscheinungen

- Entgiftung und Entwöhnungsbehandlungen. 
4-7.1 Statistische Auswertung der Benzodiazepinabhängigkeit

a-Gesamtkollektivvergleich-Kruskal-Wallis-Test

Ränge

\begin{tabular}{|l|l|l|}
\hline Gruppe & N & $\begin{array}{l}\text { mittlerer } \\
\text { Rang }\end{array}$ \\
\hline $\begin{array}{l}\text { Männer } \\
\text { schizophrene } \\
\text { Frauen }\end{array}$ & 40 & 59,93 \\
\hline $\begin{array}{l}\text { Kontrollkollektiv } \\
\text { Männer }\end{array}$ & 35 & 66,74 \\
\hline Kontrollkollektiv & 22 & 57,19 \\
Frauen & & 55,50 \\
\hline Gesamt & 118 & \\
\hline
\end{tabular}

Statistik für Test a

\begin{tabular}{|l|l|}
\hline & $\begin{array}{l}\text { Benzodiazepin- } \\
\text { abhängigkeit }\end{array}$ \\
\hline Chi-Quadrat & 7,422 \\
\hline df & 3 \\
\hline $\begin{array}{l}\text { Asymptotische } \\
\text { Signifikanz }\end{array}$ &, 060 \\
\hline
\end{tabular}

Statistik für Test $a, b$
a. Kruskal-Wallis- Test
b. Gruppenvariable : Gruppe

b- Benzodiazepinabhängigkeit im Einzelkollektivvergleich- Mann-Withney-Test

Ränge

\begin{tabular}{|l|l|l|l|}
\hline $\begin{array}{l}\text { Benzodiazepin- } \\
\text { abhängigkeit }\end{array}$ & N & mittlerer Rang & Rangsumme \\
\hline schizophrene Männer & 40 & $\mathbf{3 8 , 8 1}$ & 1552,50 \\
\hline $\begin{array}{l}\text { Kontrollkollektiv } \\
\text { Männer }\end{array}$ & 35 & 37,07 & 1297,50 \\
\hline gesamt & 75 & & \\
\hline
\end{tabular}

Statistik für Test a

\begin{tabular}{|l|l|}
\hline & $\begin{array}{l}\text { Benzodiazepin } \\
\text { Abhängigkeit }\end{array}$ \\
\hline Mann-Withney-U & $\mathbf{6 6 7 , 0 0}$ \\
Wilcoxon-W & $\mathbf{1 2 9 7 , 5 0 0}$ \\
Z &,- 887 \\
asymptotische & \\
Signifikanz (2 seitig) &, 375 \\
\hline
\end{tabular}


Ränge

\begin{tabular}{|l|l|l|l|}
\hline Benzodiazepinabhängigkeit & N & Mittlerer Rang & Rangsumme \\
\hline schizophrene Frauen & 21 & $\mathbf{2 4 , 1 0}$ & $\mathbf{5 0 6 , 0 0}$ \\
\hline Kontrollkollektiv Frauen & 22 & $\mathbf{2 0 , 0 0}$ & $\mathbf{4 4 0 , 0 0}$ \\
\hline gesamt & 43 & & \\
\hline
\end{tabular}

\section{Statistik für Test a}

\begin{tabular}{|l|l|}
\hline & $\begin{array}{l}\text { Benzodiazepin } \\
\text { Abhängigkeit }\end{array}$ \\
\hline Mann-Withney-U & 187,00 \\
Wilcoxon-W & 440,00 \\
Z & $-2,124$ \\
asymptotische & \\
Signifikanz (2 seitig) & $\mathbf{0 , 0 3 4}$ \\
\hline
\end{tabular}

\section{Ränge}

\begin{tabular}{|l|l|l|l|}
\hline Benzodiazepinabhängigkeit & N & Mittlerer Rang & Rangsumme \\
\hline schizophrene Patienten & 61 & $\mathbf{6 2 , 2 7}$ & $\mathbf{3 7 9 8 , 5 0}$ \\
\hline Kontrollkollektiv Patienten & $\mathbf{5 7}$ & $\mathbf{5 6 , 5 4}$ & \\
\hline Gesamt & 118 & & $\mathbf{3 2 2 2 , 5 0}$ \\
\hline
\end{tabular}

Statistik für Test a

\begin{tabular}{|l|l|}
\hline & $\begin{array}{l}\text { Benzodiazepin- } \\
\text { abhängigkeit }\end{array}$ \\
\hline Mann-Withney-U & $\mathbf{1 5 6 9 , 5 0 0}$ \\
Wilcoxon-W & $\mathbf{3 2 2 2 , 5 0 0}$ \\
$\mathrm{Z}$ & $-\mathbf{2 , 0 9 0}$ \\
asymptotische & \\
Signifikanz (2 seitig) & $\mathbf{0 , 0 3 7}$ \\
\hline
\end{tabular}


BeimVergleich der Häufigkeiten der Benzodiazepinabhängigkeiten ergaben sich signifikante Unterschiede im Einzelkollektivvergleich schizophrene Frauen und Kontrollkollektiv Frauen, sowie bei der Gegenüberstellung des Gesamtkollektivs schizophrene Patienten versus Kontrollkollektiv, hingegen nicht im Gruppenvergleich schizophrene Männer versus Kontrollkollektiv Männer.

\section{4-8 Cannabisgebrauch, Cannabismissbrauch/ICD 10 [Dilling et al. 1993]: F12.1 und Cannabisabhängigkeit/ ICD 10 [Dilling et al. 1993]: F12.2}

Bei der Auswertung des Cannabiskonsums wurde zuerst die Einteilung: Cannabis nie genutzt, Cannabis ausprobiert - kein längerer Gebrauch, regelmäßige Nutzung früher und regelmäßige Nutzung aktuell gewählt.

Im zweiten Schritt wurde für die aktuelle und in der Vergangenheit liegende Cannabisnutzung die Häufigkeit differenziert (täglich/ 2-3 x wöchentlich/ 1-2x wöchentlich/1-2 x monatlich). Die Ermittlung des Cannabiskonsums und der Cannabisabhängigkeit erfolgte mit Hilfe der Befragung. Eine Cannabisabhängigkeit wurde definiert bei täglichem Gebrauch über eine Dauer von mehr als 3 Monaten, Entzugserscheinungen bei Einstellen der Cannabisnutzung, sowie kompensatorischer Konsum von THC bei Entzugserscheinungen.Die Mengen des täglichen Konsums wurden erfragt und differierten zwischen 1-3 g/d THC.

In der Gruppe der Kontrollgruppenfrauen bestand der höchste Anteil der Cannabisnichtnutzerinnen mit 86,36\%, im Vergleich dazu zeigte sich der Anteil der schizophrenen Frauen bei 66,66\%. Dieser Wert lag unter dem Wert für Nichtnutzer im Kontrollkollektivder Männer von 77,14\%. Der niedrigste Wert für den Nicht-Cannabisnutzer bestand bei den schizophrenen Männern mit 57,5\%, daraus folgt, dass der höchste Kontakt mit der Droge Cannabis sich in dem Kollektiv der schizophrenen Männern zeigte. Auch die höchsten Anzahlen für einen aktuellen regelmäßigen Cannabiskonsum fanden sich im Kollektiv der schizophrenen Patienten (schizophrene Männer > schizophrene Frauen). Bei den schizophrenen Frauen zeigte sich in der Vergangenheit häufiger täglicher Cannabisgebrauch imVergleich zu den schizophrenen Männern. 
Tabelle 13

\begin{tabular}{|l|l|l|l|l|}
\hline & Cannabis nie genutzt & $\begin{array}{l}\text { Cannabis ausprobiert, } \\
\text { kein aktueller } \\
\text { Konsum }\end{array}$ & $\begin{array}{l}\text { Regelmäßige aktuelle } \\
\text { Nutzung von } \\
\text { Cannabis }\end{array}$ & $\begin{array}{l}\text { Früher regelmäßige } \\
\text { Nutzung von } \\
\text { Cannabis }\end{array}$ \\
\hline Schizophrene Männer & 23 & 6 & $3+\mathbf{4}$ & 4 \\
\hline $\begin{array}{l}\text { Kontrollkollektiv } \\
\text { Männer }\end{array}$ & 27 & 7 & $1+\mathbf{0}$ & 0 \\
\hline $\begin{array}{l}\text { Kontrollkollektiv } \\
\text { Frauen }\end{array}$ & 19 & 1 & 1 & 1 \\
\hline Schizophrene Frauen & 14 & & $0+\mathbf{1}$ & 4 \\
\hline
\end{tabular}

Cannabisnutzung: 61 Psychose-Patienten, Kontrollkollektiv 57 Patienten,

Fett gedruckte Zahlen unter regelmäßige Nutzung sind Daten für die tägliche aktuelle Nutzung von Cannabis.

Tabelle 14

\begin{tabular}{|l|l|l|l|l|l|}
\hline & $\begin{array}{l}\text { Cannabis } \\
\text { nie } \\
\text { genutzt }\end{array}$ & $\begin{array}{l}\text { Cannabis } \\
\text { ausprobiert, } \\
\text { kein } \\
\text { aktueller } \\
\text { Konsum }\end{array}$ & $\begin{array}{l}\text { Regelmäßige } \\
\text { aktuelle } \\
\text { Nutzung von } \\
\text { Cannabis }\end{array}$ & $\begin{array}{l}\text { Früher } \\
\text { regelmäßige } \\
\text { Nutzung von } \\
\text { Cannabis }\end{array}$ & $\begin{array}{l}\text { Gesamtnutzer } \\
\text { regelmäßig } \\
\text { aktuelle und } \\
\text { regelmäßige } \\
\text { Cannabisnutzung } \\
\text { In der } \\
\text { Vergangenheit) }\end{array}$ \\
\hline $\begin{array}{l}\text { Schizophrene } \\
\text { Männer }\end{array}$ & $57,5 \%$ & $15 \%$ & $17,5 \%$ & $10 \%$ & $27,5 \%$ \\
\hline $\begin{array}{l}\text { Kontrollkollektiv } \\
\text { Männer }\end{array}$ & $77,14 \%$ & $20 \%$ & $2,86 \%$ & $0 \%$ & $2,86 \%$ \\
\hline $\begin{array}{l}\text { Kontrollkollektiv } \\
\text { Frauen }\end{array}$ & $86,36 \%$ & $4,56 \%$ & $4,56 \%$ & $4,56 \%$ & $9,02 \%$ \\
\hline $\begin{array}{l}\text { Schizophrene } \\
\text { Frauen }\end{array}$ & $66,66 \%$ & $9,52 \%$ & $4,76 \%$ & $19,05 \%$ & $23,81 \%$ \\
\hline
\end{tabular}

Cannabisnutzung: 61 Psychose-Patienten, Kontrollkollektiv 57 Patienten, 


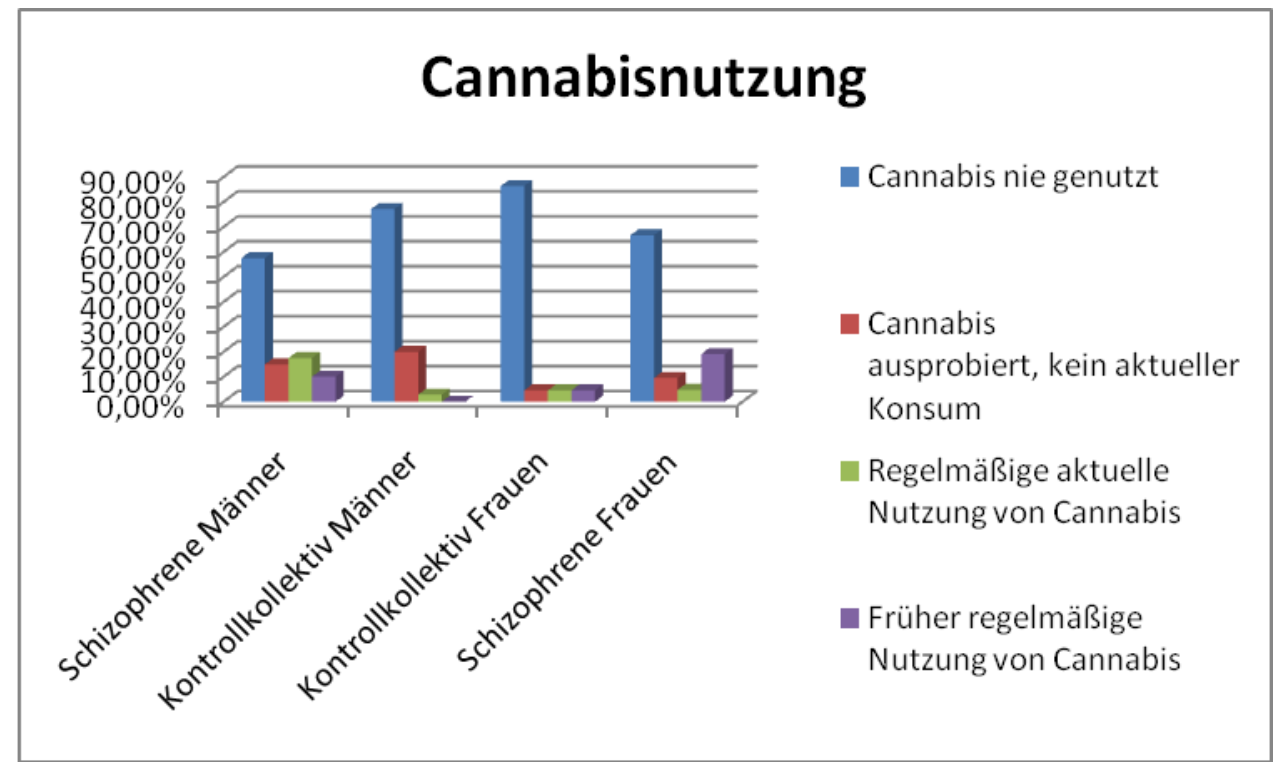

Cannabisnutzung: 61 Psychose- Patienten, Kontrollkollektiv 57 Patienten,

Abbildung 8a

\section{Cannabisnutzung/ Gesamtnutzer}

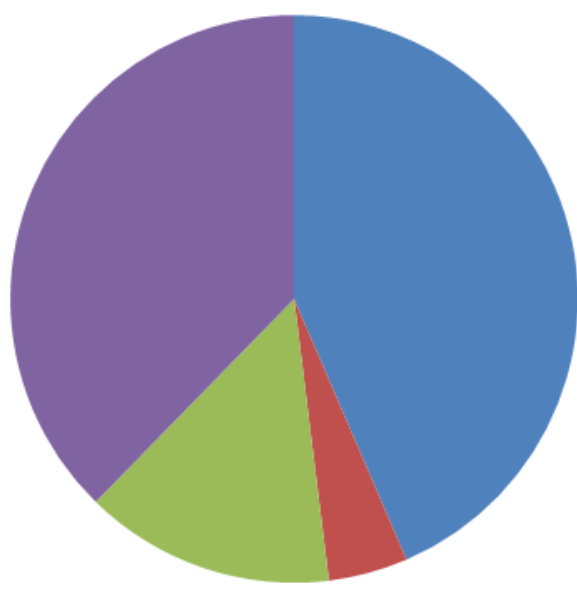

- Schizophrene Männer

[ Kontrollkollektiv Männer

Kontrollkollektiv Frauen

- Schizophrene Frauen

Cannabisgesamtnutzer Darstellung im Kollektivvergleich: 61 Psychose-Patienten, Kontrollkollektiv 57 Patienten, 
4-8.1 Signifikanz der Cannabisnutzung im Gesamtkollektiv

a-Gesamtkollektivvergleich-Cannabisnutzung-Kruskal-Wallis-Test

Statistik für Test a

Ränge
\begin{tabular}{|l|l|l|}
\hline Gruppe & N & $\begin{array}{l}\text { Mittlerer } \\
\text { Rang }\end{array}$ \\
\hline $\begin{array}{l}\text { schizophrene } \\
\text { Männer }\end{array}$ & 40 & 68,03 \\
\hline $\begin{array}{l}\text { schizophrene } \\
\text { Frauen }\end{array}$ & 21 & 63,00 \\
\hline $\begin{array}{l}\text { Kontrollkollektiv } \\
\text { Männer }\end{array}$ & 35 & 53,61 \\
\hline $\begin{array}{l}\text { Kontrollkollektiv } \\
\text { Frauen }\end{array}$ & 22 & 50,02 \\
\hline Gesamt & 118 & \\
\hline
\end{tabular}

\begin{tabular}{|l|l|}
\hline & Cannabisnutzung \\
\hline Chi-Quadrat & 8,366 \\
\hline Df & 3 \\
\hline $\begin{array}{l}\text { asymptotische } \\
\text { Signifikanz }\end{array}$ &, 039 \\
\hline
\end{tabular}

Statistik für Test a,b

b- Signifikanz der Cannabisnutzung im Einzelkollektivvergleich

Ränge

\begin{tabular}{|l|l|l|l|}
\hline Cannabisnutzung & N & Mittlerer Rang & Rangsumme \\
\hline schizophrene Männer & 40 & 42,43 & 1697,00 \\
\hline $\begin{array}{l}\text { Kontrollkollektiv } \\
\text { Männer }\end{array}$ & 35 & 32,92 & 1153,00 \\
\hline Gesamt & 75 & & \\
\hline
\end{tabular}

Statistik für Test a

\begin{tabular}{|l|l|}
\hline & Cannabisnutzung \\
\hline Mann-Withney-U & $\mathbf{5 2 1 , 0 0 0}$ \\
Wilcoxon-W & 1153,000 \\
Z & $-2,250$ \\
Asymptotische & \\
Signifikanz (2 seitig) &, 024 \\
\hline
\end{tabular}


Ränge

\begin{tabular}{|l|l|l|l|}
\hline Cannabisnutzung & N & mittlerer Rang & Rangsumme \\
\hline schizophrene Frauen & 21 & $\mathbf{2 4 , 3 3}$ & $\mathbf{5 1 1 , 0 0}$ \\
\hline Kontrollkollektiv Frauen & $\mathbf{2 2}$ & 19,77 & $\mathbf{4 3 5 , 0 0}$ \\
\hline Gesamt & 43 & & \\
\hline
\end{tabular}

Statistik für Test a

\begin{tabular}{|l|l|}
\hline & Cannabisnutzung \\
\hline Mann-Withney-U & 182,00 \\
Wilcoxon-W & 435,000 \\
Z & $-1,611$ \\
asymptotische & \\
Signifikanz (2 seitig) &, 107 \\
\hline
\end{tabular}

Ränge

\begin{tabular}{|l|l|l|l|}
\hline Cannabisnutzung & N & Mittlerer Rang & Rangsumme \\
\hline schizophrene Patienten & 61 & 66,30 & 4044,00 \\
\hline $\begin{array}{l}\text { Kontrollkollektiv } \\
\text { Patienten }\end{array}$ & 57 & 52,23 & 2977,00 \\
\hline gesamt & 118 & & \\
\hline
\end{tabular}

Statistik für Test a

\begin{tabular}{|l|l|}
\hline & Cannabisnutzung \\
\hline Mann-Withney-U & 1324,000 \\
Wilcoxon-W & 2977,000 \\
Z & $-2,771$ \\
asymptotische & \\
Signifikanz (2 seitig) &, 006 \\
\hline
\end{tabular}

Die Cannabisnutzung zeigte eine Signifikanz im Gesamtgruppenvergleich, die sich im Einzelkollektivvergleich schizophrene Männer versus Kontrollkollektiv Männer sowie im Einzelkollektivvergleich schizophrene Patienten versus Kontrollkollektivpatienten bestätigte. Daraus folgte schizophrene Patienten nutzten signifikant häufiger Cannabis als Kontrollpersonen in dieser Untersuchung. Im Einzelkollektivvergleich nutzen schizophrene Männer im Gegensatz zu Kontrollkollektiv Männern signifikant mehr Cannabis. Unterschiede in der Häufigkeit der Cannabisnutzung, bei den schizophrenen Frauen imVergleich zu Frauen der Kontrollgruppe zeigten sich hingegen nicht signifikant. 


\section{4-8.2 Häufigkeitsverteilung der aktuellen regelmäßigen Cannabisnutzung}

Tabelle 14 a

\begin{tabular}{|l|l|l|l|l|}
\hline Häufigkeit & $1-2 \times$ Monat & $1-2 \times$ Woche & $2-3 \times$ Woche & täglich \\
\hline schizophrene Männer & 1 & 3 & 1 & 4 \\
\hline schizophrene Frauen & 0 & 0 & 0 & 1 \\
\hline $\begin{array}{l}\text { Kontrollkollektiv } \\
\text { Männer }\end{array}$ & 0 & 1 & 0 & 0 \\
\hline $\begin{array}{l}\text { Kontrollkollektiv } \\
\text { Frauen }\end{array}$ & 1 & 0 & 0 & 0 \\
\hline
\end{tabular}

Häufigkeit der Cannabisnutzung: 61 Psychose-Patienten, 57 Kontrollkollektivpatienten

\section{4-8.3 Häufigkeitsverteilung der regelmäßigen Cannabisnutzung in der Vergangenheit}

Tabelle $14 \mathrm{~b}$

\begin{tabular}{|l|l|l|l|l|}
\hline Häufigkeit & $1-2$ x Monat & $1-2$ x Woche & $2-3$ x Woche & Täglich \\
\hline Schizophrene Männer & 2 & 1 & 0 & 0 \\
\hline Schizophrene Frauen & 0 & 2 & 0 & 2 \\
\hline $\begin{array}{l}\text { Kontrollkollektiv } \\
\text { Männer }\end{array}$ & 0 & 0 & 0 & 0 \\
\hline $\begin{array}{l}\text { Kontrollkollektiv } \\
\text { Frauen }\end{array}$ & 0 & 0 & 0 & 1 \\
\hline
\end{tabular}

Häuigkeitsverteilung der Cannabisnutzung: 61 Psychose-Patienten, 57 Kontrollkollektivpatienten 


\section{4-8.4 Darstellung der Cannabisabhängigkeit}

Tabelle 15

\begin{tabular}{|l|l|l|}
\hline $\begin{array}{l}\text { täglicher } \\
\text { Cannabiskonsum/aktuell } \\
\text { oder früher > 3 Monaten } \\
\text { Abhängigkeit F }\end{array}$ & Abhängig & Nichtabhängig \\
\hline schizophrene Männer & $10 \%$ & $90 \%$ \\
\hline $\begin{array}{l}\text { Kontrollkollektiv } \\
\text { Männer }\end{array}$ & $0 \%$ & $100 \%$ \\
\hline $\begin{array}{l}\text { Kontrollkollektiv } \\
\text { Frauen }\end{array}$ & $0 \%$ & $100 \%$ \\
\hline schizophrene Frauen & $14,28 \%$ & $85,28 \%$ \\
\hline
\end{tabular}

Cannabisabhängigkeit: 61 Psychose- Patienten, Kontrollkollektiv 57 Patienten .

Abbildung 9

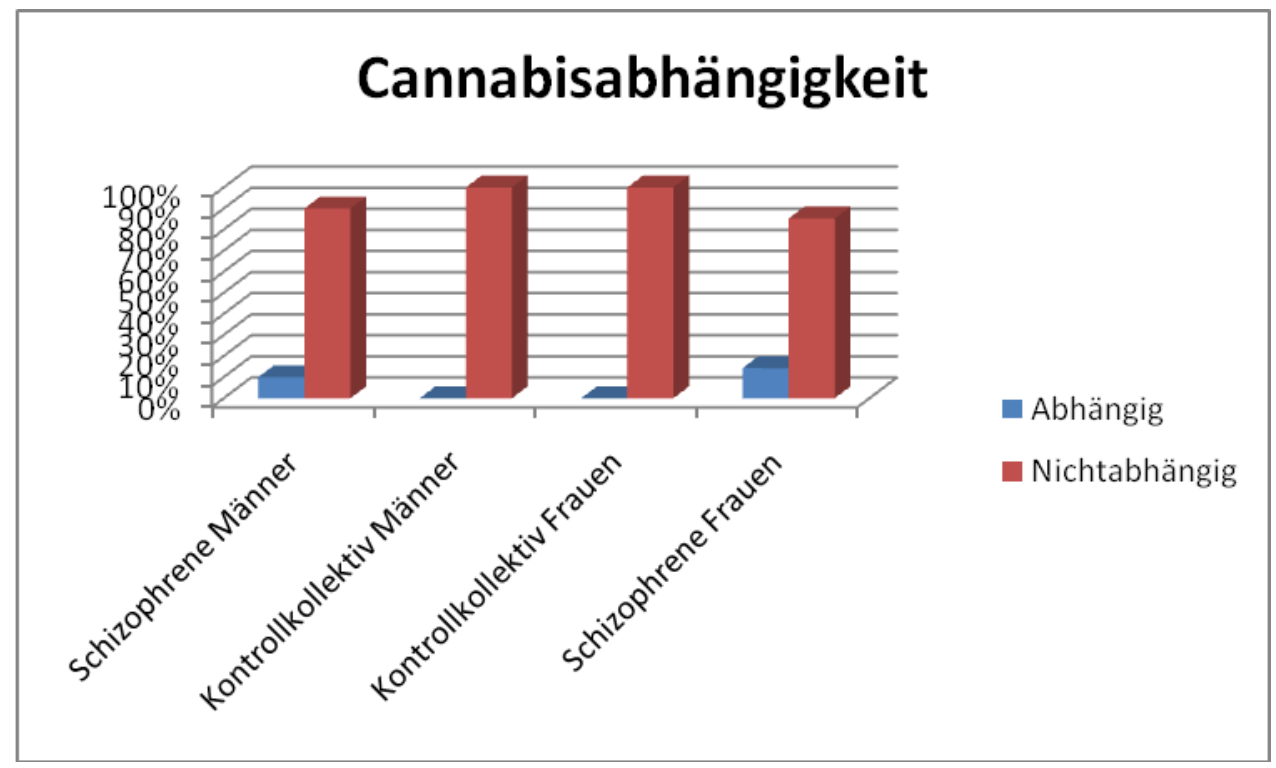

Cannabisabhängigkeit: 61 Psychose-Patienten, Kontrollkollektiv 57 Patienten.

Ermittlung des Cannabiskonsums laut Befragung. Abhängigkeit definiert sich bei täglichem Gebrauch > 3 Monaten,

Toleranzentwicklung, Entzugserscheinungen beim Absetzen. Mengenangaben differierten zwischen 1-3 g/d bei Angabe für den täglichen Gebrauch. 
4-8.5 Statistische Auswertung der Cannabisabhängigkeit a-Gesamtkollektivvergleich Cannabisabhängigkeit-Kruskal-Wallis-Test

\begin{tabular}{|l|l|l|}
\hline Gruppe & N & \\
\hline $\begin{array}{l}\text { Schizophrene } \\
\text { Männer }\end{array}$ & 40 & 61,9 \\
\hline $\begin{array}{l}\text { Schizophrene } \\
\text { Frauen }\end{array}$ & 21 & 64,43 \\
\hline $\begin{array}{l}\text { Kontrollkollektiv } \\
\text { Männer }\end{array}$ & 35 & 56,00 \\
\hline $\begin{array}{l}\text { Kontrollkollektiv } \\
\text { Frauen }\end{array}$ & 22 & 58,00 \\
\hline Gesamt & 118 & \\
\hline
\end{tabular}

Statistik für Test a

\begin{tabular}{|l|l|}
\hline & Cannabisabhängigkeit \\
\hline Chi-Quadrat & 7,344 \\
\hline df & 3 \\
\hline $\begin{array}{l}\text { Asymptotische } \\
\text { Signifikanz }\end{array}$ & 0,062 \\
\hline
\end{tabular}

b- Einzelkollektivvergleich Cannabisabhängigkeit-Mann-Withney-Test

Ränge

\begin{tabular}{|l|l|l|l|}
\hline Cannabisabhängigkeit & $\mathrm{N}$ & mittlerer Rang & Rangsumme \\
\hline schizophrene Männer & $\mathbf{4 0}$ & $\mathbf{3 9 , 7 5}$ & $\mathbf{1 5 9 0 , 0 0}$ \\
\hline $\begin{array}{l}\text { Kontrollkollektiv } \\
\text { Männer }\end{array}$ & 35 & $\mathbf{3 6 , 0 0}$ & $\mathbf{1 2 6 0 , 0 0}$ \\
\hline gesamt & $\mathbf{7 5}$ & & \\
\hline
\end{tabular}

Statistik für Test a

\begin{tabular}{|l|l|}
\hline & Cannabisabhängigkeit \\
\hline Mann-Withney-U & 630,000 \\
Wilcoxon-W & 1260,000 \\
Z & $-1,910$ \\
asymptotische & \\
Signifikanz (2 seitig) &, 056 \\
\hline
\end{tabular}


Ränge

\begin{tabular}{|l|l|l|l|}
\hline Cannabisnutzung & N & Mittlerer Rang & Rangsumme \\
\hline schizophrene Frauen & 21 & 23,57 & 495,00 \\
\hline Kontrollkollektiv Frauen & 22 & 20,50 & 451,00 \\
\hline gesamt & 43 & & \\
\hline
\end{tabular}

Statistik für Test a

\begin{tabular}{|l|l|}
\hline & Cannabisabhängigkeit \\
\hline Mann-Withney-U & 198,00 \\
Wilcoxon-W & 451,00 \\
Z & $-1,817$ \\
asymptotische & \\
Signifikanz (2 seitig) &, 069 \\
\hline
\end{tabular}

Ränge

\begin{tabular}{|l|l|l|l|}
\hline Cannabisabhängigkeit & N & Mittlerer Rang & Rangsumme \\
\hline schizophrene Patienten & 61 & 62,77 & $\mathbf{3 8 2 9 , 0 0}$ \\
\hline $\begin{array}{l}\text { Kontrollkollektiv } \\
\text { Patienten }\end{array}$ & 57 & $\mathbf{5 6 , 0 0}$ & $\mathbf{3 1 9 2 , 0 0}$ \\
\hline gesamt & 118 & & \\
\hline
\end{tabular}

Statistik für Test a

\begin{tabular}{|l|l|}
\hline & Cannabisabhängigkeit \\
\hline Mann-Withney-U & 1539,000 \\
Wilcoxon-W & 3192,000 \\
Z & $-2,66$ \\
asymptotische & \\
Signifikanz (2 seitig) &, 009 \\
\hline
\end{tabular}

Bei der Cannabisabhängigkeit zeigt sich ein Trend beim Vergleich des Gesamtkollektivs (alle vier Vergleichsgruppen schizophrene Frauen, schizophrene Männer, Kontrollkollektiv Männer und Kontrollkollektiv Frauen). Im Einzelkollektivvergleich schizophrene Patienten versus Kontrollkollektiv zeigten sich signifikante Werte für die Cannabisabhängigkeit, daraus folgte, dass signifikant mehr schizophrene Patienten Cannabis abhängig sind im Vergleich zu nicht schizophrenen Kontrollpersonen. 
4-8.6 Zeitlicher Zusammenhang der Cannabisnutzung und der Erstdiagnostik einer Schizophrenie:

Die Daten der schizophrenen Patienten wurden untersucht auf einen Zusammenhang zwischen Cannabisnutzung (aktuell und in der Vergangenheit) und der Erstdiagnostik einer Schizophrenie. Es ergaben sich keine signifikanten Daten.

4-8.7 Statistische Auswertung des zeitlichen Zusammenhanges zwischen der Erstdiagnostik einer Schizophrenie und des erhobenen Cannabiskonsums

a-Gesamtkollektivvergleich Erstdiagnostik Schizophrenie und CannabiskonsumKruskal-Wallis-Test

Ränge

\begin{tabular}{|l|l|l|}
\hline Gruppe & N & \\
\hline $\begin{array}{l}\text { schizophrene } \\
\text { Männer }\end{array}$ & 40 & 32,60 \\
\hline $\begin{array}{l}\text { schizophrene } \\
\text { Frauen }\end{array}$ & 21 & 27,95 \\
\hline
\end{tabular}

Statistik für Test a,b

\begin{tabular}{|l|l|}
\hline & $\begin{array}{l}\text { ED Schizophrenie und } \\
\text { Cannabisnutzung }\end{array}$ \\
\hline Chi-Quadrat & 2,501 \\
\hline df & 1 \\
\hline $\begin{array}{l}\text { asymptotische } \\
\text { Signifikanz }\end{array}$ & $\mathbf{0 , 1 1 4}$ \\
\hline
\end{tabular}

a. Kruskal-Wallis- Test

b. Gruppenvariable : Gruppe 
4-9 Abhängigkeit von Heroin /ICD 10 [Dilling et al. 1993] : F 11.2 und

\section{Abhängigkeit von Kokain/ ICD 10 [Dilling et al. 1993]: F 14.2}

Die Ermittlung der Substanzabhängigkeit erfolgte in der direkten Befragung einer aktuell bestehenden oder früher bestandenen Abhängigkeit von illegalen Drogen, differenziert gefragt wurde nach Kokain und Heroin. Bei den in der Studie untersuchten Klientel zeigte sich allein bei den schizophrenen Männern eine bestehende Abhängigkeit bei 2,5\%, dies entsprach einem männlichen schizophrenen Patienten, bei dem bereits über mehrere Jahre eine Polytoxikomanie incl. Opiatabhängigkeit bestand.

Tabelle 16

\begin{tabular}{|l|l|l|}
\hline $\begin{array}{l}\text { Heroin- bzw. Kokainabhängigkeit F11 } \\
\text { und F14 }\end{array}$ & nein & $J a$ \\
\hline schizophrene Männer & $97,5 \%$ & $2,5 \%$ \\
\hline schizophrene Frauen & $100 \%$ & $0 \%$ \\
\hline Kontrollkollektiv Männer & $100 \%$ & $0 \%$ \\
\hline Kontrollkollektiv Frauen & $100 \%$ & $0 \%$ \\
\hline
\end{tabular}

Heroinabhängigkeit: 61 Psychose-Patienten, Kontrollkollektiv 57 Patienten

\section{4-9.1 Statistische Auswertung der Heroin-/ Kokainabhängigkeit} a-Gesamtkollektivvergleich Heroin/Kokainabhängigkeit-Kruskal-Wallis-Test

\begin{tabular}{|l|l|}
\hline & $\begin{array}{l}\text { Besteht eine } \\
\text { Heroin/Kokainabhängigkeit }\end{array}$ \\
\hline Chi-Quadrat & $\mathbf{3 , 1 1 8}$ \\
\hline df & $\mathbf{3}$ \\
\hline $\begin{array}{l}\text { asymptotische } \\
\text { Signifikanz }\end{array}$ &, 374 \\
\hline
\end{tabular}




\section{4-10 Vermehrter täglicher Kaffeekonsum/ Missbrauch für Kaffee /ICD 10 [Dilling et al.}

1993]: F 15.1

Zur Ermittlung einer Abhängigkeit bzw. eines vermehrten Konsum wurde eine tägliche Trinkmenge von Kaffee bzw. koffeinhaltigem Tee von mehr als einem Liter definiert. Die größte Gruppe mit gesteigerten Kaffeekonsum, zeigte sich bei den schizophrenen Frauen mit 33,34\%, gefolgt von den schizophrenen Männern mit 20\%. Der Wert für das Kontrollkollektiv Frauen lag bei 9,1\% im Vergleich dazu bei den Männern des Kontrollkollektivs bei 5,71\%. Signifikante Unterschiede zeigten sich nicht.

Tabelle 17

\begin{tabular}{|l|l|l|}
\hline vermehrter Kaffeekonsum />1Liter/d & nein & Ja \\
\hline schizophrene Männer & 32 & 8 \\
\hline schizophrene Frauen & 14 & 7 \\
\hline Kontrollkollektiv Männer & 33 & 2 \\
\hline Kontrollkollektiv Frauen & 20 & 2 \\
\hline
\end{tabular}

Vermehrter Kaffeekonsum 1: 61 Psychose-Patienten, Kontrollkollektiv 57 Patienten

Tabelle 17a

\begin{tabular}{|l|l|l|}
\hline vermehrter Kaffeekonsum/>1 Liter/d & nein & $J a$ \\
\hline schizophrene Männer & $80 \%$ & $20 \%$ \\
\hline schizophrene Frauen & $66,66 \%$ & $33,34 \%$ \\
\hline Kontrollkollektiv Männer & $94,29 \%$ & $5,71 \%$ \\
\hline Kontrollkollektiv Frauen & $90,90 \%$ & $9,10 \%$ \\
\hline
\end{tabular}

Vermehrter Kaffeekonsum 2: 61 Psychose- Patienten, Kontrollkollektiv 57 Patienten. 
Abbildung 10

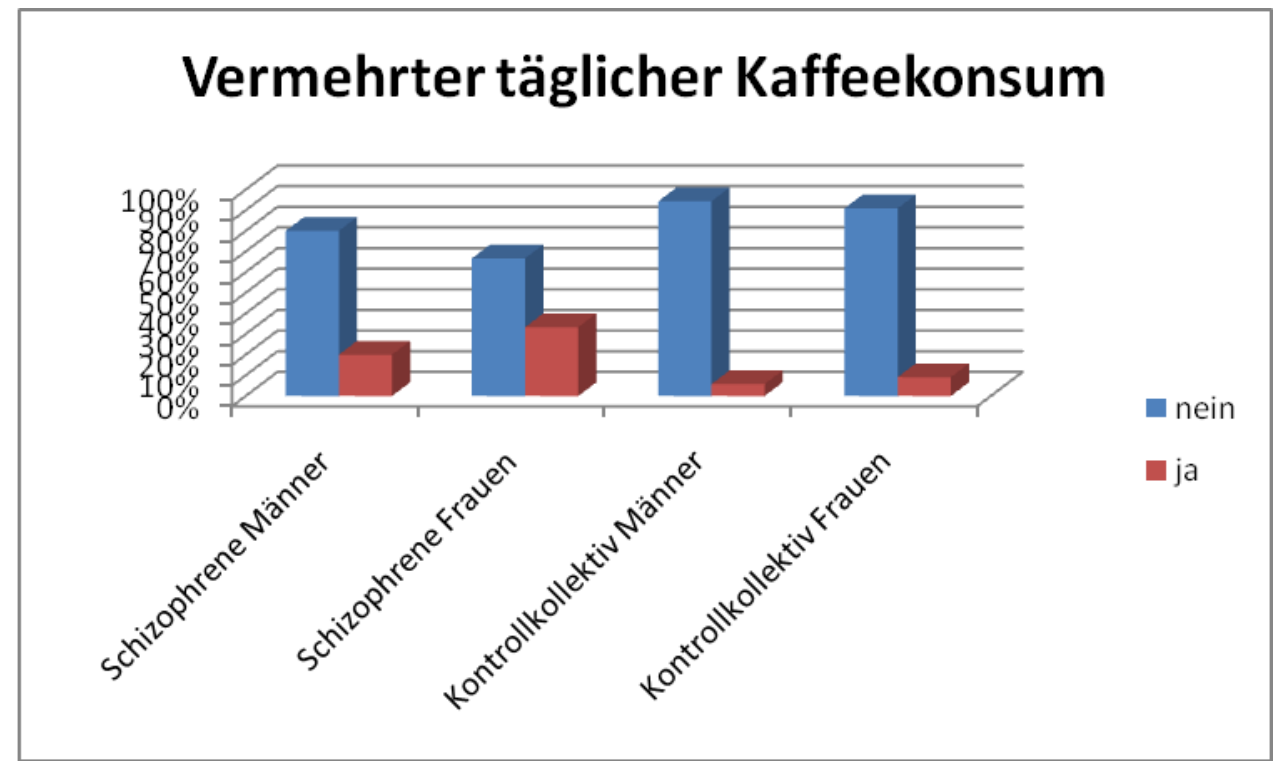

Vermehrter Kaffeekonsum: 61 Psychose-Patienten, Kontrollkollektiv 57 Patienten.

Items für täglicher Kaffeekonsum > 1 Liter täglich

\section{4-10.1 Statistische Auswertung des vermehrten Kaffeekonsums} a-Gesamtkollektivvergleich -vermehrter Kaffeekonsum-Kruskal-Wallis-Test

\begin{tabular}{|l|l|}
\hline & $\begin{array}{l}\text { vermehrter täglicher } \\
\text { Kaffeekonsum }\end{array}$ \\
\hline Chi-Quadrat & $\mathbf{2 , 8 2 7}$ \\
\hline Df & $\mathbf{3}$ \\
\hline $\begin{array}{l}\text { asymptotische } \\
\text { Signifikanz }\end{array}$ & $\mathbf{. 4 1 9}$ \\
\hline
\end{tabular}

a. Kruskal-Wallis- Test

b. Gruppenvariable : Gruppe 


\section{4-11 Mehrfachabhängigkeiten /ICD 10 [Dilling et al. 1993]: F19.2}

\section{4-11.1 Alkohol und Benzodiazepine}

Tabelle 18

\begin{tabular}{|l|l|l|}
\hline $\begin{array}{l}\text { Mehrfachabhängigkeit Alkohol und } \\
\text { Benzodiazepine }\end{array}$ & Nein & Ja \\
\hline schizophrene Männer & $\mathbf{5}$ & $\mathbf{1}$ \\
\hline schizophrene Frauen & $\mathbf{3}$ \\
\hline Kontrollkollektiv Männer & $\mathbf{1}$ & $\mathbf{1}$ \\
\hline Kontrollkollektiv Frauen & $\mathbf{0}$ & $\mathbf{0}$ \\
\hline
\end{tabular}

kombinierte Alkohol- und Benzodiazepinabhängigkeit: 61 Psychose-Patienten, Kontrollkollektiv 57 Patienten.

Bei Betrachtung der Mehrfachabhängigkeiten sollte eruiert werden, ob es Kollektiv- oder geschlechtspezifische Unterschiede in der Kombination bzw. der alleinigen Nutzung der Abhängigkeit verursachenden Stoffe gibt.

In der Gruppe der schizophrenen Männer bestand bei einem Patienten eine

Mehrfachabhängigkeit von Alkohol und Benzodiazepinen. Bei zwei schizophrenen Männern bestand eine isolierte Benzodiazepinabhängigkeit, bei drei schizophrenen Männern fand sich eine alleinige Alkoholabhängigkeit.

Bei den schizophrenen Frauen fanden sich demgegenüber drei Frauen mit einer kombinierten Alkohol- und Benzodiazepinabhängigkeit und nur eine Patientin mit einer alleinigen

Benzodiazepinabhängigkeit.

Im männlichen Kontrollkollektiv bestanden eine kombinierte Alkohol- und

Benzodiazepinabhängigkeit, sowie eine alleinige Alkoholabhängigkeit

\section{4-11.2 Alkohol und Cannabis}

Tabelle 18a

\begin{tabular}{|l|l|l|}
\hline $\begin{array}{l}\text { Mehrfachabhängigkeit Alkohol und } \\
\text { Cannabisabhängigkeit }\end{array}$ & Nein & Ja \\
\hline schizophrene Männer & 5 & 1 \\
\hline schizophrene Frauen & 4 & 1 \\
\hline Kontrollkollektiv Männer & 2 & $\mathbf{0}$ \\
\hline Kontrollkollektiv Frauen & 1 & $\mathbf{0}$ \\
\hline
\end{tabular}

kombinierte Alkohol- und Cannabisabhängigkeit: 61 Psychose-Patienten, Kontrollkollektiv 57 Patienten. 
Im Kollektiv der Schizophrenen zeigten sich bei den Männern und Frauen je eine kombinierte Abhängigkeit von Cannabis und Alkohol.

\section{4-11.3 Cannabis und Benzodiazepine}

Tabelle 19

\begin{tabular}{|l|l|l|}
\hline $\begin{array}{l}\text { Mehrfachabhängigkeit Cannabis } \\
\text { und Benzodiazepin-Abhängigkeit }\end{array}$ & Nein & Ja \\
\hline schizophrene Männer & $\mathbf{2}$ & $\mathbf{1}$ \\
\hline schizophrene Frauen & $\mathbf{3}$ & $\mathbf{1}$ \\
\hline Kontrollkollektiv Männer & $\mathbf{1}$ & $\mathbf{0}$ \\
\hline Kontrollkollektiv Frauen & $\mathbf{0}$ & $\mathbf{1}$ \\
\hline
\end{tabular}

kombinierte Benzodiazepin- und Cannabisabhängigkeit: 61 Psychose-Patienten, Kontrollkollektiv 57 Patienten.

Die kombinierte Mehrfachabhängigkeit von Cannabis und Benzodiazepine zeigte sich jeweils bei einem männlichen schizophrenen Patienten, einer schizophrenen Patientin und einer Patientin des Kontrollkollektivs.

\section{4-11.4 Cannabis und Nikotin}

Abschließend wurde die Mehrfachabhängigkeit Nikotin und Cannabisabhängigkeit untersucht. Interesssanterweise zeigte sich bei allen erhobenen Cannabisabhängigen, dass sie zudem abhängige Raucher waren.

Tabelle 20

\begin{tabular}{|l|l|l|}
\hline $\begin{array}{l}\text { Mehrfachabhängigkeit Nikotin und } \\
\text { Cannabisabhängigkeit }\end{array}$ & Nein & Ja \\
\hline schizophrene Männer & $\mathbf{0}$ & $\mathbf{3}$ \\
\hline schizophrene Frauen & $\mathbf{0}$ & $\mathbf{3}$ \\
\hline Kontrollkollektiv Männer & $\mathbf{0}$ & $\mathbf{0}$ \\
\hline Kontrollkollektiv Frauen & $\mathbf{0}$ & $\mathbf{1}$ \\
\hline
\end{tabular}

kombinierte Nikotin- und Cannabisabhängigkeit: 61 Psychose-Patienten, Kontrollkollektiv 57 Patienten. 


\section{4-12 Auswertungen der Blut- und Urinbefunde}

Tabelle 21

\begin{tabular}{|c|c|c|c|}
\hline & Blutbild & keine Alkoholabhängigkeit & bestehende Alkoholabhängigkeit \\
\hline schizophrene Männer & $\begin{array}{l}\text { Normbereich } \\
\text { außerhalb der Norm, aber nicht } \\
\text { relevant } \\
\text { pathologisch erhöht }\end{array}$ & $\begin{array}{l}26 \\
4 \\
1\end{array}$ & $\begin{array}{l}4 \\
0 \\
0\end{array}$ \\
\hline $\begin{array}{l}\text { schizophrene } \\
\text { Frauen }\end{array}$ & $\begin{array}{l}\text { Normbereich } \\
\text { außerhalb der Norm, aber nicht } \\
\text { relevant } \\
\text { pathologisch erhöht }\end{array}$ & $\begin{array}{l}18 \\
0 \\
0\end{array}$ & $\begin{array}{l}2 \\
0 \\
0\end{array}$ \\
\hline Kontrollkollektiv Männer & $\begin{array}{l}\text { Normbereich } \\
\text { außerhalb der Norm, aber nicht } \\
\text { relevant } \\
\text { pathologisch erhöht }\end{array}$ & $\begin{array}{l}31 \\
0 \\
0\end{array}$ & $\begin{array}{l}2 \\
0 \\
0\end{array}$ \\
\hline Kontrollkollektiv Frauen & $\begin{array}{l}\text { Normbereich } \\
\text { außerhalb der Norm, aber nicht } \\
\text { relevant } \\
\text { pathologisch erhöht }\end{array}$ & $\begin{array}{l}22 \\
0 \\
0\end{array}$ & 0 \\
\hline
\end{tabular}

Blutbild bei Alkoholabhängigkeit: 35 schizophrene männliche Patienten, 20 schizophrene weibliche Patienten, 33 Männer Kontrollkollektiv,

22 Frauen Kontrollkollektiv.

Tabelle 22

\begin{tabular}{|c|c|c|c|}
\hline & Leberwerte & keine Alkoholabhängigkeit & bestehende Alkoholabhängigkeit \\
\hline schizophrene Männer & $\begin{array}{l}\text { Normbereich } \\
\text { außerhalb der Norm, aber nicht } \\
\text { relevant } \\
\text { pathologisch erhöht }\end{array}$ & $\begin{array}{l}27 \\
2 \\
2\end{array}$ & $\begin{array}{l}1 \\
0 \\
3\end{array}$ \\
\hline $\begin{array}{l}\text { schizophrene } \\
\text { Frauen }\end{array}$ & $\begin{array}{l}\text { Normbereich } \\
\text { außerhalb der Norm, aber nicht } \\
\text { relevant } \\
\text { pathologisch erhöht }\end{array}$ & $\begin{array}{l}17 \\
1 \\
0\end{array}$ & $\begin{array}{l}1 \\
1 \\
0\end{array}$ \\
\hline Kontrollkollektiv Männer & $\begin{array}{l}\text { Normbereich } \\
\text { außerhalb der Norm, aber nicht } \\
\text { relevant } \\
\text { pathologisch erhöht }\end{array}$ & $\begin{array}{l}24 \\
1 \\
6\end{array}$ & $\begin{array}{l}1 \\
0 \\
1\end{array}$ \\
\hline Kontrollkollektiv Frauen & $\begin{array}{l}\text { Normbereich } \\
\text { außerhalb der Norm, aber nicht } \\
\text { relevant } \\
\text { pathologisch erhöht }\end{array}$ & $\begin{array}{l}18 \\
2 \\
1\end{array}$ & 0 \\
\hline
\end{tabular}

Leberwerte bei Alkoholabhängigkeit: 35 schizophrene männliche Patienten, 20 schizophrene weibliche Patienten, 33Männer

Kontrollkollektiv, 21 Frauen Kontrollkollektiv. 
Tabelle 23

\begin{tabular}{|c|c|c|c|}
\hline & Leberwerte & $\begin{array}{l}\text { Keine } \\
\text { Benzodiazepinabhängigkeit }\end{array}$ & $\begin{array}{l}\text { bestehende } \\
\text { Benzodiazepinabhängigkeit }\end{array}$ \\
\hline Schizophrene Männer & $\begin{array}{l}\text { Normbereich } \\
\text { Außerhalb der Norm, aber nicht } \\
\text { relevant } \\
\text { Pathologisch erhöht }\end{array}$ & $\begin{array}{l}27 \\
2 \\
3\end{array}$ & $\begin{array}{l}1 \\
0 \\
2\end{array}$ \\
\hline $\begin{array}{l}\text { Schizophrene } \\
\text { Frauen }\end{array}$ & $\begin{array}{l}\text { Normbereich } \\
\text { Außerhalb der Norm, aber nicht } \\
\text { relevant } \\
\text { Pathologisch erhöht }\end{array}$ & $\begin{array}{l}16 \\
0 \\
1\end{array}$ & $\begin{array}{l}2 \\
0 \\
1\end{array}$ \\
\hline Kontrollkollektiv Männer & $\begin{array}{l}\text { Normbereich } \\
\text { Außerhalb der Norm, aber nicht } \\
\text { relevant } \\
\text { Pathologisch erhöht }\end{array}$ & $\begin{array}{l}24 \\
1 \\
7\end{array}$ & $\begin{array}{l}1 \\
0 \\
0\end{array}$ \\
\hline Kontrollkollektiv Frauen & $\begin{array}{l}\text { Normbereich } \\
\text { Außerhalb der Norm, aber nicht } \\
\text { relevant } \\
\text { Pathologisch erhöht }\end{array}$ & $\begin{array}{l}18 \\
2 \\
1\end{array}$ & 0 \\
\hline
\end{tabular}

Leberwerte bei Benzodiazepinabhängigkeitt: 35 schizophrene männliche Patienten, 20 schizophrene weibliche Patienten, 33 Männer Kontrollkollektiv, 21 Frauen Kontrollkollektiv.

Tabelle 24

\begin{tabular}{|c|c|c|c|}
\hline & $\begin{array}{l}\text { Drogenscreening im Urin } \\
\text { einbezogen } \\
\text { THC,Benzodiazepine,Alkohol, } \\
\text { Opiate }\end{array}$ & keine Cannabisabhängigkeit & $\begin{array}{l}\text { bestehende } \\
\text { Cannabisabhängigkeit }\end{array}$ \\
\hline schizophrene Männer & $\begin{array}{l}\text { Normbereich } \\
\text { außerhalb der Norm, aber nicht } \\
\text { relevant } \\
\text { positiver Urinbefund }\end{array}$ & $\begin{array}{l}23 \\
0 \\
3\end{array}$ & $\begin{array}{l}1 \\
0 \\
3\end{array}$ \\
\hline $\begin{array}{l}\text { schizophrene } \\
\text { Frauen }\end{array}$ & $\begin{array}{l}\text { Normbereich } \\
\text { außerhalb der Norm, aber nicht } \\
\text { relevant } \\
\text { positiver Urinbefund }\end{array}$ & $\begin{array}{l}13 \\
0 \\
2\end{array}$ & $\begin{array}{l}1 \\
0 \\
1\end{array}$ \\
\hline Kontrollkollektiv Männer & $\begin{array}{l}\text { Normbereich } \\
\text { außerhalb der Norm, aber nicht } \\
\text { relevant } \\
\text { positiver Urinbefund }\end{array}$ & $\begin{array}{l}27 \\
1 \\
4\end{array}$ & $\begin{array}{l}0 \\
0 \\
0\end{array}$ \\
\hline Kontrollkollektiv Frauen & $\begin{array}{l}\text { Normbereich } \\
\text { außerhalb der Norm, aber nicht } \\
\text { relevant } \\
\text { positiver Urinbefund }\end{array}$ & $\begin{array}{l}15 \\
5 \\
1\end{array}$ & 0 \\
\hline
\end{tabular}

Drogenscreening bei Cannabisabhängigkeit: 29 schizophrene männliche Patienten, 17 schizophrene weibliche Patienten, 32 Männer Kontrollkollektiv, 21 Frauen Kontrollkollektiv. 
Die Tabellen geben die Auswertung der Urin- und Blutbefunde wieder. Zum Teil verweigerten Patienten die Uringabe, zum anderen lagen Blutbefunde in den Patientenakten nicht vor, das erklärt die abweichende Anzahl der Auswertungen gegenüber der untersuchten Klientenzahl. Auch ist die Aussage des Drogenscreenings nicht aussagekräftig, da Patienten einen positiven Nachweis im Urin hatten, wenn das Interview nach Operationen durchgeführt wurde, und sich Medikamente der Narkose (Benzodiazepine) im Urin zeigten. Demgegenüber sind negative Befunde kritisch zu bewerten, da sich Drogenabbauprodukte nur eine bestimmte Zeit im Urin nachweisen lassen, z.B. Benzodiazepine drei Tage bis zu sechs Wochen nach Halbwertszeit, Opiate bis zu sieben Tagen, Cannabinoide ( je nach Länge und Konsum) 24-36 h (akut), 5-20 Tage bis zu mehreren Wochen bei chronischem Konsum [Tretter,Werner 2009]. 


\section{Diskussion}

\section{5-1 Soziodemographische Daten, Struktur und Charakter der untersuchten Gruppen}

In der vorliegenden Arbeit ist die Auswahl der Gruppe der schizophrenen Patienten hinsichtlich ihres Geschlechts und Alter zufällig. Es wurden 65,57\% männliche Schizophrenie-Patienten und 34,43\% weibliche Schizophrenie-Patientinnen befragt. Diese Verteilung ergab sich aus der Rekrutierbarkeit der Patienten und entspricht nicht den epidemiologischen Untersuchungen, danach erkranken Männer und Frauen etwa gleich häufig an Schizophrenie [Falkai et al. 2007]. Geschlechtsspezifische Unterschiede zeigten sich hingegen in der Altersverteilung der Erstmanifestation der Schizophrenie, Männer erkranken ca. 3 bis 4 Jahre früher als Frauen. Die Ersterkrankung zeigt sich meist zwischen dem 15. und 35. Lebensjahr, sodass der hier erhobene Altersdurchschnitt der Befragten in der Gruppe der Schizophrenen (Männer 34,60 Jahren/ Frauen 37,33 Jahre) epidemiologischen Studien gerecht wird.

Die Gruppe der schizophrenen Patienten wurde in der Ambulanz und auf den Stationen der Psychiatrischen Klinik des Universitätsklinikums Göttingen rekrutiert. Die Diagnose der Schizophrenie wurde zuvor von Seiten der behandelnden Ärzte gestellt und bestand insbesondere bei Patienten der Ambulanz bereits über mehrere Jahre, sodass die Diagnosesicherheit als relativ hoch anzusehen ist. In der Literatur beschriebene Unterformen der Schizophrenie in die paranoide, hebephrene und katatone Form und das Auftreten der häufigsten Form der paranoid-halluzinatorischen Psychose bei mehr als $65 \%$ findet sich auch bei dieser Befragung bestätigt - hier lag der Anteil der Patienten des Kollektivs der schizophrenen Patienten mit einer paranoid-halluzinatorischen Psychose bei 67,21\%. Auffällig bei der Betrachtung der soziodemographischen Daten ist die Bedeutung des Ersterkrankungsalters bei Schizophrenie, welches im Zeitraum der beruflichen Weiterentwicklung und Familienplanung liegt. Die Auswirkungen der Schizophrenieerkrankung zeigen sich in Form der hohen Werte für berufliche Misserfolge, Nichterwerbstätigkeit und des ledigen Familienstatus. Die genannten Werte für den subjektiv empfundenen sozialen Abstieg lagen bei den schizophrenen Patienten bei einem Wert von 47,5\%, dieser subjektiven Selbsteinschätzung stehen in der Literatur Werte bei Huber aus 1994 gegenüber, der beschreibt, dass 56\% der an Schizophrenie Erkrankten nach Jahrzehnte langem Verlauf der Erkrankung als sozial geheilt, d.h. auf früherem Niveaus (38\%) oder unterhalb (18\%) oder voll erwerbstätig waren [Huber 1994]. 
Die erhobenen Daten der eigenen Studie für Erwerbstätigkeit liegen unterhalb dieser Zahlen (Erwebstätigkeit für schizophrene Männer bei 27,5\%, schizophrene Frauen 33,33\%), gegebenenfalls liegt die Differenz darin begründet, dass einige der Patienten erst eine kürzere Erkrankungsdauer hatten, gegebenenfalls sind die Daten aber auch durch eine schlechtere Arbeitsplatzlage in Deutschland seit Beginn der 90-er Jahre bedingt, in diesem Zeitraum stiegen die Arbeitslosenzahlen von 1,9 Millionen (1990) bis auf 4,4 Millionen (2004) [Bundesagentur für Arbeit 2008]. Aus der Sicht der Abhängigkeitserkrankungen hingegen ist die Geschlechterverteilung des Kollektivs den epidemiologischen Studien angenähert. Bei der Abhängigkeit von Alkohol und illegalen Drogen ist die Geschlechterverteilung ca. 2/3 Männer und 1/3 Frauen; bei der Medikamentenabhängigkeit ist es genau umgekehrt: 2/3 Frauen und 1/3 Männer [Kraus, Augustin 2001]. Die Kontrollgruppen sind in der Geschlechterverteilung und dem Altersdurchschnitt soweit möglich dem Kollektiv der schizophrenen Patienten angepasst. Diese Verteilung wurde bewusst gewählt, um die Vergleichbarkeit der Gruppen und der geschlechtsspezifischen Unterschiede zu gewährleisten.

\section{5-2 Nikotinkonsum im Kollektivvergleich}

Die Auswertung der Daten für Nikotinkonsum ergab signifikante Unterschiede zwischen schizophrenen und nicht schizophrenen Probanden. Der Anteil der Raucher, insgesamt oder differenziert in abhängige Raucher und nichtabhängige Raucher, liegt bei den schizophrenen Patienten im Vergleich zu den Kontrollkollektiven deutlich höher. Signifikanz besteht bei der Gegenüberstellung aller Gruppen des Gesamtkollektivs, in der Gegenüberstellung schizophrene Frauen und Kontrollkollektiv Frauen sowie Vergleich schizophrene Patienten und Kontrollkollektiv, (Schizophrene Männer: 45\% abhängige Raucher, schizophrene Frauen 42,86\% abhängige Raucherinnen versus Kontrollkollektivmänner abhängige Raucher 25,71\% und weibliche Probandinnen des Kontrollkollektivs abhängige Raucherinnen bei 9,09\%). Im Vergleich dazu zeigten Repräsentativerhebungen in der Normalbevölkerung, entnommen aus einem Artikel von Thomas Lampert im Rahmen des 12. bundesweiten Kongress Armut und Gesundheit, folgende Daten zur Verbreitung des Tabakskonsums in Deutschland [Lampert 2007]. Dort lagen die prozentualen Werte für männliche tägliche Raucher zwischen $26,1 \%$ bei den 45 bis 64 Jährigen, bei $36.5 \%$ bei den 30 bis 44 Jährigen und 39,3\% bei den 18 bis 29 
Jährigen - bei den Frauen der entsprechenden Altersgruppe 45 bis 64 Jahre wurden 22\%, in der Altersgruppe 30 bis 44 Jahre bei 29,3\% und bei den 18 bis 29jährigen 33,6\% tägliche Raucherinnen erhoben. Bei Mittelung der Daten ergaben sich für die männlichen täglichen Raucher 33,96\% und für die täglichen Raucherinnen 28,3\% in der Normalbevölkerung. Weitere Daten aus 2000 von Kraus und Augustin zeigten 3,9 Millionen Tabakabhängige in Deutschland, die 12- Monats- Prävalenz für Raucher lag bei Frauen bei $31 \%$ für Männer bei $39 \%$ [Kraus, Augustin 2001].

Ursache für den höheren Anteil Rauchender im schizophrenen Patientenklientel in dieser Erhebung kann die von Cattapan-Ludewig et al. dargestellte These sein, dass schizophrene Patienten die Wirkung des Nikotin nutzen, um ihre kognitiven Leistungen zu steigern. In einer Studie aus 2004 zeigte sich eine Verbesserung der Daueraufmerksamkeit, der gerichteten Aufmerksamkeit, des Arbeitsgedächtnisses, sowie des Kurzzeitgedächtnisses und der Wiedergabe neuerworbener Erkenntnisse aus dem Gedächtnis bei schizophrenen Patienten nach Nikotinkonsum [Cattapan-Ludewig et al. 2005]. DesWeiteren scheint Nikotin die extrapyramidalen Nebenwirkung von Neuroleptika zu mindern.

Cattapan-Ludewig fand 88\% Raucher bei ambulanten Schizophrenie-Patienten in den USA. Dieser Wert liegt deutlich über den hier erhobenen Werten: Schizophrene Männer gesamt Raucher 77.5\%, schizophrene Frauen gesamt Raucher 71,43\% ( Ex-Raucher, nichtabhängige und abhängige Raucher).

In einer weiteren Studie von Strand in Skandinavien und der Schweiz zeigten sich $82 \%$ Raucher bei ambulanten Schizophrenie-Patienten und 70\% Raucher unter stationär behandelten Schizophrenie-Patienten [Strand, Nybäck 2005]. Desweiteren wurden in dieser Erhebung höhere Konzentrationen des Nikotinmetaboliten Cotinin im Speichel von schizophrenen Rauchern als bei psychisch gesunden Rauchern gemessen. Schizophrene scheinen intensiver zu inhalieren. Auch erhielten rauchende Psychiatriepatienten in dieser Untersuchung doppelt so viele Neuroleptika wie Nichtrauchern. Strand zieht daraus den Schluss, dass schizophrene Patienten Nikotin als Selbstmedikation nutzen, insbesondere um mit der Minus Symptomatik besser klar zu kommen.

Eine weitere Untersuchung an 230 männlichen schizophrenen chinesischen Patienten an der Sichuan Universität ergab, dass Tabakrauchen in der Adoleszenz Einfluss auf die Erstmanifestation der Schizophrenieerkrankung hatte, Nichtraucher hatten in dieser Erhebung ein jüngeres Alter bei Erstmanifestation der Schizophrenie als Raucher und ehemalige Raucher. Auch wurde im Rahmen kognitiver Testungen ein Zusammenhang zwischen Rauchen und kognitiven Leistungen erhoben [ Ma et al. 2009]. 
Erwähnt sei auch eine aktuellere Studie der Universität in New Jersey aus dem Jahre 2008, die bei schizophrenen Patienten im Vergleich zu nicht schizophrenen Patienten eine höhere Blutserumnikotinkonzentration nach Rauchen einer einzelnen Zigarette aufwies, was meines Erachtens die oben von Strand genannte These des intensiveren Rauchens bzw. Inhalierens bestätigt [Williams et al. 2008].

Schizophrene scheinen Nikotin zur Verbesserung ihrer kognitiven Leistungen zu nutzen, neurobiologische Forschungen zeigten, dass bei Rauchern im Vergleich zu nicht rauchenden Probanden eine niedrigere Verfügbarkeit von Dopamin-Rezeptoren im Bereich des bilateralen Putamens vorliegt. In diesem Teil des Striatums wird dem Dopamin eine Funktion für die Aufnahme neuer Informationen und für das Belohnungslernen zugeschrieben. Vergleichbare Dopaminrezeptorveränderungen bestehen auch bei Alkohol-, Kokain-, Heroinund Amphetaminabhängigen [Fehr et al. 2008]. Auch ist der geringe geschlechterspezifische Unterschied zwischen schizophrenen männlichen und weiblichen Rauchern bemerkenswert, der deulich niedriger liegt als in den vergleichenden oben genannten Repräsentativerhebungen und somit die Funktion des Nikotins für schizophrene Patienten noch unterstreicht.

Kritisch hingegen ist anzumerken, dass der Anteil abhängiger Raucherinnen des Kontrollkollektivs wesentlich geringer liegt, als in vergleichbaren Studien.Ursächlich dafür könnte ein Einfluss einer internistischen Erkrankung sein, da ein Teil der Patienten des Kontrollkollektivs aus einer Rehabilitationseinrichtung für Lungenerkrankungen, Allergien und orthopädischen Erkrankungen rekrutiert wurde, auch wenn darauf geachtet wurde, Patienten mit mittelgradigem oder schwerem Asthma auszuschließen. Möglicherweise liegt der Grund des geringen Raucherinnenanteils auch an dem sozialen Status (hoher Angestelltenstatus der weiblichen Kontrollkollektivprobandinnen), da der Anteil der männlichen Kontrollkollektivpatienten nicht so stark von vergleichenden Studien differiert. Der soziale Status hat einen gravierenden Einfluss auf das Rauchverhalten. Häufigeres Rauchen ist mit statusniedrigen Berufen assoziert [Lampert 2007]. Des Weiteren geht vermehrtes Rauchen mit Verlust an sozialen Kontakten, mangelnder Anerkennung oder fehlender Möglichkeit zur persönlichen Entfaltung durch Arbeitslosigkeit einher [Grobe, Schwartz 2003]. Dies könnte zusätzlich die erhöhte Anzahl Rauchender im Patientenklientel der Schizophrenen erklären, da ein relativ hoher Prozentsatz der schizophrenen Patienten dieser Erhebung arbeitslos waren ( Männer 30\%, Frauen 28,56\%) und zudem die Schizophrenie an sich, bedingt durch Rezidive, nicht vollständige Remission, häufige Hospitalisierung möglicherweise mit mangelnder Anerkennung und Verlust an sozialen Kontakten und verhinderter persönlicher Entfaltung verbunden ist. 


\section{5-3 Alkoholkonsum im Kollektivvergleich}

Untersuchungen über Alkoholismus und Schizophrenie wurden bereits Anfang des letzten Jahrhunderts von Eugen Bleuer durchgeführt. In der vorliegenden Erhebung wurde zur Fragestellung des Alkoholkonsums bei Schizophrenen zuerst der risikoreiche tägliche Alkoholkonsum bestimmt.

Der risikoreiche tägliche Alkoholkonsum wurde von Seiten der British Medical Association [BMA 1995] bei einer täglich getrunkenen Menge von 30g reinem Alkohol für Männer und $20 \mathrm{~g}$ reinem Alkohol für Frauen definiert. Studien zeigten, dass bei auch nur geringem Überschreiten der angegebenen Menge ein erhöhtes Risiko bestand, auf Dauer an alkoholbedingten somatischen und psychischen Beeinträchtigungen zu erkranken [Allebeck, Rydberg 1998]. Gesundheitliche Schäden durch erhöhten Alkoholkonsum betreffen vorrangig die Leber als Entgiftungsorgan. Pankreatitis, Gastritis, Herzmuslelerkrankungen, Schädigungen des zentralen und des peripheren Nervensystems können zudem durch chronischen schädlichen Alkoholkonsum verursacht werden [BundesGesundheitssurvey Alkohol 2003].

Das Genussmittel Alkohol wurde in Deutschland seit dem 2. Weltkrieg zunehmend genutzt, der Pro-Kopf-Verbrauch reinen Alkohols stieg seit 1950 von 3,3 1 auf 12,5 1 (1980) und fiel leicht auf 11,2 1 im Jahre 1990 [Soyka 1999]. Bereits bei einem täglich getrunkenen Glas Wein (0.2 1) ist für Frauen die Grenze des risikoreichen Alkoholkonsum erreicht. Männer mit zwei Flaschen Bier (0,3 1) täglich, überschreiten den riskanten Konsum bereits. In der jüngeren Vergangenheit zeigten Studien bei schizophrenen Patienten im stationären und ambulanten Setting einen gesteigerten Substanzkonsum für Alkohol von 9\% bis 37.5\% [Linszen et al. 1994, Hambrecht und Häfner 1996, 2000, Rabinowitz et al.1998]. Joachim Zeiler veröffentlichte 1990 Daten zum Alkoholmissbrauch bei Schizophrenen. Diese Studie umfasste die Daten von 96 ambulant betreuten schizophrenen Patienten eines sozialpsychiatrischen Dienstes, die über einen Zeitraum von einem Jahr untersucht wurden. Dort zeigte sich eine 1-Jahres-Prävalenz für Alkoholmissbrauch zwischen 11\% und 27\% [Zeiler 1990,1997].

In der vorliegenden Studie wurden ambulante und stationäre schizophrene Patienten befragt. Es zeigte sich bei den schizophrenen Männern die Gruppe mit dem höchsten täglichen riskanten Alkoholkonsum bei 37,5\% im Vergleich zu dem Kontrollkollektiv Männer die einen Wert von 25,71\% erreichten. Bei den Frauen lagen die Werte für die schizophrenen Frauen bei $19,05 \%$ und bei dem Kontrollkollektiv Frauen bei 9,09\% 
In einer Repräsentativerhebung zum Gebrauch und Missbrauch psychoaktiver Substanzen bei Jugendlichen und Erwachsenen, durchgeführt 2006 in Berlin [Kraus, Rösner 2008], berichtete die Mehrheit der 15- bis 59-jährigen einen durchschnittlichen Konsum von weniger als 30g (Männer) bzw. 20g (Frauen) reinen Alkohols pro Tag. Über diesem gesundheitsgefährdenden Schwellenwert lagen 19,9\% der Männer und 10,4\% der Frauen. Diese Daten entsprechen etwa denen für Alkoholmissbrauch des Kontrollkollektivs in der hier vorgelegten eigenen Erhebung. Die Werte für Alkoholmissbrauch für schizophrene Frauen liegen im Vergleich dazu fast zwei mal so hoch bei 19,05\%. Bei den schizophrenen Männen wurde ein risikoreicher Konsum von 37,5\% erhoben, folgernd übersteigt dieser Wert mit 12,14\% den Wert des männlichen Kontrollkollektivs und liegt mit 15,1\% über den Daten der oben genannten Repräsentativerhebung.

Trotz der deutlichen Differenz zeigte sich keine Signifikanz der Daten für den risikoreichen Alkoholkonsum, jedoch liegt meines Erachtens ein Hinweis auf einen vermehrten und von der Norm abweichenden täglichen riskanten Konsum von Alkohol bei Schizophrenen vor, der sich in den genannten Erhebungen gezeigt hat.

Folgend wurde die Alkoholabhängigkeit erhoben. Die Alkoholabhängigkeit wurde ermittelt unter Betrachtung der täglich getrunkenen Alkoholmenge, Dosissteigerung, Dauer des erhöhten Alkoholkonsums, auftretenden Entzugserscheinungen nach Beendigung des Alkoholtrinkens, bzw. kompensatorischen Alkoholtrinkens und unter Einbeziehen von Vorbefunden und anamnestische Angaben über Entgiftungs- bzw. Entwöhnungstherapien. Bei 10\% der schizophrenen Männern bestand nach diesen Kriterein in der vorliegenden Untersuchung eine Alkoholabhängigkeit versus 5,71\% bei den Männern des Kontrollkollektivs, die Auswertung für die schizophrenen Frauen ermittelte sogar noch eine höhere Rate für Alkoholabhängigkeit bei 14,28\%, dem gegenüber bestand bei keiner der Frauen des Kontrollkollektivs eine Abhängigkeit von Alkohol. Die Werte der schizophrenen Patienten lagen deutlich über denen des Kontrollkollektives.

Auch der Vergleich zu Gender Daten für Alkoholabhängigkeit in Deutschland [Pabst, Kraus 2006] zeigte einen manifesten Unterschied. Danach lagen in einer Untersuchung mit einer Beobachtungsgröße N=1.300.000 Personen die Werte für Alkoholabhängigkeit für Frauen bei 1,2\% und 3,4\% für Männer.

Risikofaktoren für Alkoholabhängigkeit bei Schizophrenie sind laut Zeiler (1990): Männliches Geschlecht, präschizophrener habitualisierter Missbrauch, ausgeprägter schizophrener Persönlichkeitswandel und fehlende Akzeptanz neuroleptischer Prophylaxe, geringe Remission und soziale Isolation. 
Soyka zeigte 1994 auf, dass bei alkoholabhängigen schizophrenen Patienten eine vermehrte Positivsymptomatik und weniger Minussymptomatik im Vergleich zu nicht alkoholabhängigen schizophrenen Patienten besteht [Soyka 1994a]. Er beschreibt bei fortbestehender Komorbidität eine höhere Re- und Hospilitationsrate, sowie eine höhere Anzahl von Suiziden bei schizophrenen Patienten mit bestehender Alkoholerkrankung im Vergleich zu nichtabhängigen schizophrenen Patienten [Soyka 1994b].

Die hohen Werte der Alkoholabhängigkeit und der hohe riskante Alkoholkonsum bei der hier untersuchten Klientel könnten in der von Zeiler beschriebenen Ursache liegen, dass der niedrige Preis, die freie Erhältlichkeit und die soziale Akzeptanz des Alkohols diesen zur wichstigsten psychotropen Substanz für Schizophrene zur Selbstmedikation werden lassen [Zeiler 1997]. Vergleichsdaten zu ähnlich hohen Werten für Alkoholabhängigkeit bei weiblichen schizophrenen Patientinnen konnten der Fachliteratur nicht entnommen werden. Vermutlich ist es ist auf Grund des kleinen Kollektivs keine repräsentative Auswertung, sondern ein zufälliges Ergebnis.

Interessanterweise jedoch zeigten sich auch die Maximal- Werte für den täglich getrunkenen reinen Alkoholgehalt bei den schizophrenen Patientinnen, dieser lag bei $280 \mathrm{~g} / \mathrm{d}$. Im Vergleich fanden sich Werte bis $160 \mathrm{~g} / \mathrm{d}$ reinen getrunkenen Alkohols bei den schizophrenen Männern. Im Rahmen größerer Studie wäre es interessant geschlechtsspezifische Vergleichsdaten diesbezüglich zu ermitteln.

Zusammenfassend liegen in den letzten Jahren vermehrt Studien über Alkohol- und Drogengebrauch bei Schizophrenie vor [ Bericht der Europäischen Ministeriellen WHOKonferenz Psychische Gesundheit 2005], die auf Grund von steigendem THC-Konsums, Zeilers Theorie in Frage stellen, Alkohol sei die häufigste von Schizophrenen genutzte psychotrope Substanz [Sadichha et al. 2010, Schnell et al. 2010].

Auch ich teile aus meiner klinischen Erfahrung nicht Zeilers Ansicht für jüngere Patienten mit Schizophrenie und illegaler Drogenabhängigkeit. Meines Erachtens wird in dieser Gruppe bei gleich leichter Verfügbarkeit von illegalen Drogen und Alkohol (Schizophrene in der Drogenszene etabliert, Selbstanbau von Cannabis oder leichter rekrutierbare künstliche Cannabinoide „Spice“) eine differenzierte Selbstmedikation zum Beispiel der Konsum von THC dem Alkoholkonsum vorgezogen.

Doch für die weitaus größere Anzahl der nicht illegale Drogen nutzenden schizophrenen Patienten und für ältere schizophrene Patienten sehe ich Zeilers Theorie bestätigt. 


\section{5-4 Benzodiazepinabhängigkeit im Kollektivvergleich}

Bei der Benzodiazepinabhängigkeit unterscheidet man eine Niedrig- und Hochdosisabhängigkeit. Die Charakteristik der Niedrigdosisabhängigkeit differiert von den Suchtkriterien der in der ICD 10 [Dilling et al. 1993] definierten Punkten der Dosissteigerung und Toleranzentwicklung [Rumpf 2009]. Die Niedrigdosisdabhängigkeit findet sich vermehrt bei älteren Menschen, eine Hochdosisabhängigkeit bei Jüngeren ( < 60 Jahren). Eine Quantifizierung der genauen Abhängigkeitsrate ist schwierig, da Benzodiazepine oft auf Privatrezept verordnet werden und statistisch der Krankenkassenverordnung entgehen [BAK 2008].

Laut DHS-Jahrbuch Sucht aus dem Jahr 2008 muss immer noch von einer Anzahl von rund 1,0 bis1,2 Millionen Menschen in Deutschland ausgegangen werden, bei denen eine Benzodiazepinabhängigkeit besteht [Glaeske 2008]. Soyka schätzt die Anzahl in seinem Artikel aus 2005 noch höher bei 1,9 Millionen Menschen in Deutschland ein [Soyka et al. 2005].

Die therapeutische Wirksamkeit der Benzodiazepine erklärt die häufige Verordnung, auf Grund der rasch einsetzenden Anxiolyse indiziert für Angsterkrankungen und Erregungszustände, die hypnotische Wirkung erklärt die breite Verordnungspraxis bei Schlafstörungen. Des Weiteren kommen Benzodiazepine bei muskulär bedingten Schmerzzuständen wegen ihrer Muskel relaxsierenden Funktion zum Einsatz. Auch die antikonvulsive Wirkung, insbesondere zum Alkoholentzug, kann bei nicht sachgemäßer Verordnung zur Abhängigkeit führen.

Neurobiologisch wirken die Benzodiazepine über die Verstärkung der GABAergen Neurotransmission im ZNS. In die Gruppe der Hypnotika und Sedativa werden zu den Benzodiazepinen noch die sogenannten Z-Substanzen (Zolpidem, Zopiklon, Zalpedon), Clomethialzol (Barbiturat ähnliche Substanz) und y-Hydroxybutyrat (GBH) und yButyrolactat einbezogen [Poser et al.2006]. In der vorliegenden Arbeit wurde aber das hauptsächliche Augenmerk auf die Verordnung der Benzodiazepine gelegt und es zeigten sich deutlich höhere Werte für den Benzodiazepinmissbrauch sowie für die Benzodiazepinabhängigkeit für das Kollektiv der schizophrenen Frauen im Vergleich zu den Kontrollkollektiven und den schizophrenen Männern. 
Eine Forschungsgruppe aus New Hampshire untersuchte den Zusammenhang von

Benzodiazepinverordnungen bei psychischen Erkrankungen und der Verdacht auf eine höhere Rate von Benzodiazepinabusus bei einer höheren Verordnung wurde aufgezeigt [Brunette et al. 2003]. Folgend fand sich eine 5-Jahres-Prävalenz für Benzodiazepine bei 54\% der schizophrenen Patienten ohne Substanzmissbrauch versus 63\%, wenn eine Schizophrenie und eine Substanzabhängigkeit vorbeschrieben waren [Clark et al. 2004].

In einer Cochranen Metaanalyse über Benzodiazepine in der Behandlung schizophrener Psychosen wurden insgesamt 34 Studien mit 2454 Teilnehmern eingeschlossen. Darin wurde eine signifikant häufigere erwünschte Sedierung unter Benzodiazepine in der Akutbehandlung ermittelt [Khorsand 2006], die den häufigen Einsatz von Benzodiazepinen in der Kombinationsbehandlung mit einem Neuroleptikum zur Dämpfung der Positivsymptomatik bei akuter Exazerbation der Schizophrenie rechtfertigt.

In dieser Erhebung zeigt sich jedoch auch ein prägnanter geschlechtsspezifischer Unterschied in der Benzodiazepinnutzung zwischen schizophrenen Männern und Frauen. Und es wurde eine deutlich höhere Verordnungsrate für Benzodiazepine bei schizophrenen Frauen im Vergleich zu schizophrenen Männern und ein höherer Anteil zurückliegenden Benzodiazepinmissbrauchs und -abhängigkeit bei den schizophrenen Frauen ermittelt. Die geschlechtsspezifischen Unterschiede des Kontrollkollektivs sind hingegen nicht so eindeutig, obwohl laut Statistik des Jahrbuchs Sucht 2008 eine geschlechtsspezifische Differenz des Benzodiazepinsgebrauchs besteht ( 2/3 Frauen zu 1/3 Männer) [Glaeske 2008], der sich hier nicht so deutlich zeigt. Gegebenenfalls besteht die Ursache diesbezüglich darin, dass ein Teil des Kontrollkollektivs nach Durchführung eines elektiv geplanten oder kleinen chirurgischen Eingriffes befragt wurde, dem eine präoperative Benzodiazepineinnahme vorrausging und somit die erhöhte Benzodiazepinverordnung bei dem Kontrollkollektiv Männer erklärt.

Der Grund hingegen, warum die schizophrenen Frauen im Vergleich zu den schizophrenen Männern in einem größeren Maß Benzodiazepine einnahmen, auch über den vermuteten geschlechtsspezifischen Unterschied hinaus, kann darin liegen, dass Frauen im Gegensatz zu Männern bei Krankheitssymptomen häufiger Ärzte konsultieren [Robert-Koch- Institut 2003], und somit die ärztliche Verordnung von Benzodiazepinen eher gegeben war bei Beginn einer präpsychotischen Symptomatik, während Männer eine Selbstmedikation (riskanter Alkoholkonsum oder Cannabis) vorzogen. In einer im Februar 2009 veröffentlichten 
Studie der Techniker-Krankenkasse [TK Gesundheitsreport 2010] wird eine geschlechtsspezifische Differenzierung der Arzneimittelverordnung aufgeführt, die auch eine bevorzugte Verordnung von Psychopharmaka bei Frauen im Vergleich zu Männern

dokumentiert. Zwar liegen die Verordnungszahlen für Arzneimittel bei Männern und Frauen seit 2008 gleich hoch, jedoch unterscheidet sich die Art der Medikamente insofern, dass Männer doppelt so viele Herz-Kreislauf-Medikamente wie Frauen verordnet bekommen. Dafür ist der Bedarf der Frauen an Schilddrüsenpräparaten, Sexualhormonen, Psychopharmaka und Antibiotika höher.

Abschließend sei auf einen Artikel im Deutschen Ärzteblatt aus 2001 verwiesen, der vom internationalen Spitzenkonkress zum Thema „Women’s Mental Health“ berichtet, in dem darauf hingewiesen wird, dass in deutschsprachigen Ländern Frauen häufiger Benzodiazepine und Tranquillanzien zur „Beruhigung“ verordnet bekommen als Männer [Richter 2001].

\section{5-5 Cannabisnutzung/ Cannabisabhängigkeit im Kollektivvergleich}

Cannabis ist die häufigste illegal genutzte Droge in Deutschland [Thomasius, Stolle 2008]. Bereits seit mehr als 50 Jahren wird sie zunehmend von jungen Erwachsenen und Jugendlichen auch in Europa konsumiert. Es zeigte sich ein nochmals verstärkter Anstieg des THC Konsums in Deutschland seit Beginn der 90er Jahre bis 2004.

Cannabis (Cannabis sativa) wird aus der blühenden weiblichen Hanfpflanze gewonnen. Der botanische Ursprung liegt in Zentralasien.Cannabispflanzen fanden seit Beginn des 19. Jahrhunderts Verbreitung auch in Europa und Nordamerika. Bereits 1925 wurde Cannabis auf Grund der Gefahr rauscherzeugender Wirkung in einigen Staaten Nordamerikas verboten. Die wirksamen Inhaltsstoffe der Hanfplanze werden als Cannabinoide bezeichnet. Der erste wesentliche Hauptmetabolit, das THC (Delta-9-Tetra-Hydro-Cannabinol), wurde 1964 von den Wissenschaftlern Yehiel Gaoni und Raphael Mechoulam aus der Hanfpflanze isoliert und wird hauptsächlich für den Rauschzustand verantwortlich gemacht [Gaoni, Mechoulam 1964,1971]. Delta-9-Tetra-Hydro-Cannabinol wirkt auf das endogene Cannabinoidsystem über den Cannabinoid 1- Rezeptor [Bonnet et al. 2006].

Körpereigenes Cannabinoid entspricht dem Anandamid, einem Derivat der Arachnidonsäure. Auswirkungen des Anandamid und THC zeigten im Tierversuch eine Beeinflussung der Koordination und Bewegungen (Kleinhirn und Basalganglien), eine Beeinflussung der Gedächtnisfunktion (Hippocampus und vordere Großhirnrinde) sowie der Auslösung für Euphorie und traumähnliche Zustände (Hippocampus und vordere Großhirnrinde). Auch 
zeigte sich im Tierversuch unter Delta-9-THC ein Anstieg der extrazellulären Dopaminkonzentration im Nucleus accumbens [Tanda et al. 1997]. Der zweite wesentliche Hauptmetabolit, das Cannabidiol, ohne rauschinduzierende Funktion, zeigte im Tierexperiment antipsychotische und anxiolytische Wirkung [Zuardi et al. 2001]. Bereits seit Ende der achtziger Jahre wurde ein Zusammenhang zwischen der konsumierten THC-Menge und dem Zusammenhang einer später auftretenden psychotischen Störung vermutet [Andreasson et al. 1987; Grotenhermen 1999]. In einer Studie an 45.570 schwedischen Rekruten über den Zeitraum von 15 Jahren wurde der Zusammenhang zwischen Cannabiskonsum und einer später auftretenden Schizophrenieerkrankung aufgezeigt. Viele Studien bestätigten daraufhin die Hypothese des vermehrten Zusammentreffens einer THC- Nutzung im frühen Jugendalter, einer hochfrequenten Cannabisnutzung, täglich oder mehrfach wöchentlich [Di Forti et al. 2010], sowie einer höheren THC-Konzentration [Hopkin 2004] und dem früheren Auftreten einer long Illness Schizophrenie [Murray 2005 ; Dragt et al. 2010; Caspari, Wobrock 2004; Barkus, Murray 2010; Henquet et al.2008 ]. Robin Murray erklärt in einem Artikel in der Zeitschrift Guardian 2009 [ Murray 2009] : „, Für Cannabis gilt, ein sechsfach erhöhtes Risiko für das Auftreten einer Psychose bei langjähriger hochdosierten THC Nutzung “ und verweist in mehreren Artikeln auf oben genannten stetigen Anstieg des Cannabiskonsums seit Beginn der neunziger Jahre und der Problematik des höheren THC-Gehaltes in Cannabiseigenzüchtungen, die in den letzten Jahren zunehmend den handelsüblichen Markt bestimmen. Im Rahmen von Eigenzüchtungen kann unter künstlich optimierten Bedingungen (Licht/Raumluft) ein 4-5 mal höherer THC- Gehalt in den Cannabispflanzen erzielt werden (Anstieg THC-Gehalt von 4\% auf bis zu 20\%). Hochfrequente Cannabisnutzung, der höhere THC- Gehalt und ein frühes Einstiegalters des Cannabiskonsumenten werden mittlerweile als Teilkomponente der Ätiologie der Schizophrenie angesehen, wenn zudem eine genetische Disposition (Val/Val - Variante des COMT-Gens) und sozialer Stress gegeben sind [Brzozka et al. 2009, Gouzoulus-Mayfrank 2007, 2010]. Auch wenn die Inzidenz der Schizophrenie gleich geblieben bzw. global leicht rückläufig ist, gibt es regional starke Anstiege der Inzidenz für Schizophrenie, die die oben genannte Theorie bestätigen. Abzuwarten ist die Entwicklung in den nächsten Jahren, da laut DHS-Sucht 2008 [DHS- Jahrbuch Sucht] der Cannabiskonsum seit 2004 erstmals in Deutschland sinkt.

Cannabiskonsum bei Schizophrenen beeinflusst hingegen nicht nur die Prävalenz der Schizophrenieerkrankung. Es gibt zudem mehrere Studien, die den negativen Einfluss der 
Droge Cannabis auf den Verlauf der Schizophrenieerkrankung aufdecken. Cannabisnutzung scheint die Positivsymptomatik zu verstärken [Häfner 2000], die vermehrte Prävalenz von Suiziden sowie längere Krankenhausaufenthalte [Dervaux et al. 2003] und häufigere Rehospitalisierungen [Diehl et al. 2010] bei schizophrenen Patienten zu verursachen, im Vergleich zu nicht Cannabis nutzenden schizophrenen Patienten.

In der vorliegenden Untersuchung wurden eine regelmäßige Cannabisnutzung und eine Cannabisabhängigkeit ermittelt. Signifikante Daten zeigten sich in der Cannabisnutzung im Vergleich der schizophrenen Männer versus Kontrollkollektiv Männer, sowie der Gesamtbetrachtung der schizophrenen Patienten versus des Kontrollkollektiv. Deutlich mehr schizophrene Männer sowie Frauen nutzen bzw. nutzten Cannabis zum Zeitpunkt der Befragung, schizophrene Männer 27,5\% und schizophrene Frauen 23,81\% versus 2,86\% der Männer bzw. 9,02\% Frauen des Kontrollkollektivs.

Auch bei der Cannabisabhängigkeit besteht Signifikanz bei Betrachtung des schizophrenen Kollektivs im Vergleich zu den Kontrollgruppen. 14,28\% Cannabisabhängigkeit bestand bei den schizophrenen Frauen versus 10\% Cannabisabhängigkeit bei den schizophrenen Männern, es zeigte sich keine Cannabisabhängigkeit im Kontrollkollektiv.

Zu bemerken ist weiterhin, dass die Befragung in den Jahren 1996 bis 2001 durchgeführt wurde und der Altersdurchschnitt der befragten Patienten oberhalb der hauptnutzenden Gruppe für Cannabis liegt, und bei einigen Patienten die Erstdiagnostik der Schizophrenie länger zurück lag, gegebenenfalls würde sich bei Befragung in den späteren Jahren, in denen der Anstieg der Cannabisnutzung weiter anhielt, ein noch deutlicherer Zusammenhang zwischen Schizophrenie und Cannabiskonsum zeigen und die Werte für den Cannabisgebrauch auch im Bereich der Kontrollkollektive höher liegen. Aktuelle Repräsentativstudien ermittelten die Anzahl für Daueruser von Canabis bis zu 22,9\% für Erwachsene [ Kraus, Augustin 2001].

Interessant ist auch die Frage des Einflusses des gestiegenen THC-Gehaltes für eine Mitverantwortung bei der Entwicklung einer Schizophrenie und der Verstärkung der Positivsymptomatik bei bereits an Schizophrenie erkrankten Patienten.Vielleicht ist der protektive Faktor des zweiten Hauptmetaboliten Cannabidiol, der sich im Tierversuch antipsychotisch zeigte durch das Ungleichgewicht der höheren THC-Konzentrationen in Hanfpflanzenzüchtungen, die in denletzen Jahren Verbreitung fanden,verloren gegangen.

\section{5-6 Heroin- und Kokainabhängigkeit im Kollektivvergleich}

In dem untersuchten Klientel war die ermittelte Abhängigkeit für Heroin bzw. Kokain 
zu gering, um einen verwertbaren Vergleich zwischen den untersuchten Gruppen und

Repräsentativdaten zu ermitteln. Es zeigte sich ein Patient mit einer Polytoxikomanie inklusive Opiat- und Kokainabhängigkeit.( Definition der Polytoxikomanie nach Havemann Reinecke 2004) [ Havemann-Reinecke et al. 2004]. An weiteren illegalen Drogen wurde der isolierte oder kombinierte Drogenkonsum, über einen längeren Zeitraum ( > 4 Wochen ) anhaltend bei 16 Patienten mit THC, vier Patienten mit LSD, einem Patienten mit Kokain und bei zwei Patienten mit Partydrogen (Amphetamine, XTC) in der Anamnese erhoben.

\section{5-7 Koffeinnutzung im Kollektivvergleich}

Kaffee steigert die Vigilanz, die Konzentrationsleistung und die Merkfähigkeit, insbesondere für das Kurzzeitgedächtnis. Kaffee fördert den Gedankenfluss und die schnellen Assoziationen, hebt die Stimmung und verbessert den Antrieb [Faust 1996], diese Erklärung gibt Volker Faust in seinem Artikel über psychosoziale Gesundheit und erklärt Kaffee zum Genussmittel Nr.1 in Deutschland, er nennt einen Gebrauch von 160 Litern pro Kopf und Jahr. Eine Kaffeeabhängigkeit hingegen wird in der Literatur kontrovers diskutiert. 1999 wurde von Astrid Nehlig und dem französischen Gesundheitsinstitut Inserm in Tierversuchen der Einfluss von Koffeineinnahme mit Hilfe kernspintopographischer Untersuchungen ermittelt, es zeigte sich keine Anregung der für Sucht verantwortliche Strukturen bei Tieren nach moderaten Kaffeedosen [Nehlig 1999].

Amerikanische Studien stellten einen Zusammenhang zwischen einer möglichen

Kaffeeabhängigkeit und einer positiven Familienanamnese für Alkoholerkrankungen bei Schwangeren - es zeigte sich in einer Untersuchung an 44 schwangeren Frauen, dass Schwangere mit alkoholkranken Familienangehörigen während der Schwangerschaft den Kaffeekonsum nicht unter 300 mg/d senken konnten im Vergleich zu Schwangeren ohne Alkoholabhängigkeit bei Familienmitgliedern [Svikis et al. 2005].

Ein einmaliger Fall von Koffeinabhängigkeit wurde beschrieben nach langwierigem Gebrauch eines koffeinhaltigen Misch-Analgetikums [Aichmüller et al. 1997].

Zur Ermittlung einer Abhängigkeit von Kaffee in dieser Untersuchung wurde eine tägliche Trinkmenge von Kaffee, bzw. koffeinhaltigem Tee von mehr als einem Liter täglich definiert. Auch wenn sich keine Signifikanz der Daten zeigte, trinken schizophrene Patienten im Vergleich zum Klientel des Kontrollkollektivs deutlich mehr Kaffee. Die größte Gruppe der Kaffeeabhängigen zeigte sich bei den schizophrenen Frauen mit 33,34\%, gefolgt von den 
schizophrenen Männern mit $20 \%$. Die Werte für das Kontrollkollektiv Frauen lagen bei 9,1\% im Vergleich dazu bei den Männern des Kontrollkollektivs bei 5,71\%.

Abhängigkeitskriterien wie Entzugserscheinungen und kompensatorisches Kaffeetrinken wurden leider nicht erhoben, so dass der Terminus Abhängigkeit zu hinterfragen ist. Doch die Daten zeigten eine vermehrte Nutzung von Kaffee bei den schizophrenen Patienten, insbesondere bei den schizophrenen Frauen.Vermutlich nutzen die schizophrenen Patienten die anregende Wirkung des Kaffees zur Gegenregulation einer gegebenensfalls bestehenden Neuroleptikanebenwirkung und zum Ausgleich bestehender Negativsymptomatik.

In drei aktuellen Studien aus den USA wurde die Interaktion zwischen Nikotin und vermehrt gestiegenem Kaffeekonsum bei schizophrenen Patienten im Vergleich zu Kontrollgruppen untersucht, es zeigte zum einen ein stärkeres Craving für Kaffee bei Rauchern [Adolfo et al. 2009], des Weiteren einen höheren Koffeinblutserumspiegel bei rauchenden Schizophrenen im Vergleich zu Kontrollgruppen mit gleichem Rauchverhalten [Gandhi et al. 2010]. Der Verdacht auf eine Selbstmedikation durch Kaffee und Nikotin wurde gestellt und die Hypothese geäußert, dass übermäßiger Kaffeekonsum in Kombination mit Nikotin die Beurteilung von Schizophreniesymptomen und Neuroleptikanebenwirkungen erschweren kann [Williams, Gandhi 2008]. Keine der Untersuchungen beweist die gestellte These der Selbstmedikation, jedoch zeigte sich auch dort ein auffällig vermehrter Kaffeekonsum bei schizophrenen Patienten.

\section{Zusammenfasssung}

Die in der Studienplanung aufgestellte Hypothese, dass bei an Schizophrenie erkrankten Patienten vermehrt Abhängigkeitserkrankungen im Vergleich zu nicht an Schizophrenie erkrankten Patienten bestehen, konnte klar bestätigt werden.

Es zeigten sich signifikant erhöhte Prävalenzen für Nikotin (abhängiges Rauchen) bei schizophrenen Männern und schizophrenen Frauen sowie signifikant erhöhte Prävalenzen für Benzodiazepinabhängigkeit bei schizophrenen Frauen im Vergleich zu Kontrollkollektiven und Repräsentativdaten. Der risikoreiche Alkoholkonsum und die Alkoholabhängigkeit waren im Vergleich zu den erhobenen Daten der Kontrollgruppe erhöht. Werte für Cannabisnutzung und Cannabisabhängigkeit ergaben für das Kollektiv der schizophrenen Klienten im Vergleich zu nicht schizophrenen Klienten eine vermehrte Cannabisabhängigkeit und Cannabisnutzung. 
Eine geschlechtsspezifische Differenzierung ermittelte interessanterweise für Nikotin fast keine geschlechtsspezifischen Unterschiede der erhobenen Daten zwischen schizophrenen Männern und schizophrenen Frauen, die aber in den Kontrollgruppen bestehen. Hingegen zeigten sich geschlechtsspezifische Unterschiede bei der Auswertung des riskanten Alkoholkonsums und der Alkoholabhängigkeit, die in beiden untersuchten Gruppen Schizophrene versus Kontrollkollektiv ähnlich waren (Männer mehr risikoreicher Alkoholkonsum als Frauen).

In beiden untersuchten Patientengruppen ergab sich eine Korrelation zwischen täglichem Cannabiskonsum und abhängigem Rauchen (Nikotin).

Schließlich wurde auch eine erheblich gesteigerte tägliche Trinkmenge koffeinhaltiger Getränke (Kaffee) bei schizophrenen Patienten im Vergleich zum Kaffeegenuss des Kontrollkollektivs ermittelt.

Abschließend ergab die Auswertung der soziodemographischen Daten, dass unabhängig von einer Komorbidität mit einer Abhängigkeitserkrankung die Manifestation einer Schizophrenie, auch bei vergleichbaren soziodemographischen Ausgangsbedingungen der Untersuchten, zu einer gravierenden Einschränkung der beruflichen und familiären Entwicklung führte. 


\section{Literaturverzeichnis}

Adolfo AB, AhnAllen CG, Tidey JW (2009): Effects of smoking cues on caffeine urges in heavy smokers and caffeine consumers with and without schizophrenia; Schizophr Res $\underline{107(2-3)}: 192-7$

Aichmüller C, Schütze C, Soyka M (1997): Missbrauch und Abhängigkeit von Mischanalgetika. Psychiatr Prax 24, 262-263

Allebeck P, Rydberg U (1998): Risks and protective effects of alocohol on the individual. Alcohol Clin Exp Res 22,269

Andreasson S, Allebeck P, Engström A, Rydberg U (1987): Cannabis and schizophrenia. A longitudinal study of Swedish conscripts; Lancet 2(8574): 1483-6

Asenbaum S (2009) : Rezeptorszintigraphie in der Neurologie; Neurol Neurochir Psychiatrie 10 (2), 48-54

Backhaus K, Erichson B, Plinke W, Weiber R: Multivariate Analysemethoden; 8.Verb. Auflage, Springer Verlag, Berlin, Heidelberg, New York, 1996

BAK 2008: Medikamente. Abhängigkeit und Missbrauch; Leitfaden apothekerlicher Praxis; Herausgegeben von der Bundesapothekerkammer (BAK) Berlin 2008

Barkus E, Murray RM ( 2010): Substance use in adolescence and psychosis: clarifying the relationship; Annu Rev Clin Psychol 27,6:365-89

Bericht der Europäischen Ministeriellen WHO- Konferenz Psychische Gesundheit: Alkohol und psychische Gesundheit; Helsinki Finnland 12-15 Januar 2005

BMA (British Medical Association): Guidelines on Sensibles Drinking. British Medical Association, London 1995 
Bonnet U, Harries-Hedder K, Leweke FM, Schneider U, Tossmann HP (2006) : AWMF-

Leitlinien: Cannabisbezogene Störungen. Sucht 50 (4), 143-165

Brunette FM, Noordsy DL, Xie H, Draeke RE (2003): Benzodiazepine use and abuse among patients with severe mentall illness and co-occurring substance use disorders.Psychiatr Serv $\underline{54(10): 1395-401}$

Brzozka M, Falkai P, Havemann-Reinecke U (2009): Für Schizophrenie braucht man Drei; Suchtmedizin $11(3)$ : 98-103

Bundesagentur für Arbeit (BA) : Analytikreport der Statistik 4/2008

Bundes - Gesundheitssurvey - Alkohol : Konsumverhalten in Deutschland - Beiträge zur Gesundheitsberichterstattung des Bundes; Robert- Koch- Institut, Berlin 2003 (S.74)

Carboni E, Imperato A, Perezzani L, Di Chiara G (1989) : Amphetamine, cocaine, phencyclidine and nomifensine increase extracellular dopamine concentrations preferentially in the nucleus accumbens of freely moving rats; Neuroscience $\underline{28}$, (3), 653-661

Caspari D, Wobrock T (2004): Cannabispsychosen - vom eigenständigen Krankheitsbild zum Komorbiditätsmodell; Sucht- Z Wiss Prax-Hamburg 50:320-326 ( S.80)

Cattapan-Ludewig K, Ludewig S, Jaquenoud Sirot E, Etzensberger M, Hasler F (2005): Warum rauchen Schizophreniepatienten; Nervenarzt 76; 287-294

Clark RE, Xie H, Brunette MF (2004): Benzodiazepine prescription practices and substance abuse in persons with severe mental illness, J Clin Psychiatry 65(11):1577-8;

D’Amelio R, Behrendt B, Wobrock T: Psychoedukation Schizophrenie und Sucht; 1.Auflage, Urban \& Fischer Elsevier, München 2007 
de Raison F: Psychische Abhängigkeit bei Parkinson- Patienten und die Rolle der Dopaminergen Bahnen im Zentralnervensystem bei der Entstehung von Sucht; Med.Diss. Göttingen, 1997

Dervaux A, Laqueille X, Bourdel MC, Leborgne MH, Olie JP, Loo H, Krebs MO ( 2003):

Cannabis and schizophrenia:demographic and clinical correlates; Encephale 29(1):11-7

DHS: Jahrbuch Sucht 08. Herausgegeben von der deutschen Hauptstelle für Suchtfragen e.V., Neuland Verlag, Geesthacht 2008

Diehl A, Cordeiro DC, Laranjeira R (2010) : Cannabis abuse in patients with psychiatric disorders : an update to old evidence; Rev Bras Psyquiatr 32Suppl 1: S41-5

Di Forti M, Morgen C, Dazzan P, Pariante C, Mondelli V, Marques TR, Handley R, Luzi S, Russo M, Paparelli A, Butt A et al. (2010): High- potency cannabis and the risk of psychosis; Br J Psychiatry 196 : 332-3

Dilling H, Mombour W, Schmidt MH (Hrsg) : Internationale Klassifikation psychischer Störungen; ICD 10, klinisch-diagnostische Leitlinien/Weltgesundheitsorganisation -2.korrig. Auflage, Huber Verlag, Bern; Göttingen;Toronto; Seattle; 1993

Dragt S, Nieman DH, Becker HE, van de Fliert R, Dingemans PM, de Haan L, van Amelsvoort TA, Linszen DH (2010): Age of onset of cannabis use is associated with age of onset of high-risk symptoms for psychosis. Can J Psychiatry 55(3):165-71

Duller C: Einführung in die Statistik mit Excel und SPSS; Ein anwendungsorientiertes Lehrund Arbeitsbuch; 2. Auflage, Physica-Verlag, Heidelberg 2006 ( S.18)

Falkai P, Pajonk F : Psychotische Störungen; Georg Thieme Verlag - Stuttgart 2003

Falkai P, Haen E, Hargater L : Paliperidon ER ( INVEGA®) Der nächste Schritt zur optimalen Schizophrenietherapie; Georg Thieme Verlag KG- Stuttgart 2007 
Faust V, Baumhauer H : Medikamentenabhängigkeit In: V. Faust (Hrsg.):

Psychiatrie - Ein Lehrbuch für Klinik, Praxis und Beratung. Gustav-Fischer-Verlag, Stuttgart, Jena, New York 1996

Fehr C, Yakushev I, Hohmann N, Buchholz HG, Landvogt C, Deckers H, Eberhardt A, Kläger M, Smolka MN, Scheurich A et al. (2008) : Association of low striatal dopamine d2 receptor avaibility with nicotine dependence similar to that seen with other drugs of abuse; Am J Psychiatry.165(4):507-14

Gandhi KK, Williams JM,Menza M, Galazyn M, Benowitz NL (2010): Higher serum caffeine in smokers with schizophrenia compared to smoking kontrols; Drug Alcohol Depend 110(12):151-5.Epub 2010 Mar 12

Gaoni Y, Mechoulam R (1964) : Isolation, structure and partial synthesis of an active

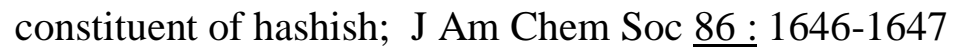

Gaoni Y, Mechoulam R (1971) : The isolation and structure of delta-l-tetrahydrocannabiol and other neutral cannabinoids from hashish. J Am Chem Soc 93, 217-224

Gerrits MA, Van Ree JM (1996): Effect of nucleus accumbens dopamine depletion on motivational aspects involved in initiation of cocaine and heroin self-administration in rats; Brain Res 713(1-2) : 114-24

Glaeske G: Psychotrope und andere Arzneimittel mit Missbrauchs- und Abhängigkeitspotential. In : Deutsche Hauptstelle gegen die Suchtfragen (Hrsg.) : Jahrbuch Sucht 2008, Neuland Verlag, Geesthacht; 2008, S.73-95

Gouzoulis-Mayfrank E: Komorbidität Psychose und Sucht- Grundlagen und Praxis2.erweiterte Auflage, Steinkopff Verlag Darmstadt 2007

Gouzoulis- Mayfrank E (2010): Komorbidität von Psychose und Sucht; Psychiatr.Psychother up2date $\underline{4}: 81-90$ 
Grobe T, Schwartz FM: Arbeitslosigkeit und Gesundheit (Gesundheitsberichterstattung des Bundes Heft 13). Robert Koch- Institut, Berlin 2003

Grotenhermen F (1999):The effects of cannabis and THC; Forsch Komplementarmed. $\underline{6(3)}: 7-11$

Häfner H: Das Rätsel der Schizophrenie- Eine Krankheit wird entschlüsselt, Beck-Verlag, München 2000

Hambrecht M und Häfner H( 1996): Substance abuse and the onset of schizophrenia. Biol Psychiatry $\underline{40} ; 1155-1163$

Hambrecht M und Häfner H (2000): Cannabis vulnerability, and the onset of schizophrenia, an epidemiological perspective. Aust NZJ Psychiatry $\underline{34 ; 468-475}$

Havemann -Reinecke U : Die Bedeutung zentraler dopaminerger Neurone für die Entwicklung von Abhängigkeit am Beispiel der Opioide; Med. Habilitationsschrift Göttingen 1998

Havemann- Reinecke U (2006) : Veranlagung - Über die Forschung zur genetischen Disposition für Suchterkrankungen und ihren Verlauf; Niedersächs Ärztebl 10:8-9

Havemann-Reinecke U, Kuschinsky K (1982): Neurochemical aspects of the opiod-induced “catatonia. Neurochem Int $\underline{4}, 199-215$

Havemann-Reinecke U, Kuschinsky K : Development of dependence and dopaminerc mechanisms. In : Bühringer G, Platt JJ (Hrsg), Drug Addiction Treatment Research-German and Amerikan Perspectives, Krieger Publishing Company, Florida 1992, 163-171

Havemann- Reinecke U, Küfner H, Schneider U, Günthner N, Schalast N,Vollmer H.C. (2004) : AWMF-Leitlinien: Postakutbehandlung bei Störungen durch Opioide. Sucht. Z Wiss Prax-50 (4), 226-256 
Heinz A (1999) : Psychopathologische Korrelate dopaminerger Dysfunktion bei alkoholabhängigen und schizophrenen Patienten; Nervenarzt.5: 399-407

Heinz A, Braus DF, Romero B, Gallinat J, Puls I, Juckel G, Weinberger DR (2004) : Genetische und medikamentöse Einflüsse auf die Funktion des präfrontalen Kortex bei schizophrenen Patienten; Nervenarzt $\underline{75}$ : 845-856

Henquet C, Di Forti M, Morrison P, Kuepper R, Murray RM ( 2008) : Gene-environment interplay between cannabis and psychosis; Schizophr Bull 34(6): 1111-21

Hopkin M (2004): Cannabis boots risk of psychosis; published online 1.December 2004, in Nature. www.nature.com/news /2004/041201

Huber G Psychiatrie : Lehrbuch für Studierende und Ärzte- 5. neubearb. und erw. Aufl.Schattauer Verlag, Stuttgart 1994

Kasper S, Volz H: Psychiatrie und Psychotherapie compact, Georg Thieme Verlag KG Stuttgart 2009

Klein T, Neumann J, Reuter M, Hennig J, von Cramon DY, Ullsperger M (2007) : Einfluss einer genetischen Variation des Dopaminrezeptors- D2- Rezeptors auf das Lernverhalten, Science 275: 1593-1599

Khorsand V: Cochrane Metaanalysen über Benzodiazepine in der Behandlung schizophrener Psychosen; Med.Diss. München 2006

Kraus L, Augustin R (2001): Repräsentiverhebung zum Gebrauch psychoaktiver Substanzen bei Erwachsenen in Deutschland 2000. Sucht 47, Sonderheft 1:3-86

Kraus L, Rösner S: Repräsentiverhebung zum Gebrauch psychaktiver Substanzen bei Erwachsenen in Berlin, (IFT- Berichte BD.167), Institut für Therapieforschung, München 2008 
Kuschinsky K (1981) : Psychic dependence on opioids: mediated by dopaminergic mechanisms in the striatum? Trends Pharmacol.Sci. 11 (1981) :287-289

Lampert T: Einfluss der sozialen Lage auf das Rauchverhalten von Männern und Frauen; Gesundheit Berlin (Hrsg): Dokumentation im Rahmen des 12. Bundesweiten Kongresses Armut und Gesundheit, o. Verlag, Berlin 2007, Seite 8 - 10

Linszen DH, Dingemans PM, Lenior ME (1994): Cannabis abuse and the course of recentonset schizophrenic disorders; Arch Gen Psychiatry 51: 273-279

Luzi S, Morrison PD, Powell J, Di Forti M, Murray RM ( 2008) : What is the mechanism whereby cannabis use increases risk of psychosis?; Neurotox Res 14(2-3): 105-12

Ma X, Meng H, Du L, Wang Q,Wang Y,Deng W, Liu X,HU X, Murray RM, Collier LA, Li T (2009) : Premorbid tobacco smoking is associated with later age at onset in schizophrenia; Psychiatry Res 178(3) : 461-6

Murray RM: Schizophrenia Research Forum Interviews, Interviewed by GabrielleStrobel, published online 18.October 2005.www.schizophreniaforum.org/for/int//Murray/murray.asp

Murray RM (2009): A clear danger from cannabis. www.guardian.co.uk/ Thursday 29.Oktober 2009, S.1

Murray RM , Lappin J, Di Forti M ( 2008) : Schizophrenia: from developmental deviance to Dopamine dysregulation; Eur Neuropsychopharmacol 18 Suppl 3:S129-34

Nehlig, A (1999) : Are we depent upon coffee and caffeine? A review on human and animal data; Neurosci Biobehav Rev 23, 563-576

Pabst A, Kraus L (2006) : Alkoholkonsum, alkoholbezogene Störungen und Trends. Ergebnisse des Epidemiologischen Suchtsurveys 2006. Sucht, 54 (Sonderheft 1), 36-46 
Poeck K : Neurologie 9. aktualisierte Aufl, Springer Verlag, Berlin; Heidelberg; New York ; 1994

Poser W, Böning R, Holzbach L, Schmidt G : Medikamentenabhängigkeit (Sedativa, Hypnotika, Analgetika, Psychostimulanzien ), Evidenzbasierte Suchtmedizin, Deutscher Ärzte- Verlag Gmbh Köln 2006. S 271- 300

Rabinowitz J , Bronet E J, Lavelle J, Carlson G, Korvasznay B, Schwartz E ( 1998) : Prevalence and severity of substance use disorders and onset of psychosis in first-admissions psychotic patients. Psychol Med 28 (6): 1411-1419

Regier DA, Farmer ME, Rae DS, Locke BZ, Keith SJ,Judd LL, Goodwin FK (1990) : Comorbidity of mental disorders with alcohol and other drug abuse. Results from the Epidemiologic Catchment Area (ECA) Study. JAMA 264 (19):2511-2518

Richter E (2001) : Gesundheit von Frauen (I), Dtsch Ärztebl 98(14): 877

Robert- Koch Institut: Gesundheitsberichterstattung des Bundes Heft 16, Hrsg. Statistisches Bundes Amt - Berlin 2003

Rumpf HJ (2009): Behandlung von Benzodiazepinabhängigkeit; Psychiatr Psychother up2date $\underline{3}: 81-89$

Sadichha S, Sur S, Sinha BN, Khess CR (2010): How is substance use linked to psychosis? A study of course and patterns of substance dependence in psychosis; Subst Abus 31(1); 58-67

Saß H, Wittchen HU, Zaudig M: Diagnostisches und Statistisches Manual Psychischer Störungen, DSM-IV. Deutsche Bearbeitung. Hogrefe Verlag, Göttingen 1996

Schmidt LG, Gastpar M, Falkai P, Gaebel W (Hrsg):Evidenzbasierte Suchtmedizin; Behandlungsleitlinie Substanzbezogener Störungen; Deutscher Ärzte-Verlag Köln 2006

Schneider K (1913) : Zur Frage der chronischen Morphinpsychose und des Zusammenhangs von Sinnestäuschungen und Wahnideen. Z Gesamte Neurol und Psychiatr 19,1 25-41 
Schnell T, Neisius K, Daumann J, Gouzoulis- Mayfrank E (2010): Prevalence of psychosis, substance abuse comorbidity: Clinical-epidemiological findings from different treatment settings in a large German city; Nervenarzt 81(3): 32-38

Soyka M (1994 a): Addiction and schizophrenia. Nosological,clinical and therapeutic questions. Alcoholism and schizophrenia; Fortschr Neurol Psychiatr 62(3):71-87

Soyka M (1994 b) : Addiction and schizophrenia. Nosological, clinical and therapeutic questions. 2. Sustance dependence and schizophrenia; Fortschr Neurol Psychiatr 62(6):186-96

Soyka M : Alkoholabhängigkeit, Grundlagen und Therapie; Springer Verlag, Berlin, Heidelberg 1999

Soyka M, Queri S, Küfner H, Rösner S (2005) : Wo verstecken sich 1.9 Millionen Medikamentenabhängige ?; Nervenarzt 76: 72-77

Strand JE, Nybäck H (2005): Tobacco use in schizophrenia:a study of cotinie concentrations in the saliva of patients and controls. Eur Psychiatry (20):50-54;

Svikis DS, Berger N, Haug NA, Griffiths RRl (2005): Caffeine dependence in combination with a family history of alcoholism as predictor of continued use of caffeine during pregnancy. Am J Psychiatry 162(12): 2344-51 ( S.82)

Tanda G, Pontieri FE, Di Chiara GD (1997): Cannabinoid and heroin activation of mesolimbic dopamine transmission by a common $\mu 1$ opiod receptor mechanism. Science 276:2048-2050

TK- Gesundheitsreport 2010 erschienen online unter www.tk.de

Thomasius R, Stolle M ( 2008) : Diagnostik und Behandlungen psychischer Störungen durch Cannabiskonsum; Psychiatrie Psychother up2date 2:225-239 
Tölle R: Psychiatrie; 10. Auflage , Springer Verlag Berlin, Heidelberg, New York 1994

Trepel M : Neuroanatomie Struktur und Funktion; 4.Auflage Urban \& Fischer Verlag, München, Jena 2008

Tretter F, Werner P (2009) : Polytoxikomanie- Grundlagen, Diagnostik und Behandlung; Psychiatr Psychother update 3(4): 225-240

Williams JM, Gandhi KK (2008): Use of caffeine and nicotine in people with schizophrenia. Curr Drug Abuse Rev 1829:155-61

Williams JM, Gandhi KK, Lu SE, Kumar S, Shen J, Foulds J, Kipen H, Benowitz NL (2008) : Higher nicotine levels in schizophrenia compared with controls after smoking a single cigarette; Nicotine Tob Res. 12(8): 855-9

Wobrock T, Pajonk F, D’ Amelio R, Falkai P (2005) : Schizophrenie und Sucht; psychoneuro 31(9): $433-440$

Zeiler J: Schizophrenie und Alkohol; Zur Psychopathologie schizophrener Bewältigungstile. Springer-Verlag Berlin 1990

Zeiler J (1997): Alkoholismus bei schizophrenen Patienten; Dtsch Ärztebl;94;A-596-597

Zuardi AW, Guimaräes FS, Guimaräes VMC, Del Bel EA : Cannabidiol. In: Grotenhermen F (ed) Cannabis und Cannabinoide. Huber Verlag, Bern 2001. S.383-393. 


\title{
8. Anhang: Fragebogen und Patientenaufklärungsbogen und
}

\section{Patienteneinwilligung}

\author{
Jutta Buße Lichtenbergstraße 837075 Göttingen
}

FRAGEBOGEN ZUR ERFASSUNG PSYCHISCHER ABHÄNGIGKEIT

Interviewnummer:

Patientennummer:

Einteilung der psychiatrischen Erkrankungen

\begin{tabular}{|c|c|c|c|}
\hline Erkrankung & $\begin{array}{l}\text { Diagnose } \\
\text { seit }\end{array}$ & $\begin{array}{l}\text { Behandlungs- } \\
\text { zeitraum }\end{array}$ & $\begin{array}{l}\text { Diagnose- } \\
\text { Sicherheit } \\
1 \text { ja } 2 \text { nein }\end{array}$ \\
\hline 01 keine & & & \\
\hline $\begin{array}{l}02 \text { Parkinson } \\
\text { Tremor } \\
\text { Akinese } \\
\text { Rigor }\end{array}$ & & & \\
\hline $\begin{array}{l}03 \text { PHP } \\
\text { Desorganisierter T. } \\
\text { Katatoner Typ } \\
\text { Paranoider Typ } \\
\text { Undifferenzierter T. } \\
\text { Residual Typ }\end{array}$ & & & \\
\hline 04 sonstige: & & & \\
\hline
\end{tabular}

Ausschlusskriterien: Tumorerkrankungen, chronische Schmerzzustände (Bewegungsapparat etc.), schwere hirnorganische Vorschädigung, Demenz, endogene Depression, Oligophrenie schweren Ausmaßes, medikamentöser Parkinsonismus

Einschätzung des Interviewers:

Missbrauch von:

Abhängigkeit von:

Fragen

\section{Geschlecht}

1 männlich

2 weiblich

2. Wie alt sind Sie?

..... Jahre

3. Familienstand

1 ledig

2 eheähnliche Lebensgemeinschaft

3 verheiratet

4 verheiratet, aber getrennt lebend

5 geschieden

6 verwitwet

4. Welche Schulbildung haben Sie erworben (zuletzt besuchte Schule)?
1 Sonderschule
2 Hauptschule ohne Abschluss
3 Hauptschule mit Abschluss
4 weiterführende Schule ohne Abschluss
5 weiterführende Schule mit Abschluss
6 Hochschule/Fachhochschule ohne Abschluss
7 Hochschule/Fachhochschule mit Abschluss

5. Berufsausbildung

1 keine Berufsausbildung

2 angelernte Tätigkeit

3 in Berufsausbildung

4 abgebrochene Berufsausbildung

5 abgeschlossene Berufsausbildung

6 Sonstiges: 
6. Überwiegende Erwerbstätigkeit im letzten Jahr

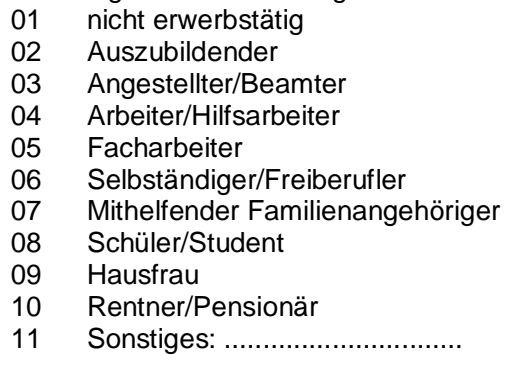

7. Sind Sie zum momentanen Zeitpunkt arbeitslos?

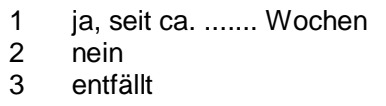

8. Haben Sie im letzten Jahr häufig Ihre Arbeitsstelle gewechselt?

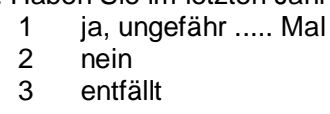

9. Womit haben Sie im letzten Jahr Ihren Lebensunterhalt überwiegend bestritten?

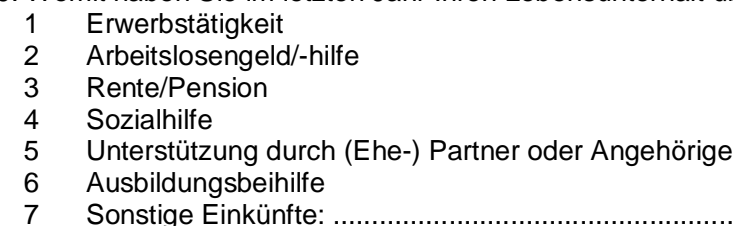

10. In welchem der folgenden Bereiche haben Sie im letzten Jahr überwiegend gelebt?
01 allein in eigener Wohnung
02 zusammen mit Partner/in oder eigener Familie
03 bei Angehörigen
04 in einer Wohngemeinschaft
05 in therapeutischer Einrichtung
06 in psychiatrischem Krankenhaus
07 im Allgemeinkrankenhaus
08 in einer Nachsorgeeinrichtung
09 in einem Altenheim/Pflegeheim
10 sonstige Wohngelegenheit:
11 ohne festen Wohnsitz

11. Eltern

Können Sie sagen, wie alt Sie waren, als die Trennung vom Elternhaus erfolgte? .... Jahre

12. Leiden Sie an einer Erkrankung, die zeitweise oder ständig medizinischer Behandlung bedarf?

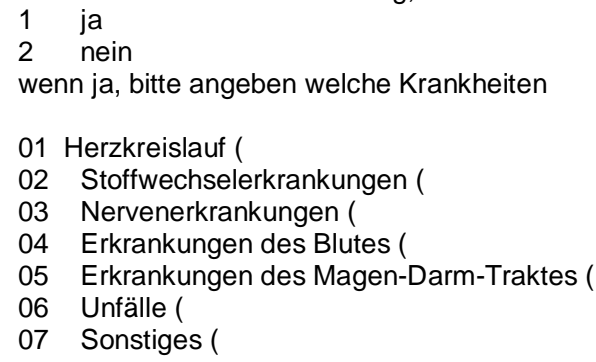

13. Haben Sie im letzten Jahr eine Behandlung o. Betreuung wegen psychischer Probleme in Anspruch genommen?

1 ja, durch: 09 Selbsthilfegruppe und/oder Freundeskreis

$\begin{array}{lll} & 10 & \text { Psychosoziale Beratungsstelle } \\ & 11 & \text { niedergelassenen Arzt } \\ & 12 & \text { niedergelassenen Psychotherapeuten/Diplompsychologen } \\ & 13 & \text { teilstationäre Behandlung } \\ 2 \text { nein } & 14 & \text { stationäre Behandlung }\end{array}$


14. Sind Sie im letzten Jahr wegen Abhängigkeitsproblemen behandelt oder betreut worden?

1 ja, durch: 09 Selbsthilfegruppe und/oder Freundeskreis

10 Psychosoziale Beratungsstelle

11 niedergelassenen Arzt

12 niedergelassenen Psychotherapeuten/Diplompsychologen

13 teilstationäre Behandlung

2 nein

14 stationäre Behandlung

15. Welche Medikamente nehmen Sie regelmäßig ein?

Vom Arzt verordnet:

Eigene Medikation (auch Stärkungsmittel):

16. Halten Sie bei der Einnahme der Medikamente die empfohlene Menge und auch die Tageszeit der Einnahme ein?

1 überhaupt nicht

2 nur teilweise

3 meistens

4 sehr genau

17. In welchem Lebensjahr haben Sie zum ersten Mal folgende Mittel genommen?

Über welchen Zeitraum haben Sie regelmäßig diese Mittel eingenommen?

Welche Mengen dieser Mittel haben Sie eingenommen?

Haben Sie die anfängliche Menge beibehalten oder erhöht?

$\begin{array}{cccc}\text { Interviewerauswertung } & \text { * } & \text { Zeitindex } & \\ \text { Einige } & 1-5 & >5-10 & >10 \\ \text { Monate } & \text { Jahre } & \text { Jahre } & \text { Jahre } \\ 1 & 2 & 3 & 4\end{array}$

\begin{tabular}{|c|c|c|c|c|}
\hline & $\begin{array}{l}\text { Erst- } \\
\text { Einnahme }\end{array}$ & $\begin{array}{l}\text { Einnahme- } \\
\text { zeitraum }\end{array}$ & $\begin{array}{l}\text { Menge bei } \\
\text { letzter } \\
\text { Einnahme }\end{array}$ & $\begin{array}{l}\text { Dosis } \\
\text { erhöht }\end{array}$ \\
\hline $\begin{array}{l}01 \text { Schmerzmittel } \\
\text { Welche: ........................... }\end{array}$ & & & & \\
\hline $\begin{array}{l}02 \text { Schlafmittel } \\
\text { Welche: }\end{array}$ & & & & \\
\hline $\begin{array}{l}03 \text { Beruhigungsmittel } \\
\text { Welche: }\end{array}$ & & & & \\
\hline $\begin{array}{l}04 \text { Appetitzügler, Aufputsch } \\
\text { Welche: }\end{array}$ & & & & \\
\hline $\begin{array}{l}05 \text { Sonstige Medikamente } \\
\text { (z.B. Akineton,Tremarit }\end{array}$ & & & & \\
\hline 06 Alkohol & & & & \\
\hline 07 Tabak & & & & \\
\hline $\begin{array}{l}08 \text { Marihuana, Haschisch, } \\
\text { LSD, Kokain, Heroin }\end{array}$ & & & & \\
\hline 09 Koffein (Tee, Kaffee) & & & & \\
\hline
\end{tabular}


18 Welchen Beruf haben Sie ausgeübt, als Sie begonnen haben, regelmäßig Ihr Mittel (s.o.) einzunehmen?

Üben Sie jetzt einen anderen Beruf aus?

1 nein

2 ja

wenn ja, welchen:

Hatten Sie jemals einen medizinischen Beruf?

01 ja

02 nein

19. Welche der folgenden Mittel nehmen Personen ein, die mit Ihnen in engem Kontakt stehen (z. B. Angehöriger, Freunde, Arbeitskollegen)?

\begin{tabular}{|l|l|}
\hline 01 Tabak & \\
\hline 02 Alkohol & \\
\hline $\begin{array}{l}03 \text { Medikamente } \\
\text { Welches:............................................. }\end{array}$ & \\
\hline 04 Marihuana, Haschisch & \\
\hline 05 Heroin, Kokain & \\
\hline
\end{tabular}

20. Versuchen Sie bitte zu benennen, in welchen Situationen Sie die von Ihnen am häufigsten gebrauchten Mittel einnehmen

01 am Arbeitsplatz

02 allein zu Haus

03 in Gesellschaft zu Haus

04 beim Feiern

05 bei der Freizeitgestaltung

06 keine typische Situation

21. Was machen Sie überwiegend in Ihrer Freizeit?

01 Fernsehen

02 Lesen

03 Handarbeiten/Heimwerken

04 Gartenarbeiten

05 spazieren gehen

06 Haustiere

07 aktive Vereinstätigkeit Welche:.....

08 nichts besonderes

09 sonstiges:.

22. Wie zufrieden sind Sie mit Ihrer Freizeitbeschäftigung?

01 zufrieden

02 mäßig zufrieden

03 unzufrieden

Was macht Sie zufrieden, bzw. unzufrieden?

23. Lieben Sie Spiele mit Geld (Kartenspiele, Automatenspiele, Wetten, Casino, etc.)?
1 nein, gar nich
2 etwas
3 ziemlich
4 sehr

24. Können Sie sich durch diese Geldspiele in einen rauschähnlichen Zustand versetzen? 1 nie

2 gelegentlich

3 häufig

4 immer 
25. Ist es Ihnen schon einmal passiert, dass Sie durch Musik oder Lichteffekte (z. B. Ampel, Beleuchtung) in einen Rauschzustand versetzt wurden (ohne etwas getrunken oder eingenommen zu haben)?

1 noch nie

2 gelegentlich

3 häufiger

4 immer

26. War dieser Rauschzustand genau so, wie wenn Sie getrunken bzw. Medikamente o. ä. eingenommen haben?
1 überhaupt nicht
2 teilweise
3 genauso
4 viel intensiver

27. Haben Sie immer einen Vorrat an Alkohol, Tabak oder Medikamenten (Akineton, Tremarit, Mao- Hemmer etc.) bei sich?
01 nie
02 gelegentlich
03 häufig
04 immer

28. Beunruhigt es Sie, wenn Sie nichts an Alkohol, Tabak, Medikamenten (Akineton, Tremarit, Mao- Hemmer etc.) bei sich bzw. zu Hause haben?
1 nein
2 mittel
3 stark
4 sehr stark

29. Essen Sie manchmal soviel, dass Sie danach brechen müssen?
1 nie
2 gelegentlich
3 häufig
4 immer

30. Können Sie sich tagsüber in einen traumähnlichen Zustand versetzen, ohne etwas eingenommen zu haben?
nie
2 gelegentlich
3 häufig
4 ständig

\section{DROGENKONSUM}

( ) kein Konsum

31. Haben Sie Drogen zur Verbesserung der eigenen Stimmung eingenommen?
1 nicht genommen
2 gelegentlich
3 häufig
4 fast täglich oder täglich

32. Haben Sie bei Einstellung der Drogeneinnahme „Entzugserscheinungen“ (innere Unruhe, Reizbarkeit, Angst, Schlaflosigkeit u. a.) bemerkt?
1 nie
2 gelegentlich
3 häufig
4 fast täglich oder täglich

33. Haben Sie Drogen oder Medikamente eingenommen, um diese Erscheinungen zu beseitigen?
1 nie
2 gelegentlich
3 häufig
4 fast täglich oder täglich 
MEDIKAMENTENKONSUM

( ) kein Konsum

34. Wie häufig nehmen Sie Medikamente in den folgenden Situationen und Stimmungen?

\begin{tabular}{|l|l|l|l|l|}
\hline & nie & Gelegentlich & häufig & immer \\
\hline bei Stress & & & & \\
\hline zur Beruhigung & & & & \\
\hline zur Anregung & & & & \\
\hline $\begin{array}{l}\text { zur Stimmungs- } \\
\text { verbesserung }\end{array}$ & & & \\
\hline kein besonderer Grund & & & & \\
\hline Rezept & & & \\
\hline
\end{tabular}

35. Sind beim Absetzen des von Ihnen häufig benutzten Medikamentes Erscheinungen wie innere Unruhe, Reizbarkeit, Angst oder Schlaflosigkeit aufgetreten?

1 nie

2 gelegentlich

3 häufig

4 fast täglich oder täglich

36. Haben Sie Medikamente benutzt, um sogenannte Entzugserscheinungen wie Zittern, Schweißausbrüche und Unruhe zu verhindern?

1 nicht genommen

2 gelegentlich

3 häufig

4 fast täglich oder täglich

\section{ALKOHOLKONSUM}

( ) kein Konsum

37. Wie häufig trinken Sie Alkohol?
1 nie
2 gelegentlich
3 häufig
4 fast täglich oder täglich
5 immer

38. Wieviel Alkohol trinken Sie pro Tag?

Auswerttabelle * Interviewer

\begin{tabular}{|c|c|c|}
\hline & Durchschnittliche Trinkmenge pro Tag & Alkoholmenge in Gramm \\
\hline Bier & $\begin{array}{l}\ldots . \text { Gläser m. 0,2 - 0,3 I } \\
\ldots . \text { Gläser m. 0,4 - 0,5 I }\end{array}$ & \\
\hline Wein, Sekt, Südwein & ...... Gläser m. 0,2-0,25। & \\
\hline Likör, Schnaps & $\begin{array}{l}\ldots . . \text { Gläser m. 0,02 I } \\
\ldots . . . \text { Gläser m. 0,04 I }\end{array}$ & \\
\hline Sonstiges & & \\
\hline Summe (Alkoholmenge in Gramm) & & \\
\hline
\end{tabular}

39. Wie oft haben Sie bis zum Rausch getrunken?
1 nie
$21 \mathrm{x}$
$32-5 x$
$46-15 x$
5 16-30x
6 mehr als $30 x$

40. Wie häufig trinken Sie Alkohol in den folgenden Situationen und Stimmungen?

\begin{tabular}{|l|l|l|l|l|}
\hline \multicolumn{2}{|c|}{ nie } & Gelegentlich & häufig & immer \\
\hline bei Stress & & & & \\
\hline zur Beruhigung & & & & \\
\hline zur Anregung & & & & \\
\hline zur Stimmungsverbesserung & & & & \\
\hline ohne besonderen Grund & & & \\
\hline
\end{tabular}


41. Beobachten Sie Entzugserscheinungen, wenn Sie keinen Alkohol trinken (z. B. Händezittern, Unruhe)?
1 nein
2 gelegentlich
3 häufig
4 fast täglich oder täglich

42. Haben Sie Alkohol getrunken, um Entzugserscheinungen (z. B. Händezittern, Unruhe) zu unterdrücken?
1 nein
2 gelegentlich
3 häufig
4 fast täglich oder täglich

\section{NIKOTINKONSUM}

() kein Konsum

43. Wie häufig rauchen Sie?
1 nie
2 gelegentlich
3 häufig
4 fast täglich oder täglich

44. Wie viele Zigaretten rauchen Sie am Tag?

............ Zigaretten

Welche Marke:

45. Wie häufig rauchen Sie in den folgenden Situationen und Stimmungen?

\begin{tabular}{|c|c|c|c|c|}
\hline \multirow{2}{*}{\multicolumn{5}{|c|}{ bei Stress }} \\
\hline & & & & \\
\hline zur Beruhigung & & & & \\
\hline zur Anregung & & & & \\
\hline zur Stimmungsverbesserung & & & & \\
\hline ohne besonderen Grund & & & & \\
\hline
\end{tabular}

46. Welche Entzugserscheinungen erscheinen bei Ihnen, wenn Sie nicht rauchen?
1 keine
2 Unruhe, Reizbarkeit
3 Müdigkeit
4 Heißhunger
5 Verstopfung

47. Rauchen Sie, um diese obengenannten Entzugserscheinungen zu unterdrücken?
1 nie
2 gelegentlich
3 häufig
4 immer

48. Waren Sie bereits einmal in stationärer Entgiftungsbehandlung?

1 nein

$2 \mathrm{ja}$

...... Anzahl der bisherigen stationären Aufenthalte

Vor wie vielen Jahren war der letzte Aufenthalt?

Vor ..... Jahren

49. Waren Sie schon einmal im Zusammenhang mit Alkohol-, Drogen- oder Medikamentenmissbrauch in stationärer Entwöhnungsbehandlung?

$1 \mathrm{ja}$, in Zusammenhang mit: 11 Alkoholmissbrauch

12 Drogenmissbrauch

13 Medikamentenmissbrauch

14 Alkohol- und Drogenmissbrauch

15 Alkohol- und Medikamentenmissbrauch

16 Drogen- und Medikamentenmissbrauch

17 Alkohol-, Drogen- und Medikamentenmissbrauch

2 nein

...... Anzahl der bisherigen stationären Aufenthalte

Vor wie vielen Jahren war der letzte Aufenthalt?

Vor ..... Jahren 
50. Haben Sie Versuche unternommen, sich davon zu lösen, Medikamente/Drogen/Alkohol zu konsumieren?

Zeitindex für Tabelle:

$1 \mathrm{ja}$, ich habe es versucht und es ist mir über einen langen Zeitraum auch gelungen, davon loszukommen

2 ja, doch es ist mir überhaupt nicht geglückt

3 nein, ich habe es nie versucht

4 ja, seitdem abstinent

\begin{tabular}{|l|l|}
\hline Nikotin & \\
\hline Alkohol & \\
\hline Medikamente (z. B. Valium, Akineton, & \\
Tremarit) & \\
Welches:.................................... & \\
\hline Marihuana, Haschisch & \\
\hline Heroin, Kokain & \\
\hline
\end{tabular}

51. Gibt es bei Ihrem (Ehe-) Partner Abhängigkeitsprobleme?

1 keine Suchtprobleme

2 gefährdet (Missbrauch von Drogen, Alkohol, Medikamenten)

3 früher in Behandlung, jetzt abstinent

4 jetzt abhängig

5 trifft nicht zu

52. Halten Sie sich selbst für abhängig von ?

1 nein

2 vielleicht

3 ja

Wenn ja oder vielleicht, fühlen Sie sich zur Zeit von Ihrem Partner/Verwandten unterstützt, von den Suchtmitteln zu lassen?

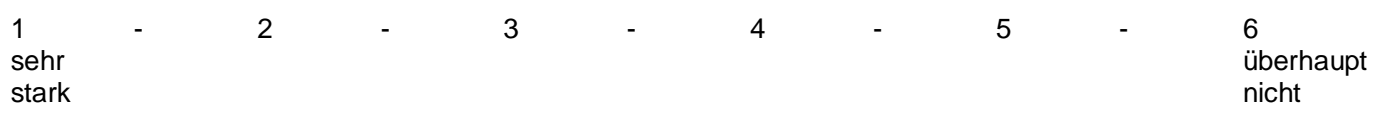

53. Sollten Ihrer Meinung nach illegale Drogen (z. B. Haschisch, Kokain, Heroin) gesetzlich erlaubt werden?

1 nein

2 teilweise (welche:

3 ja

54. Haben Sie schon einmal an einen Selbstmordversuch gedacht oder haben Sie schon einmal einen Selbstmordversuch gemacht?
1 nein
2 daran gedacht
3 schon einmal versucht
4 schon mehrmals versucht

Wann war der letzte Versuch:

Haben Sie versucht, sich mit Medikamenten umzubringen?

1 ja

2 nein 


\title{
Psychiatrische Klinik und Poliklinik der Universität Göttingen Prof. Dr. med. E. Rüther
}

\author{
Patientenaufklärung zur Studie \\ " Abhängigkeit bei Schizophrenie "
}

\section{Liebe Patientin/ lieber Patient}

Im Rahmen der Untersuchung“ Abhängigkeitserkrankung und Schizophrenie" unter der Leitung von Frau Priv. Doz. Dr. Havemann -Reinecke, Psychiatrische Klinik der Universität Göttingen, möchten wir den Zusammenhang zwischen der Erkrankung Schizophrenie und suchterkrankungen untersuchen. Hierzu benötigen wir auch Informationen von Personen (Patienten/Probanden), die weder an der einen noch an der anderen Erkrankung leiden, und bei denen keine psychiatrische Vorerkrankungen bekannt sind. Bevor Sie sich dafür entscheiden, lesen sie bitte in ruhe dieses Informationsblatt.

Die Teilnahme an der Studie bringt Ihnen persönlich keinen Nutzen. Die Ergebnisse werden aber vielleicht in Zukunft dabei behilflich sein, die Diagnose und Behandlung von Patienten mit einer Schizophrenie und/oder Abhängigkeitserkrankungen zu verbessern. Wenn Sie sich entschließen, an der Studie nicht teilzunehmen, wird das keine Nachteile für ihre weitere Behandlung mit sich bringen. Sie können auch zu jeder Zeit die Teilnahme an der Studie abbrechen, ohne Nachteile für Ihre weitere Behandlung befürchten zu müssen.

In einem ca. 30minütigen Interview werden Ihnen Fragen über Ihren Beruf, Ihre Schulbildung, Ihre Wohnsituation usw. sowie über Ihre Freizeitgestaltung, Essverhalten und Ihr psychisches Befinden gestellt. Wichtig ist, dass wir Sie auch fragen wollen, ob und in welchem Ausmaß Sie jemals suchtfördernde Medikamente, Alkohol, Zigaretten und Drogen wie Haschisch, Heroin, Kokain und Ecstasy zu sich genommen haben.

Verbunden mit dem Interview ist eine Untersuchung Ihres Urin auf Alkohol, Schlafmitteln, Aufputschmitteln, Heroin, Kokain und Haschisch. Die Ergebnisse der Urinuntersuchung erhalten nur die beiden oben genannten Prüfärzte, da die Urinprobe mit einem Zahlencode verschlüsselt im Labor untersucht wird.

Die bereits auf Station von Ihnen erhobenen Laborwerte (Kleines Blutbild / Leberwerte) möchten wir mit Ihrem Einverständnis in unsere Studie miteinbeziehen.

Die Urinbefunde und die Labordaten benötigen wir als Grundlage für unsere gesamte Untersuchung. Alle erhobenen Daten ( Interview, Urinprobe und Labordaten) werden vertraulich von uns behandelt und für die weitere Auswertung und wissenschaftliche Publikation vollständig anonymisiert. Die in die Untersuchung einbezogenen Ärzte unterliegen der Schweigepflicht. Nach Abschluss der Untersuchung werden Ihre gesamten Daten mit einem nicht rückführbaren Code verschlüsselt, so dass die erhobenen Daten nicht auf Ihre Person bezogen werden können.

Wir bitten um Ihre Teilnahme und danken für Ihr Interesse an unserer Untersuchung. Prüfärzte:

Frau PD.Dr.U. Havemann-Reinecke, Abteilung Psychiatrie des Universitätsklinikum Göttingen .Tel. 0551/396610

Jutta Buße, Lichtenbergstr.8, 37075 Göttingen Tel.: 0551/58957

Psychiatrische Klinik und Poliklinik der Universität Göttingen

Prof. Dr. med. E. Rüther 


\section{Patienteneinverständniserklärung zur Studie \\ ” Abhängigkeit bei Schizophrenie "}

Patientendaten/Patientencode :

Hiermit erkläre ich, dass

1. ich die Patienteninformation, d.h. den Inhalt der klinischen Untersuchung in der Landessprache, die ich verstehe, vollständig gelesen habe bzw. sie mir vorgelesen und hinreichend erklärt wurde

2. mir die Gelegenheit gegeben wurde, einen der behandelnden Ärzte Fragen zu stellen, die zufriedenstellend beantwortet wurden

3. ich für meine Unterlagen eine unterschriebene Kopie der Patienteninformation erhalten habe

4. ich verstehe, dass ich darum gebeten wurde, an der klinischen Untersuchung teilzunehmen. Ich weiss, dass die Teilnahme an der klinischen Befragung und die Verwertung meiner Labordaten (Kleines Blutbild /Leberenzyme) und die Urinprobe auf ein Drogenscreening freiwillig ist

5. Ich weiß, dass ich jederzeit und ohne Angaben von Gründen diese Zustimmung widerufen kann, ohne dass sich dieser Entschluss nachteilig auf meine nachfolgende Behandlung auswirkt.

6. Mir ist bekannt, dass meine persönlichen Daten in verschlüsselter Form gespeichert werden und die Grundsätze des Datenschutzes beachtet werden.

7. Mir ist bekannt, dass ich durch die Teilnahme an diesem Forschungsvorhaben keinerlei Nutzen ziehe.

Ich erkläre hiermit meine freiwillige Teilnahme an der klinischen Befragung.

Ort und Datum

Ort und Datum
Unterschrift des Patienten/der Patientin

Unterschrift Prüfarzt

\section{Prüfärzte:}

-Frau PD.Dr.U.Havemann- Reinecke, Universitätklinikum Göttingen - Abteilung Psychiatrie . Tel.: 0551/396610 -Frau J.Buße, Lichtenbergstr.8, 37075 Göttingen. Tel.: 0551/58957 